Florida International University FIU Digital Commons

$8-3-2016$

\title{
Patient-centered care process enabled by Integrative Social Media Platform in an outpatient setting
}

Inkyoung Hur

ihur001@fiu.edu

DOI: $10.25148 /$ etd.FIDC001177

Follow this and additional works at: https:// digitalcommons.fiu.edu/etd

Part of the Business Administration, Management, and Operations Commons, and the Business Intelligence Commons

\section{Recommended Citation}

Hur, Inkyoung, "Patient-centered care process enabled by Integrative Social Media Platform in an outpatient setting" (2016). FIU Electronic Theses and Dissertations. 3057.

https://digitalcommons.fiu.edu/etd/3057 
FLORIDA INTERNATIONAL UNIVERSITY

Miami, Florida

\section{PATIENT-CENTERED CARE PROCESS ENABLED BY INTEGRATIVE SOCIAL MEDIA PLATFORM IN AN OUTPATIENT SETTING}

A dissertation submitted in partial fulfilment of the

requirements for the degree of

DOCTOR OF PHILOSOPHY

in

BUSINESS ADMINISTRATION

by

Inkyoung Hur 
To: Acting Dean Jose M. Aldrich

College of Business

This dissertation, written by Inkyoung Hur, and entitled Patient-Centered Care Process Enabled by Integrative Social Media Platform in an Outpatient Setting, having been approved in respect to style and intellectual content, is referred to you for judgment.

We have read this dissertation and recommend that it be approved.

Joyce J. Elam

Karlene C. Cousins

Roman Lukyanenko

William Newburry

Weidong Xia, Major Professor

Date of Defense: August 3, 2016

The dissertation of Inkyoung Hur is approved.

Acting Dean Jose M. Aldrich

College of Business

Andrés G. Gil

Vice President for Research and Economic Development and Dean of the University Graduate School

Florida International University, 2016 
(C) Copyright 2016 by Inkyoung Hur All rights reserved. 


\section{ACKNOWLEDGMENTS}

I would like to thank Dr. Weidong Xia for his guidance throughout my research projects and doctoral program. I would also like to recognize the invaluable expertise and contributions of the other committee members (Drs. Joyce J. Elam, Karlene C. Cousins, Roman Lukyanenko, and William Newburry) to my dissertation research. The committee's guidance has been extremely helpful and greatly appreciated. In addition, I wish to thank Mr. Maosheng Liao and Ms. Linlin Zhang from the hospital study site for their assistance in the data collection.

I have found my coursework throughout the program to be stimulating and thoughtful, providing me with the tools with which to explore both the past and the present ideas and issues. I would also like to acknowledge my Ph.D. program cohort - my impressively smart and cool research colleagues. Arturo Castellanos, Alfred Castillo, JJ Schmidt, Shekhar Rathor, Mingyu Zhang, and John Peng Zhang - thanks for making the school life fun and for creating a supportive program culture.

Lastly, I appreciate the unlimited support from my parents, Byoungseng Hur and Silhwa Yoon and my siblings, Moonsung Hur and Yoojung Hur. Especially, this dissertation would not have been completed without the love and dedication of my family, Aidan Kang, Liam Kang, and Keumseok Kang. 
ABSTRACT OF THE DISSERTATION

\title{
PATIENT-CENTERED CARE PROCESS ENABLED BY INTEGRATIVE SOCIAL MEDIA PLATFORM IN AN OUTPATIENT SETTING
}

\author{
by \\ Inkyoung Hur \\ Florida International University, 2016 \\ Miami, Florida \\ Professor Weidong Xia, Major Professor
}

As an effort to guide patients toward being more informed and more involved as healthcare decision makers in the clinical processes, health care organizations have adopted a new technology referred to as an integrative social media platform (ISMP). This ISMP combines features of mobile technology and those of social media technology, integrating healthcare systems in order to support a more patient-centered healthcare process. However, users, both physicians and patients, have showed varied usages of ISMP, as a results, have shown mixed results of ISMP.

To provide a better understanding of the use of ISMP, especially the interaction between patients and physicians, I turned to the concept of affordances. Affordances describe the possibilities for goal-oriented actions that a technical object offers to a user.

Using a mixed-method approach with real archival event log data, conversation texts, documents, interview, and focus-group data from a large hospital which had adopted an ISMP, I confirmed three types of affordance: perceived affordance, behavioral affordance, and interactive affordance. I identified two key affordances of ISMP that lead to patient-centered care, namely ubiquitous access and virtual healthcare consultation, which represent a behavioral affordance and an interactive affordance, respectively. I also explored how different types of affordances are actualized and how they interact with each other to contribute to patient-centered care. 


\section{TABLE OF CONTENTS}

CHAPTER

PAGE

INTRODUCTION

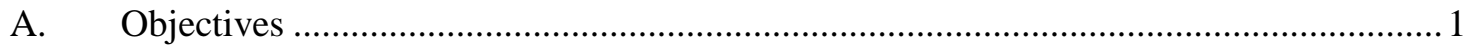

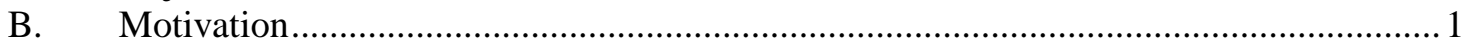

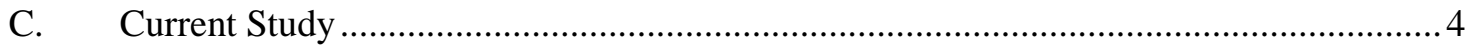

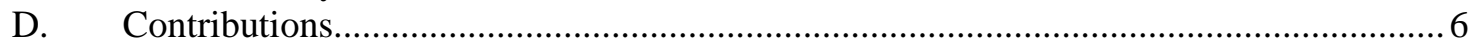

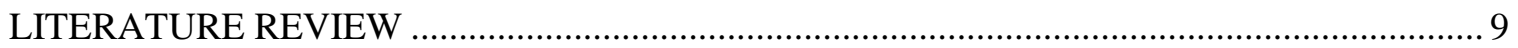

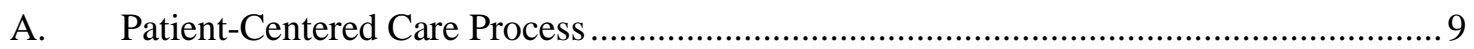



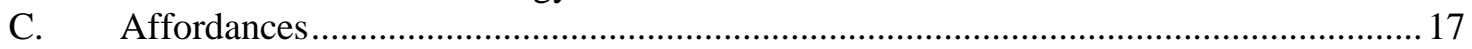

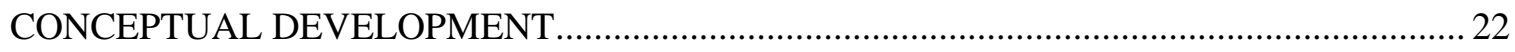

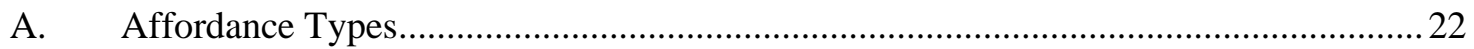

B. Proposed Affordance Types and Their Relationships ...............................................23

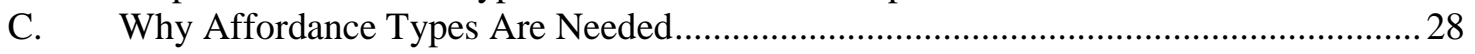



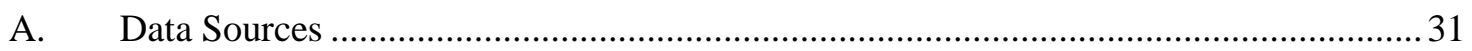

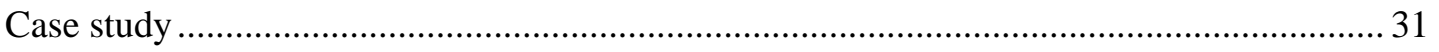

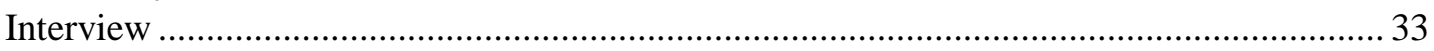

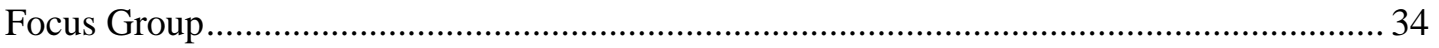



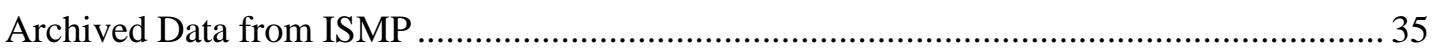

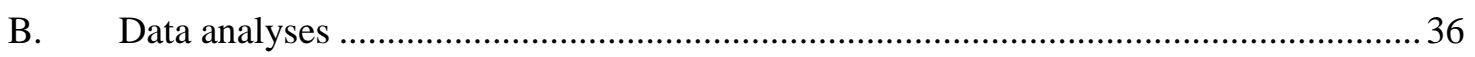



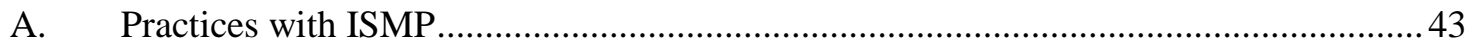



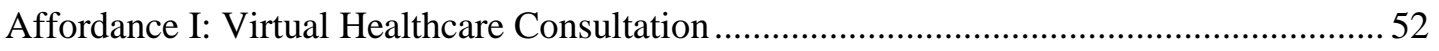



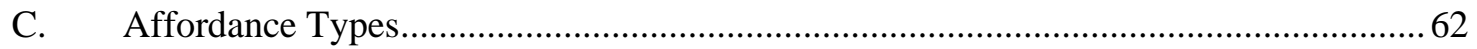

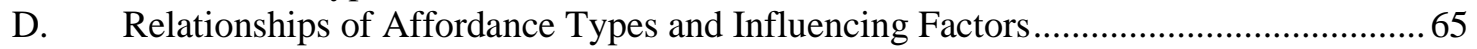

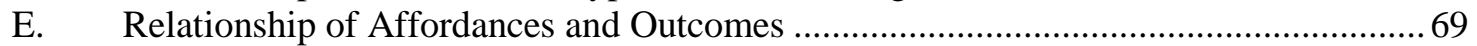

F. Why Are Some Affordances Not Perceived or Actualized............................................ 75



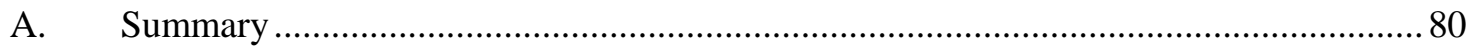

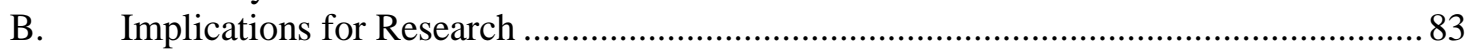

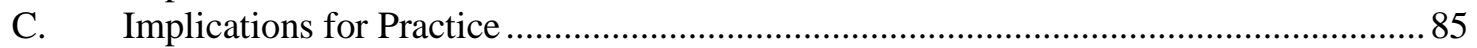

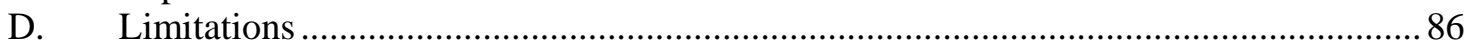

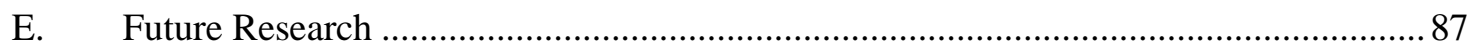




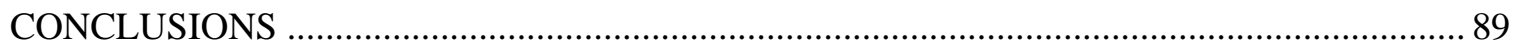

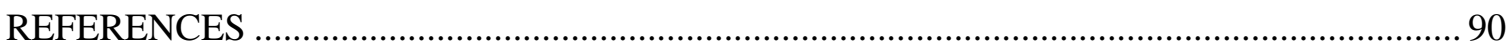

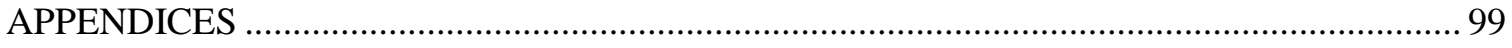

VITAE 


\section{LIST OF TABLES}

TABLE

PAGE

Table 1. Definition of Patient-Centered Care in Literature ......................................................... 10

Table 2. Dimensions of Patient-Centered Care Process in Literature......................................... 13

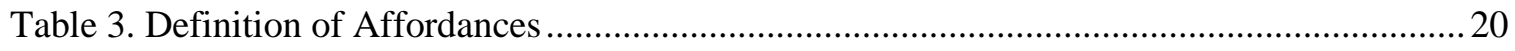

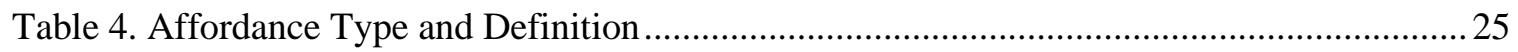



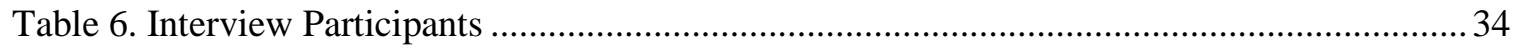





Table 9. Activities in Grounded Analysis (Adapted from (Berente and Seidel, 2014)) ................ 38

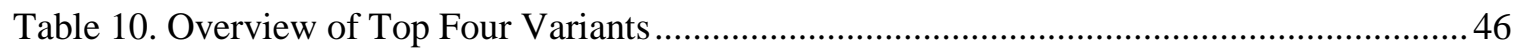

Table 11. Description of Affordance Dimensions in the Healthcare Processes..............................50

Table 12. Overview of Identified Affordances and Their Dimensions ........................................51

Table 13. Definitions of Possible Affordance Measures ...............................................................56

Table 14. Statistics of Measures of 'Virtual healthcare consultation' Affordance .........................58

Table 15. Statistics of Measures of 'Ubiquitous Access' Affordance across Departments ............60

Table 16. Descriptive Statistics of Outcome Measures ............................................................. 70 


\section{LIST OF FIGURES}

FIGURE

PAGE

Figure 1. Data Coding Process for 'Virtual Physician' ........................................................... 40

Figure 2. Overview of Patients' and Physicians' ISMP Usage .................................................. 43

Figure 3. Results of Process Mining Analysis with Event Logs Data in ISMP ........................... 45

Figure 4. Trend of the ISMP Mobile Consulting Transactions............................................... 47

Figure 5. Results of Text Clustering of Texts Made by Physicians and Patients in the ISMP

Mobile Consulting Feature (by SAS Text Miner) ..................................................................... 49

Figure 6. Results of Text Conceptual Map with Texts Made by Physicians in the ISMP Mobile

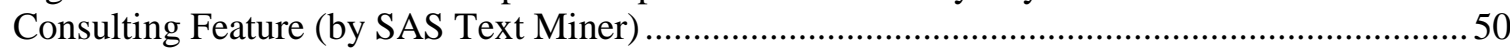

Figure 7. Result of Social Network Analysis for Interactions among Patients and Physician in

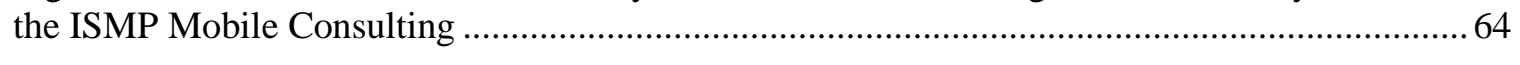

Figure 8. Relationships between User Combination and Interactive Affordances ....................... 68

Figure 9. Relationships Related to Patient's Affordances ..................................................... 72

Figure 10. Relationships Related to Physician's Affordances .................................................. 73

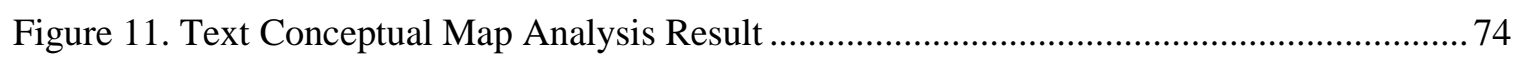

Figure 12. Relationships Related to Affordances in the Healthcare Context................................. 75 


\section{ABBREVIATIONS AND ACRONYMS}

PCCP Patient-Centered Care Process

ISMP Integrative Social Media Platform

IS Information Systems

IT Information Technology

EMR Electronic Medical Record 


\section{INTRODUCTION}

\section{A. Objectives}

The objectives of this research have four aspects: 1) to understand the interactions between patients and physicians, enabled by the use of an integrative social media platform (ISMP) in healthcare, 2) to identify key affordances that facilitate patient-centered care processes, 3) to propose and examine affordance types and their relationships, and 4) understand how affordances are perceived and actualized. Practices are understood through relations among users with technologies (Orlikowski, 2007). Interaction and impacts have no independent existence outside of these relations. With this view, I identified healthcare practices and affordances of ISMP when individuals use ISMP for patient-centered care. In addition, I investigated how different types of affordances, perceived affordance, behavioral affordance, and interactive affordance, are actualized, and how they interact with each to produce desirable outcome.

- RQ1: What interactions are emergent when people (i.e., patients and physicians) use an integrative social media platform in the healthcare context?

- RQ2: What affordances of an integrative social media platform are perceived and actualized in the healthcare process?

- RQ3: What are the key factors influencing affordances?

- RQ4: How do different types of affordances offered by ISMP affect people behaviors in the healthcare context?

\section{B. Motivation}

Patient-centered care is a paradigm and has gained widespread acceptance in healthcare, but in reality it has not been put into practices in the overall healthcare processes and structures. Most healthcare applications are designed for only healthcare providers, not 
patients, so patients are limited in their access to the health systems and health data. On the other hand, there have been efforts to develop technologies for healthcare consumers, such as mobile apps, sensory healthcare monitoring devices, and online applications. Patients who use these technologies become more knowledgeable and empowered in their healthcare. However, such technologies are often disconnected from core healthcare processes.

Patient-centered care has become feasible because of the advances of technologies that alter how healthcare data are collected, how they are shared, and how they are personalized. Patients express increasing interests in forging partnerships with their clinicians, along with gaining anytime access to their health records in order to have better quality of healthcare. There have been many empirical studies on online technologies for human connections, such as telemedicine. System data connection has also been studied with electronic medical records (EMR) systems and a feature of a patient-held medical record summary. They show positive effects of these systems on patients' knowledge and behaviors (Liaw, Lawrence, \& Rendell, 1996; Young et al., 2011). However, many studies focus on healthcare providers' practices (Lau et al., 2012). Recently an ISMP has been adopted in healthcare to support processes for both patients and healthcare providers. This new technology, a mobile app in a social media platform, allows both human connections and access to healthcare legacy systems in a healthcare organization. It means that the technology integrates medical resources and healthcare information in a unified platform shared by both physicians and patients to support healthcare processes. However, the emerging nature of interactions between the patients and the providers enabled by the new technology in the health care context has not been studied. To the best of my knowledge, this is the first empirical study on an ISMP which integrates both system connections and human connections that examines if and how the two connections promote patient-centered 
care. Additionally, this research investigates how we can find the best, right affordances that generate the desirable outcome. Answers may lie in the connections themselves (what) as well as in the characteristics of the connections (how).

There is a call for research on the interpretative features of, rather than, system features themselves, to explain the complex phenomenon of technology use (Burton-Jones \& Straub Jr, 2006; Leonardi, 2013). Technology use is determined by not only material elements, but also users' goals and users' abilities to use (Leonardi, 2011; Markus \& Silver, 2008). The users' interpretations and actions with a technology keep changing (Leonardi, 2013; Markus \& Silver, 2008), especailly interaction among multilple users, which reflects the complexity of the IT-use phenomenon. For these reasons, understanding IT phenomenon is challenging. In this study, I use the concept of affordance as a basis to provide insights on the use of ISMP in a healthcare context. Affordances come from relations of the material and the social actors. People's perceptions toward the technology use or their actions in using the technology represent different types of affordances: perceived affordances and actualized affordances, respectively. In addition, mechanisms and processes leading to different kinds of affordances by different users have not be adequately studied in the literature (Borghi et al., 2012). I am interested in the relations among affordance types, impacts of affordance types, and factors influencing affordances. This leads to one of the research questions in this paper: "How do different types of affordances provided by a technology affect users' behaviors in the healthcare context?"

An affordance is a relationship between a user and a technology (Leonardi, 2011). It emerges during a user's interactions with a technology. Identifying specific affordances has a great utility in helping explain why people use the same technology but react differently in a similar or different situation. The concept of affordance is useful in helping us understand the key factors that matter in a user's particular actions. Even a simple 
function of a technology can bring various affordances due to a user's interpretations and behaviors when the user interacts with the technology in different specific situations (Lukyanenko, Parsons, \& Wiersma, 2014). In this study, I propose three types of affordances drawn upon prior literature on affordance (e.g., Leonardi, 2011; Strong, Johnson, et al., 2014). During the technology use, before and after the use, users continuously attach their interpretations to the technology (perceived affordance) and exhibit different interactions with the technology (behavioral affordance), and interact with other users through technology uses (interactive affordance). The different types of affordances generate varied outcomes. For example, resulted from a behavioral affordance, ubiquitous access of ISMP, requires only interactions with the technology, lead to better access to healthcare. In contrast, resulted from an interactive affordance, virtual meetings between a patient and a physician using ISMP, supports shared decision-makings which is a core aspect of patient-centered care. This study investigates how those affordances are actualized and thus contribute to the patient-centered care processes.

\section{Current Study}

The research context is a large hospital in which a new healthcare system, a mobile app in a social media platform, was recently implemented. The research site, an advanced healthcare organization well known for its adoption of a cutting-edge technology, provides an excellent setting to study emergence and routinization with an ISMP in a healthcare context.

This study focuses on the identification of affordances of ISMP in a real healthcare context and investigation on how the affordances are related to each other as well as key influencing factors to the affordances. Through a mixed-method analysis with the data collected from interviews, focus groups, conversation texts, and system event log data, I 
identifies two key affordances of ISMP, virtual healthcare consultation and ubiquitous access, which are instances of an interactive affordance and a behavioral affordance, respectively. The ISMP affordances interact with each other and contribute to the patientcentered care processes, including shared decision-making and access to care. The actualized affordances are influenced by the user's perceived affordances resulted from combination of specific technology features, tasks, and users.

ISMP shares the properties of mobile technology as well as those of social media technology. One of the distinguishable mobile technical features is mobility which allows users to access the technology at any time and from any location (Abouzahra \& Tan, 2013). The social media technology offers interactive and persistent features which provide a base for interpersonal associations among users (Hawker, 2010). Those technology features lead to the key affordances of the ISMP technology, ubiquitous access and virtual healthcare consultation, and contribute to the changes in the healthcare processes.

Not all affordances of a technology are actualized; only some are actualized in particular situations. For example, depending on the disease types and stages, the types and timing of care services affect the effectiveness of the services (Jacobson, 1986; Pearlin, Semple, \& Turner, 1988). My analyses reveal that using a technology brings different perceptions and behaviors depending on a user's role, technology's features, specific situations of the uses including where and when, and relationships between users emerged during the use of the technology. Patients and physicians use the same technology, but their perceptions are different. Patients appreciate the technology's ability that enables them to access health systems or health care professionals anytime and anywhere, while physicians feel that the technology controls their time and interrupts personal lives. Patients and physicians access the same health data in ISMP, but the impacts of the access are different. Patients are able to more engage in understanding and managing their health conditions, 
while physicians are able to consider and provide more holistic and more personalized care to individual patients.

\section{Contributions}

ISMP is a new technology that integrates healthcare systems with the properties of both social media technology and mobile technology. Even though it is just a tool, the implementation of ISMP has generated a new phenomenon which leads to significant changes in healthcare processes. The analysis results show that ISMP has changed how patients and physicians interact with each other and has enabled a more patient-centered care process.

This study provides three practical contributions. First, I identify the different uses of ISMP which brings a new phenomenon in the healthcare industry. ISMP use changes healthcare processes and people's perception about medical services. Patients use the ISMP technology to access medical services and health information anytime and anywhere, and they are willing to pay for a virtual meeting with a physician which was a new type of medical service. Second, this study identifies different types of affordances of ISMP, such as 'ubiquitous access' and 'virtual healthcare consultation' affordances. They are perceived and also actualized in the real healthcare setting. Third, the analysis results show how the affordances leading to care process changes are entangled by technology features, users, tasks, and situations. It provides healthcare organizations with an insight on how the use of a new integrated technology enables healthcare process changes toward patient-centered care.

In summary, this study provides practical contributions by:

- Finding that ISMP uses affect healthcare processes, which is a new phenomenon;

- Introducing different types of affordances of an ISMP in the healthcare context; 
- Understanding how the use of an ISMP enables patient-centered care processes. Theoretically, this study introduces a new concept of a healthcare technology, referred as to ISMP, which integrates data from an EMR system with social media features in a mobile device. ISMP as an emerging technology reaches beyond a hospital system; most functionalities designed to meet patients' needs are embedded in a pervasive platform that provide universal access to patients and physicians. This new concept created a new phenomenon emerged in healthcare context, which makes a theoretical contribution. Second, this study explains the relationships among different types of affordances: perceived affordance, behavioral affordance, and interactive affordance. Categorizing affordances into different types and examining the relationships among affordances, affordance dimensions, and their outcomes contribute to the existing body of the affordance theory. More specifically, this study

- introduces a new concept of a new technology composed of social media properties, mobile properties, and healthcare information systems and a new phenomenon due to the new technology uses in health care;

- proposes a new typology for affordance, which includes perceived, behavioral, and interactive affordance;

- explains the relationships among affordance types;

- $\quad$ analyzes factors affecting affordances;

- examines the impacts of affordances.

Methodologically, this study applies a mixed-method approach by collecting subject and objective data, and by analyzing these data both qualitatively and quantitatively in order to provide a rich interpretation of the emergent patterns and their meanings from the data. Factors related to affordances and their relationships should be reflected real practices recognized with real historical data. This triangulation approach helps me to have 
confidence in understanding the complex health IT phenomena and in identifying affordances that are both perceived and actualized. 


\section{LITERATURE REVIEW}

\section{A. Patient-Centered Care Process}

A main principle of the patient-centered care is that patient is the source of control. It means that patients should be informed of their health-related information and should be involved in making own healthcare decisions. Patient-centered care has been a focus in academia, emphasizing on key aspects related to the care processes. James and his colleagues address two constructs for the patient-centered care: patient activation and patient engagement (James, Hibbard, Agres, Lott, \& Dentzer, 2013). Patient activation refers to the extent to which patients have the abilities, skills, and willingness to be involved in making decisions about their care. Patient engagement means that patients are not only activated but also involved in activities that promote positive patients' health behaviors, that is, they are taking some responsibilities for their own health (James et al., 2013). Wilson and his colleagues suggest that a patient-centered care application should integrate three themes: patient-focus, patient-activity, and patient-empowerment (Wilson, Wang, \& Sheetz, 2014). Patient-focus means that healthcare applications are developed primarily based on the needs and perspectives of patients. Patient-activity assumes that patients meaningfully participate in providing and consuming health information. Patient-empowerment means that patients want to, and are able to, control far-ranging aspects of their healthcare through technologies (Wilson et al., 2014).

Many studies have used various terms to describe the concepts of patient-centered care. In Table 1, those concepts are classified under four constructs: patient-focus, patient engagement, patient empowerment, and patient activation. Patient-focus means that physicians attend to and understand the needs and perspectives of patients. Patient engagement and empowerment emphasize the roles of patients and physicians, and their 
relationship. Patient activation refers to active participations by patients by involving in making medical decisions and by proactively seeking healthcare that meets their needs, including health-related information and medical services.

Table 1. Definition of Patient-Centered Care in Literature

\begin{tabular}{|c|c|c|}
\hline $\begin{array}{l}\text { Concept of } \\
\text { Patient- } \\
\text { Centered }\end{array}$ & Definition of Patient-Centered Care & Reference \\
\hline \multirow{6}{*}{ Patient-focus } & $\begin{array}{l}\text { Respectful of and responsive to individual patient } \\
\text { preferences, needs, and values, ensuring that patient } \\
\text { values guide all clinical decisions. }\end{array}$ & $\begin{array}{l}\text { (America, } \\
\text { 2001) }\end{array}$ \\
\hline & $\begin{array}{l}\text { Meeting the patient's needs rather than simply } \\
\text { providing diagnostic services and advice without } \\
\text { support for following recommendations. }\end{array}$ & $\begin{array}{l}\text { (Silow-Carroll, } \\
\text { Alteras, \& } \\
\text { Stepnick, 2006) }\end{array}$ \\
\hline & $\begin{array}{l}\text { Respect for the patient's values, preferences, and } \\
\text { expressed need: information, education, and } \\
\text { emotional support to relieve fear and anxiety. }\end{array}$ & $\begin{array}{l}\text { (Kahn, } \\
\text { Schneider, } \\
\text { Malin, Adams, } \\
\text { \& Epstein, } \\
\text { 2007) }\end{array}$ \\
\hline & $\begin{array}{l}\text { Tailor treatment to patient needs, set patient goals } \\
\text { based on patient preference, and increasing the } \\
\text { humaneness of care. }\end{array}$ & $\begin{array}{l}\text { (Robinson, } \\
\text { Callister, } \\
\text { Berry, \& } \\
\text { Dearing, 2008) }\end{array}$ \\
\hline & $\begin{array}{l}\text { The experience (to the extent the informed, } \\
\text { individual patient desires it) of transparency, } \\
\text { individualization, recognition, respect, dignity, and } \\
\text { choice in all matters, without exception, related to } \\
\text { one's person, circumstances, and relationships in } \\
\text { healthcare. }\end{array}$ & $\begin{array}{l}\text { (Berwick, } \\
\text { 2009) }\end{array}$ \\
\hline & $\begin{array}{l}\text { Persons exist in relationships with other persons, } \\
\text { persons are social beings, persons have a context } \\
\text { through which their personhood is articulated, being } \\
\text { recognized, respected and trusted as a person } \\
\text { impacts on a person's sense of self. }\end{array}$ & $\begin{array}{l}\text { (McCormack, } \\
\text { 2004) }\end{array}$ \\
\hline \multirow{2}{*}{$\begin{array}{c}\text { Patient } \\
\text { engagement }\end{array}$} & $\begin{array}{l}\text { The provider-patient relationship as one that } \\
\text { integrates the patient perspective and preferences } \\
\text { while involving the patient in decision making and } \\
\text { self-care. }\end{array}$ & $\begin{array}{l}\text { (Gerteis, } \\
\text { Edgman- } \\
\text { Levitan, Daley, } \\
\text { \& Delbanco, } \\
\text { 1993) }\end{array}$ \\
\hline & $\begin{array}{l}\text { Person-centered requires the formation of } \\
\text { therapeutic relationships between professionals, } \\
\text { patients and their significant others, and that these } \\
\text { relationships are built on mutual trust, } \\
\text { understanding and sharing collective knowledge. }\end{array}$ & $\begin{array}{l}\text { (McCormack \& } \\
\text { McCance, } \\
\text { 2006) }\end{array}$ \\
\hline
\end{tabular}




\begin{tabular}{|c|c|c|}
\hline & $\begin{array}{l}\text { The patients' perceptions of how understood they } \\
\text { feel, how 'at ease' the health professional appears } \\
\text { and their willingness to accept the health } \\
\text { professional's advice. }\end{array}$ & $\begin{array}{l}\text { (Selfe, } \\
\text { Matthews, \& } \\
\text { Stones, 1998) }\end{array}$ \\
\hline \multirow{7}{*}{$\begin{array}{c}\text { Patient } \\
\text { empowerment }\end{array}$} & $\begin{array}{l}\text { A partnership among practitioners, patients, and } \\
\text { their families (when appropriate) to ensure that } \\
\text { decisions respect patient's wants, needs, and } \\
\text { preferences and that patients have the education and } \\
\text { support they need to make decisions and participate } \\
\text { in their own care. }\end{array}$ & $\begin{array}{l}\text { (America, } \\
\text { 2001) }\end{array}$ \\
\hline & $\begin{array}{l}\text { The health professional's and patient's perceptions } \\
\text { of their relationship, particularly mutual regard and } \\
\text { agreement on goals. }\end{array}$ & $\begin{array}{l}\text { (Gavin, } \\
\text { Wamboldt, } \\
\text { Sorokin, Levy, } \\
\text { \& Wamboldt, } \\
\text { 1999) }\end{array}$ \\
\hline & $\begin{array}{l}\text { 1) considering patients' needs, wants, perspectives } \\
\text { and individual experiences; ( } 2 \text { ) offering patients } \\
\text { opportunities to provide input into and participate in } \\
\text { their care; and ( } 3 \text { ) enhancing partnership and } \\
\text { understanding in the patient- physician relationship } \\
\text { (all) }\end{array}$ & $\begin{array}{l}\text { (Epstein et al., } \\
\text { 2005) }\end{array}$ \\
\hline & $\begin{array}{l}\text { The similarity of health professionals' and patients' } \\
\text { beliefs about the illness, treatment, patients' } \\
\text { concerns, information given by the health } \\
\text { professional. }\end{array}$ & $\begin{array}{l}\text { (Romm \& } \\
\text { Hulka, 1979) }\end{array}$ \\
\hline & $\begin{array}{l}\text { Patients are equipped to make informed choices for } \\
\text { themselves with sufficient skills and support from } \\
\text { the health services. }\end{array}$ & $\begin{array}{l}\text { (Anderson et } \\
\text { al., 1995) }\end{array}$ \\
\hline & $\begin{array}{l}\text { Process that involves at least two participants - the } \\
\text { patient and the doctor - and often many more } \\
\text { (their respective networks of family or professional } \\
\text { colleagues). }\end{array}$ & $\begin{array}{l}\text { (Elwyn, } \\
\text { Edwards, } \\
\text { Kinnersley, \& } \\
\text { Grol, 2000) }\end{array}$ \\
\hline & $\begin{array}{l}\text { There is a jointly negotiated and agreed plan } \\
\text { between the health professional and patient and the } \\
\text { patient is given the resources needed to achieve it, } \\
\text { such as information and skills. }\end{array}$ & $\begin{array}{l}\text { (Schulman, } \\
1979 \text { ) }\end{array}$ \\
\hline \multirow{2}{*}{$\begin{array}{l}\text { Patient- } \\
\text { activity }\end{array}$} & Access to the kind of care that works for the patient. & $\begin{array}{l}\text { (Kahn et al., } \\
\text { 2007) }\end{array}$ \\
\hline & Active participants in their own healthcare. & $\begin{array}{l}\text { (Bergvik, } \\
\text { Wynn, \& } \\
\text { Sørlie, 2008) }\end{array}$ \\
\hline Combination & $\begin{array}{l}\text { 1) considering patients' needs, wants, perspectives } \\
\text { and individual experiences; ( } 2 \text { ) offering patients } \\
\text { opportunities to provide input into and participate in } \\
\text { their care; and ( } 3 \text { ) enhancing partnership and } \\
\text { understanding in the patient- physician } \\
\text { relationship; (4) Actions in service of patient- } \\
\text { centeredness, including interpersonal behaviors, }\end{array}$ & $\begin{array}{l}\text { (Epstein et al., } \\
\text { 2005) }\end{array}$ \\
\hline
\end{tabular}




\begin{tabular}{|l|l|l|}
\hline & $\begin{array}{l}\text { technical interventions and health systems } \\
\text { innovations. }\end{array}$ & \\
\hline
\end{tabular}

From the four constructs, four dimensions of the patient-centered care process are identified: access to care, focus on patient, shared decision-making, and patient engagement. Table 2 shows the four dimensions in the patient-centered care process. Access to care refers to a patent's ability to access medical services and health information (Kahn et al., 2007). Focus on patient is a basic concept of the patient-centered care (America, 2001), which emphasizes holistic views on a patient as a whole person (McCance, Slater, \& McCormack, 2008). Shared decision-making refers to a jointly negotiated and agreed upon plan between a health care professional and a patient, which has been studied by many researchers (Gavin et al., 1999; Schulman, 1979). Recently, patient engagement has become a promising construct that alters the outcome of healthcare (James et al., 2013). Patient engagement represents patients' active participations in their taking care of their own health (Bergvik et al., 2008). I focus on the four dimensions of patient-centered care process as they provide the necessary bases for studying ISMP technology use and the outcome on the healthcare processes.

Access to care means that the providers deliver accessible services to their patients with short waiting times (Davis et al., 2005). Examples of accessible services include the easiness of making an appointment for personal care, timely providers' responses to emails and telephone calls, and convenient electronic prescription refills. "With short waiting time" typically means that patients can make same-day appointments. Patients get healthcare services regardless whether or not it's within the regular operations hour, which make primary care readily accessible at nights, on weekends, and during holidays (Davis, Schoenbaum, \& Audet, 2005). Patients can access any kinds of care that work for them (Kahn et al., 2007). Access to care is facilitated by patient-activation. 
Table 2. Dimensions of Patient-Centered Care Process in Literature

\begin{tabular}{|c|c|c|c|}
\hline $\begin{array}{c}\text { Main } \\
\text { Concept }\end{array}$ & Dimension & Definition & Reference \\
\hline $\begin{array}{l}\text { Patient- } \\
\text { activity }\end{array}$ & $\begin{array}{l}\text { Access to } \\
\text { care }\end{array}$ & $\begin{array}{l}\text { The primary care delivers } \\
\text { accessible services including } \\
\text { healthcare information with } \\
\text { shorter waiting times, electronic } \\
\text { access to a member of care } \\
\text { providers (team). }\end{array}$ & $\begin{array}{l}\text { (Davis, } \\
\text { Schoenbaum, \& } \\
\text { Audet, 2005) }\end{array}$ \\
\hline Patient-focus & $\begin{array}{c}\text { Focus on } \\
\text { patient }\end{array}$ & $\begin{array}{l}\text { A physician understands a } \\
\text { patient's biopsychosocial } \\
\text { information by asking values, } \\
\text { preferences, and needs to the } \\
\text { patient. A patient provides their } \\
\text { psychosocial information to the } \\
\text { physician. }\end{array}$ & $\begin{array}{l}\text { (Cegala \& Post, } \\
\text { 2009; Epstein et al., } \\
\text { 2005; McCance et } \\
\text { al., 2008; Mead \& } \\
\text { Bower, 2000; } \\
\text { Stewart, 2001) }\end{array}$ \\
\hline $\begin{array}{c}\text { Patient } \\
\text { empowerment }\end{array}$ & $\begin{array}{l}\text { Shared } \\
\text { decision- } \\
\text { making }\end{array}$ & $\begin{array}{l}\text { A patient is involved in medical } \\
\text { decision-making process, and } \\
\text { share power and responsibility } \\
\text { with a physician. }\end{array}$ & $\begin{array}{l}\text { (Elwyn et al., 2000; } \\
\text { Epstein et al., 2005; } \\
\text { Mead \& Bower, } \\
\text { 2000) }\end{array}$ \\
\hline $\begin{array}{c}\text { Patient } \\
\text { engagement }\end{array}$ & Engagement & $\begin{array}{l}\text { The cognitive aspect reflects a } \\
\text { person's intellectual absorption } \\
\text { in an activity. The emotional } \\
\text { aspect reflects the emotional } \\
\text { bonding or impact that occurs } \\
\text { during the activity. The } \\
\text { behavioral aspect entails how } \\
\text { much attention, concentration, } \\
\text { effort, persistence, and verbal } \\
\text { participation the person shows } \\
\text { during the activity. }\end{array}$ & $\begin{array}{l}\text { (Brodie, Hollebeek, } \\
\text { Juric, \& Ilic, 2011; } \\
\text { Furrer \& Skinner, } \\
\text { 2003) }\end{array}$ \\
\hline
\end{tabular}

Focus on patient is a common component of patient centered care addressed by many researchers (e.g., Epstein et al., 2005; McCance et al., 2008; Mead \& Bower, 2000; Stewart, 2001). Cegala and Post (2009) described it as "exploring both the disease and the illness experience, understanding the whole person" (Cegala \& Post, 2009). Medical professionals know the patients, which means that they should understand the patient as a social human being, including information on values, preferences, and needs of the patients, history of healthcare the patients has received, and the environments surrounding the patients. 
Shared decision-making refers to reaching agreements on healthcare goals and plans made by both the patient and the providers during diagnosis and treatment processes (Schulman, 1979). Researchers have viewed patient involvement and shared power and responsibility as key elements of patient-centered care (Elwyn et al., 2000; Epstein et al., 2005; Mead \& Bower, 2000), emphasizing the role of patients in their own care process and their relationships with the care providers. Shared decision-making is an important component in quality healthcare (Braddock, 2012), but in practice it is still challenging to realize shared decision making without necessary social and technological supports.

Patient engagement covers cognitive, emotional, and behavioral enjoyments in healthcare process (Brodie et al., 2011; Furrer \& Skinner, 2003). The cognitive aspect reflects a person's intellectual absorption in understanding and transferring health information. The emotional aspect reflects a patient's emotional bonding or impact that occurs when the patient interacts with healthcare providers. The behavioral aspect entails how much attention, concentration, effort, persistence, and verbal participation a patient shows during health-related activities, such as dietary habits or physical exercise (Brodie et al., 2011). The patient engagement concept has been an important focus in health information system discipline.

Cognitive engagement is related to information (Protheroe, Rogers, Kennedy, Macdonald, \& Lee, 2008), risk knowledge, and decision autonomy (Agarwal \& Karahanna, 2000; Heesen et al., 2011). Emotional engagement plays a critical role in decision-making processes in which uncertainty exists, by marking different options as advantages or disadvantages (Naqvi, Shiv, \& Bechara, 2006). It improves patents' relationships with healthcare providers (Morgan \& Hunt, 1994), commitment, emotional attachment (Brodie, Ilic, Juric, \& Hollebeek, 2013), and creating co-created values (Prahalad \& Ramaswamy, 2004). The cognitive and emotional engagements extend behavioral engagement by 
recognizing the iterative nature of engagement process (Brodie et al., 2011). Behavioral engagement is related to the use of healthcare technology or health information (Bonabeau, 2009). Patient engagement improves risk knowledge (Heesen, Solari, Giordano, Kasper, \& Köpke, 2011), decision autonomy (Agarwal \& Karahanna, 2000), relationship (Kuijer et al., 2000), rapport, participation, satisfaction (Greener, Joe, Simpson, Rowan-Szal, \& Lehman, 2007), cost of care, care experiences, and health condition (Hibbard \& Greene, 2013).

Most prior literature focuses on the impacts of patient-centered care, not how to deliver patient-centered care. Some literature showed that health information systems enable patient-centered care. Patient-Centered Medical Home (PCMH), for example, improves clinical performance outcomes and patient experiences (Jackson et al., 2013). The system utilizes health information technology with team-based collaboration (Grumbach \& Grundy, 2010), and payment functionality (Bitton et al., 2012) to offer holistic patient-centered healthcare services. As such, process changes enabled by using health information systems is a promising way for transformation towards patient-centered care (Paul A Nutting et al., 2009). However, this is a lack of understanding about how a health information system and what material properties of the system make patientcentered care possible.

\section{B. Effects of Use of Technology in Healthcare}

Health information systems have been an active topic of investigation in academia. For example, telemedicine systems have changed healthcare process (Constantinides \& Barrett, 2006). Electronic services of the telemedicine systems support patient care, education, and monitoring, leading to significant positive impacts on patient's health outcomes (Clarke \& Steele, 2012), quality of care, patient's satisfaction, and care costs 
(Schwamm, 2014). The virtual world function of the telemedicine as a monitoring tool resolves patients' complaints and facilitates transparency, which in turn enhances patient experiences, patient engagement, and care coordination (Thielst, 2011). The literature has showed that telemedicine systems contribute to the changes in the healthcare industry.

The use of electronic medical record (EMR) has also been an active topic of investigation in academia (Bhargava \& Mishra, 2014; Greenhalgh, Hinder, Stramer, Bratan, \& Russell, 2010). Implementation of EMR systems change healthcare processes (Hillestad et al., 2005). Some case studies showed that patients who were able to review a consultation summary experienced less decisional conflicts with healthcare providers, and highly rated the systems (Belkora, Loth, Volz, \& Rugo, 2009; Greenhalgh, Stramer, et al., 2010). In this study I incorporate EMR system data to investigate how some features of ISMP affect care processes.

Decision support systems have been extensively used in the healthcare industry. It mainly supports physicians' decision-making process, but haven't been extended to supporting patients' processes. There are a small number of studies which investigate how shared decision-making aids help both patients and physicians. One study showed that shared decision-making applications adjusted the expectations of patients and physicians, and improved their knowledge (Weinstein, Clay, \& Morgan, 2007). Repository and infrastructure for data sharing and integration in the shared decision making applications play a role in building collaboration. Big data analysis has potentials to further enhance patient-centered care (Phillips et al., 2014).

Pervasive healthcare has started to be considered as a solution to provide better healthcare services to patients. Pervasive healthcare refers to making healthcare available to anyone, anytime, and anywhere by removing locational and time restraints, while increasing both healthcare coverage and quality (Varshney, 2005). Universal mobile 
technologies enable a convenient anytime and anywhere access to healthcare services and health information. Mobile messaging as one of the salient features in the mobile technologies used in healthcare affects communication, healthcare-seeking behaviors, and health outcomes (Gurol-Urganci, de Jongh, Vodopivec-Jamsek, Car, \& Atun, 2012). I believe that the ability to provide patients with healthcare information and services anytime and anywhere makes significant impacts on the healthcare processes.

\section{Affordances}

Giddens' (1984) structuration theory privileges human actions over structures without explicitly addressing technology. The adaptive structuration theory (DeSanctis \& Poole, 1994) modifies the structuration theory to explicitly incorporate the concept of information technology (IT). It models the relationship between social structures inherent in IT and interaction processes of IT use. During social interaction with IT use, new structures emerge depending on the process of "appropriation" or "alignment," immediate visible actions with an IT-based rule or resource in a specific context at a specific time. However, Orlikowski (2000) recommends moving from the concept of "appropriation of embedded structure" to a practice-based view of "enactment of emergent structure." The base assumption is that if organizations are as much material as they are social and if technologies are as much social as they are material, then perhaps it makes sense to break down distinctions between the social and the material altogether. The sociomaterial view has led to new insights into important IS-related phenomena such as mobile IT usage (Leclerq, Carugati, Giangreco, da Cunha, \& Jensen, 2009), work collaboration in Second Life (Orlikowski, 2009), digital innovation (Svahn, Henfridsson, \& Yoo, 2009), the impacts of social media (Scott \& Orlikowski, 2009), and digital entrepreneurship (Davidson \& Vaast, 2010). 
The sociomaterial theory reconceptualizes social worlds through the relations between the material agency of artifacts and the social agency of human (Orlikowski, 2007, 2009; Orlikowski \& Scott, 2008). It recognizes the importance of the mutual relationship between the social and the material. The theory puts forth a relational perspective between the social and the material that challenges the privileged role of the human actors. The focus is on the agencies that have so thoroughly saturated each other in a way that boundaries dissolved between them. In this study, the "material agent" refers to constituent features in an ISMP that are available to all users in the same way. The "social agent" is goal-oriented patients or physicians who are involved in healthcare processes in a healthcare organization. However, the ways patients and physicians use same technology may be different depending on individual's intentions to use it. The heterogeneity of the social agencies and the material agencies generates sociomaterial practices.

To discuss the mutuality relationships, new vocabularies (e.g., affordance entanglement, imbrication scaffold) were introduced. Leonardi (2011) addresses the concept of the affordances into the "imbrications" view of the human and the material agencies. Leonardi (2011) focuses on the affordance that arises in concert with actors' goals as the mechanisms of organizational change, not IT features themselves. Zammuto et al. (2007) argue that a technological object has functionality but needs to be recognized as a social object, because technological possibilities of actions are not given, but depend on the intents and perceptions of social actors. This study takes the same view to see different usages of ISMP, which depend on users' perceptions on ISMP and the context of ISMP use.

An affordance, according to Gibson's original definition, is what is offered, provided, or furnished to someone or something by an object (Gibson, 1979). Recently, Strong et al. (2014) propose that an affordance is a potential for behaviors associated with 
achieving an immediate concrete outcome and arises from the relation between an artifact and goal-oriented actor(s). They extend the affordance concept to actualization, which is defined as "the actions taken by actors as they take advantage of one or more affordances through their use of the technology to achieve immediate concrete outcomes in support of organizational goals" (Strong, Volkoff, et al., 2014). This study builds on the concepts of the perception and the actualization of affordances. Table 3 summarizes the definitions of affordances in literature.

Affordances are considered as a mechanism for organizational changes. The imbrication of human agencies and the material agencies creates infrastructure in the form of routines, which is the result of previous affordances (Leonardi 2011). Coordination between the social agencies and the material agencies represent a capacity for actions. Affordance actualization leads to organizational changes (Volkoff \& Strong, 2013)

However, what affordances emerge in specific technologies, and their impacts are not clear in literature. Because a technology carries various features, it brings a set of affordances. The technology for this study combines properties of mobile technology and those of social media technology, so I looked for the affordances of mobile technologies and social media technologies and their impacts. A summary of the literature on affordances of the two technologies and the effects of the affordances is provided in Appendix 1. Treem and Leonardi (2012) address four affordances of social media technology: visibility, editability, persistence, and association (Treem \& Leonardi, 2012). Each affordance brings particular actions. Association of the social media, for example, gives a possibility of social connection and access to relevant information. Persistence is good for sustaining knowledge. Mobile technologies including smart phones have a capability to carry many functionalities in various technical features, enacting various affordances (Cochrane \& Bateman, 2010). Common affordances of mobile technologies 
are ubiquitous access that is good for education (Abouzahra \& Tan, 2013; Melhuish \& Falloon, 2010), interactivity that changes behaviors (Sundar, Bellur, \& Jia, 2012), mobility, connectedness, interoperability, identifiability, and personalization that helps users achieve individual purposes (Cousins \& Robey, 2015). Two studies with social media technologies focus on knowledge (Majchrzak, Faraj, Kane and Azad, 2013) and healthcare management (Pousti, Urquhart and Linger, 2014) respectively. They articulate that affordances have positive and negative effects, which means that various affordances interact with each other in the pursuit of a particular goal.

Table 3. Definition of Affordances

\begin{tabular}{|c|c|c|}
\hline Category & Definition of Affordance & Reference \\
\hline \multirow{3}{*}{$\begin{array}{l}\text { Properties of } \\
\text { environment }\end{array}$} & $\begin{array}{l}\text { "The affordances of the environment are what it } \\
\text { offers the animal, what it provides or furnishes, } \\
\text { either for good or ill. ... I mean by it something } \\
\text { that refers to both the environment and the animal } \\
\text { in a way that no existing term does. It implies the } \\
\text { complementarity of the animal and the } \\
\text { environment." }\end{array}$ & (Gibson, 1979) \\
\hline & $\begin{array}{l}\text { "Affordances are dispositional properties of the } \\
\text { environment that pose "real possibilities" for } \\
\text { action". }\end{array}$ & (Turvey, 1992) \\
\hline & $\begin{array}{l}\text { "One can obviously perceive the affordances of } \\
\text { objects and events without engaging in the } \\
\text { afforded action, suggesting that affordances can } \\
\text { be perceived as properties". }\end{array}$ & $\begin{array}{l}\text { (Michaels, } \\
\text { 2000) }\end{array}$ \\
\hline \multirow{4}{*}{$\begin{array}{l}\text { Relations } \\
\text { between an } \\
\text { animal and its } \\
\text { environment }\end{array}$} & $\begin{array}{l}\text { An affordance is described as animal- } \\
\text { environment fit. }\end{array}$ & (Warren, 1984) \\
\hline & $\begin{array}{l}\text { "Affordances are emergent relational properties } \\
\text { of an animal-environment system". }\end{array}$ & $\begin{array}{l}\text { (Stoffregen, } \\
\text { 2003) }\end{array}$ \\
\hline & $\begin{array}{l}\text { "Affordances are relations between an animal and } \\
\text { its environment". }\end{array}$ & $\begin{array}{l}\text { (Chemero, } \\
\text { 2003) }\end{array}$ \\
\hline & $\begin{array}{l}\text { "An affordance is the relationship between users' } \\
\text { abilities and features of technology." }\end{array}$ & $\begin{array}{l}\text { (Cousins \& } \\
\text { Robey, 2015) }\end{array}$ \\
\hline \multirow{2}{*}{$\begin{array}{l}\text { Relations } \\
\text { between an } \\
\text { animal and its } \\
\text { environment/ } \\
\text { Possibility for } \\
\text { action }\end{array}$} & $\begin{array}{l}\text { "Affordance exists as a relationship between an } \\
\text { actor and an artefact, it reflects possible actions } \\
\text { on the artefact itself". }\end{array}$ & $\begin{array}{l}\text { (Hutchby, } \\
\text { 2001) }\end{array}$ \\
\hline & $\begin{array}{l}\text { "Functional affordances are a type of relationship } \\
\text { between a technical object and a specified user } \\
\text { (or user group) that identifies what the user may } \\
\text { be able to do with the object, given the user's }\end{array}$ & $\begin{array}{l}\text { (Markus \& } \\
\text { Silver, 2008a) }\end{array}$ \\
\hline
\end{tabular}




\begin{tabular}{|l|l|l|}
\hline & $\begin{array}{l}\text { capabilities and goals. More formally, functional } \\
\text { affordances are defined as the possibilities for } \\
\text { goal-oriented action afforded to specified user } \\
\text { groups by technical objects". }\end{array}$ & \\
\cline { 2 - 3 } $\begin{array}{l}\text { Affordances are "not exclusively properties of } \\
\text { people or of artifacts...[but] constituted in } \\
\text { relationships between people and the materiality } \\
\text { of the things with which they come in contact". }\end{array}$ & $\begin{array}{l}\text { (Leonardi, } \\
\text { 2011) }\end{array}$ \\
$\begin{array}{l}\text { "Affordances are new combinations of } \\
\text { technology and organizational features } \\
\text { continually create possibilities that affect } \\
\text { organizational form and function." } \\
\text { Technological functionality needs to be } \\
\text { recognized as a social object, because } \\
\text { technological possibilities of action are not given, } \\
\text { but they depend on the intents and the } \\
\text { perceptions of social actors enacting them. }\end{array}$ & $\begin{array}{l}\text { (Zammuto et } \\
\text { al., 2007) }\end{array}$ \\
\hline
\end{tabular}




\section{CONCEPTUAL DEVELOPMENT}

\section{A. Affordance Types}

Leonardi (2013) suggested the concepts of individualized affordance, shared affordance, and collective affordance. An individualized affordance is enacted by someone who uses a technology's features, reflecting a simple interaction between an individual and an object. The simple interaction has possibilities for actions, which is the traditional concept of the affordance. He also suggested the concept of shared affordance that a group of users use a system in similar way which leads to organizational changes (Leonardi, 2013). A collective affordance is proposed as an organizational affordance that is collectively created by many people to conduct non-interdependent tasks. An example lies in the study of "unity in diversity." Distinct capabilities of an EMR system and diverse feature uses allow people to complete work (Oborn, Barrett, \& Davidson, 2011). Strong and his colleagues (2014) found a set of organizational affordances with dependency, named a bundle of affordances. One affordance is "Standardizing data, process, and roles" that emerges when many people in an organization use a system with rules which restrict format for data entry and who can access data (Strong, Johnson, et al., 2014). It simply makes many people use the system features in particular ways. Another affordance is "Coordinating patient care across sites, facilities and providers" when healthcare providers use a messaging feature and information on patients. The organization-level affordances are pooled individualized affordances (Leonardi, 2013). They are mixed without distinctions between affordances when users interacting with the system and affordances when users interacting with each other through the system use. In this study, I separate them into two different types of affordance, behavioral affordance and interactive affordance, to see how they contribute to certain outcomes. 
There is a conceptual gap that affordances have not been studied at pair (one-toone) level. Pair-level affordances, with individualized affordances, play a foundational role in enacting organizational affordances, but it is missing in the literature. Interestingly, Leonardi (2013) found that divergent uses occur at the beginning phase before people converged on the use of a common set of technology's features to enact a shared affordance (Leonardi, 2013). The diverse uses exist at the level of individuals, pair, or small-sized groups with a couple of people which I see as lower-level affordances. One-to-one interaction, especially interactions between a patient and a physician, is a core interaction in the healthcare processes. The mobile consulting feature in the ISMP technology was initially designed to support communications between the two. However, this feature has not been used as much as the traditional functions such as ISMP scheduling feature, especially when physicians are busy. It motivated me to study pair-level affordances, oneto-one interaction through the technology use. Understanding lower-level affordances is important because it helps organizations to find ways to enact certain affordances that lead to desired organizational changes.

\section{B. Proposed Affordance Types and Their Relationships}

Based on the literatures, I identify three types of affordances represented in Table 4: perceived affordance, behavioral affordance, and interactive affordance. A perceived affordance $^{1}$ reflects a user's perception of possibilities for action through technology use. It refers to not only the user's semantic and syntactic understanding of a technology (what) but also the user's interpretations about the technology use (how) (Vyas, Chisalita, \& Van Der Veer, 2006). A user's perceived affordance is influenced by the user's intentions to use the technology. For example, a physician may value ISMP for a feature to communicate

\footnotetext{
${ }^{1}$ Norman (2004) acknowledged that he should have used the term 'perceived affordance.'
} 
with patients (what), while a patient may value more ISMP's features of ubiquitous connection to medical data and real-time communication for timely care (how).

Perceived affordances are identifiable based on the interviews about users' perceptions on the values of the technology use and the documents about technologycreated routines which are predefined by designers (Sjöström \& Goldkuhl, 2003). The perceived affordances can be identified based on the information about predefined actions perceived by designers. In this case, possible actions using ISMP are scheduling for doctor's appointments, querying patients' medical records, and communication between patients and physicians. Besides technological functionality ("what"), "how" aspects that the technology offers, such as anytime, real-time, may enact a perceived affordance. It reflects easiness (appropriateness, visibility, comprehensibility, and accessibility) for action possibility in relation to comfort valued (Goldkuhl, 2008).

Behavioral affordances and interactive affordances are conceptualized as actualized affordances. A behavioral affordance is defined as a user's actualized behaviors in a task involving the use of a technology. An interactive affordance is defined as a user's actualized interaction in a task which two or more users are involved in the technology use. In this study, an instance of the interactive affordances is pair-level affordance, such as affordances that a pair of a patient and a physician use the technology. Behavioral affordances and interactive affordances are more contextualized, which means that the uses of a technology are determined by specific features uses under specific contexts.

Actualized affordances are recognized with actual actions. Consequences of human activities help to explain the presence of technologies and social structures that produce them (Stinchcombe, McDill, \& Walker, 1968). An actualized affordance in an IT use context is reflected with an action when using technology features, which indicate a 
user's needs in a certain situation. Therefore, the data of 'who', 'what technology features', and 'when' reflect a user' actualized affordances of a technology.

Measures to reflect behavioral affordances indicate a goal of a user to use the technology. An example of behavioral affordance measures in this case is intensity of actions which can be assessed by a ratio between actions. Time measures such as anytime can be used to assess the 'how' aspect of an affordance.

Measures of interactive affordances reflect multiple users' behaviors in using a technology. An action for an interactive affordance in this case is communication between a patient and a physician by using the mobile consulting feature in ISMP. Derived affordance measures include time, ratio and length of the mobile consulting usage, and the duration of time to get first response.

Table 4. Affordance Type and Definition

\begin{tabular}{|c|c|c|}
\hline $\begin{array}{c}\text { Affordance } \\
\text { Type }\end{array}$ & \multicolumn{1}{c|}{ Definition } \\
\hline $\begin{array}{c}\text { Perceived } \\
\text { affordance }\end{array}$ & $\begin{array}{l}\text { - A user's understanding of a technology itself } \\
\text { (What) } \\
\text { A user's interpretations about the technology } \\
\text { 2006) }\end{array}$ \\
\hline $\begin{array}{l}\text { Behavioral } \\
\text { affordance }\end{array}$ & $\begin{array}{l}\text { A user's actualized behaviors in a task } \\
\text { involving the use of a technology } \\
\begin{array}{l}\text { Interactive } \\
\text { affordance }\end{array}\end{array}$ & $\begin{array}{l}\text { A user's actualized interaction in a task } \\
\text { which two or more users are involved in the } \\
\text { technology use }\end{array}$ \\
\hline
\end{tabular}

Factors that influence the occurrence of an affordance include a social user with different abilities in various situations, a material object with many features, and tasks with various characteristics. In this study, those factors are referred to as affordance dimensions. A social user is an important factor that alters the nature of technology use, affecting the 
emergence of an affordance (Gibson, 1979). Many material properties from even one object may enact many forms of affordances. For example, a mobile consulting technology has asynchronized posting and user-generated contents as properties; thus, a few of affordances (e.g., anytime or empowerment) could emerge from the technology properties. Task characteristics matter in enacting affordances (Leonardi, 2013). Table 5 represents affordance types I propose and their affordance dimensions with prior literature based.

Table 5. Affordance Type in Literature

\begin{tabular}{|c|c|c|c|c|c|}
\hline \multirow{2}{*}{$\begin{array}{l}\text { Proposed } \\
\text { Affordance } \\
\text { Type }\end{array}$} & \multirow[b]{2}{*}{ Level } & \multicolumn{2}{|c|}{$\begin{array}{c}\text { Affordance } \\
\text { Dimension }\end{array}$} & \multicolumn{2}{|c|}{ Literature } \\
\hline & & \# User & $\begin{array}{c}\text { \# } \\
\text { Materi } \\
\text { al } \\
\end{array}$ & $\begin{array}{c}\text { Term of } \\
\text { Affordance }\end{array}$ & Reference \\
\hline $\begin{array}{c}\text { Objective } \\
\text { affordance }\end{array}$ & Object & - & 1 & Affordance & (Gibson, 1979) \\
\hline $\begin{array}{l}\text { Perceived } \\
\text { affordance }\end{array}$ & Individual & 1 & 1 & $\begin{array}{l}\text { Perceived } \\
\text { affordance, } \\
\text { Functional } \\
\text { affordance, } \\
\text { Symbolic } \\
\text { expressions }\end{array}$ & $\begin{array}{l}\text { (Norman, 2001; } \\
\text { Markus \& } \\
\text { Silver, 2008) }\end{array}$ \\
\hline & Individual & 1 & 1 & $\begin{array}{l}\text { Individualized } \\
\text { affordance }\end{array}$ & (Leonardi, 2013) \\
\hline $\begin{array}{l}\text { Actualized } \\
\text { affordance }\end{array}$ & $\begin{array}{l}\text { Organizati } \\
\text { onal }\end{array}$ & Many & Many & $\begin{array}{l}\text { Collective } \\
\text { affordance } \\
\text { Shared affordance, } \\
\text { Bundles of } \\
\text { affordance }\end{array}$ & $\begin{array}{l}\text { (Leonardi, 2013; } \\
\text { Strong, Volkoff, } \\
\text { et al., 2014) }\end{array}$ \\
\hline
\end{tabular}

Interactive affordance is more complicated because of the additional complexity from more users. It may be determined by not only all users' perceived affordances, but also their social and cultural conditions as situations, besides technology features (Vyas et al., 2006). A user provides and reads information from systems, which may be considered as an action to interact with a system. However, the ultimate goal is to deliver information to other user(s) (Goldkuhl, 2008). Therefore, this affordance belongs to an interactive affordance that is influenced by the material component shaped by others (e.g., 
accumulative displays of other users' conversations), other users' perceptions toward the technology, and situations around the users.

Perceived affordances are relatively simpler because the things that mainly involved in the enactment of affordances are objects and users, not contexts. Markus and Silver (2008) addressed potential uses of a technology with only technical functionality and named them as functional affordances. Functional affordances are defined as the possibilities for action that are afforded by technical objects to a specified user group (Markus and Silver, 2008). Without considering contexts such as place, time, and situation, the potential technology use would be simple or a few or more, which affects a user's beliefs about the technology use, and eventually affects the actualization of affordances.

Affordance theory has investigated mechanisms that have explanatory power on how and why things happen. For example, network changes were found in organizations due to shared affordances of a new technology for collaboration work (Leonardi, 2013). However, those changes do not always occur (Markus, 2004; Poole and DeSanctis, 2004). Leonardi explained such issue with implication of affordances. Changes in material objects or social rules enact different affordances that can be actualized (Leonardi, 2011). On the other hand, a generative mechanism for organizational changes is investigated based on the dependences among affordances between technologies and complex assemblages of organizations (Volkoff \& Strong, 2013). Contexts were emphasized in the enactment of affordances, because affordances resided in the domain of real situations. They found multiple affordances and dependences among them, which can collectively change outcomes.

Changes in affordance dimensions may result in the actualization of certain affordances. First, the material, as an affordance dimension, may be altered if it does not offer a desired affordance for the user. The material changes, often with the changes of the 
object's properties, contain causal potentials for a new affordance to emerge (Leonardi, 2011). Goh et al. (2011) explain that technical artifact provides new technical features that affect the enactment of a new affordance with broaden capabilities. At the same time, it often eliminates affordances available in the old routine, forcing the flow to take a different path (Goh, Gao \& Agarwal, 2011). This could entail the disappearance of existing affordances and the emergence of new affordances (Chemero, 2003). Next, user's characteristics may change. Self-modifying individual adaption behaviors relate especially to the capabilities of the individual, which increase through the acquisition of knowledge about the technology, the domain, or the affordance outcomes such as learning (Bernhard, Recker, \& Burton-Jones, 2013; Strong, Volkoff, et al., 2014; Hutchby, 2001). Also, situations, albeit not in all cases, are changeable. If a user is too busy at work to use a technology for two-people communication, he or she can use it at a convenient time with a technology that provides free of time limitation for uses such as social media technology. Situations play a key role in the actualization of affordances. We may change these as affordance dimensions to increase the effectiveness; however, without a full understanding of related affordances, unintended consequences can occur.

\section{Why Affordance Types Are Needed}

The actualization of an affordance leads to certain consequences (Stoffregen, 2000). Impacts of the technologies are not always clear: similar outcomes from different technologies or distinct outcomes from the same technology use in different contexts. For example, social media technology supports social connection (Treem \& Leonardi, 2012) or generates increased emotional engagement and freedom of communication (Merolli, Gray, \& Martin-Sanchez, 2013). Mobile technology produces similar outcomes with smart 
phones such as continuous communications and better relationships (Cousins \& Robey, 2015) and sharing rich data and collaboration (Cochrane \& Bateman, 2010).

Literature on technology affordances cover both behavioral affordances and interactive affordances. The literature on social media affordances identifies interactive affordances of social media technology that supports multidirectional communications (e.g., association (Treem \& Leonardi, 2012), meta-voicing, networked informed associating (Majchrzak et al., 2013)). Social media technologies also show behavioral affordances, such as narration, flexibility (Merolli, Gray, \& Martin-Sanchez, 2013), and triggered attending (Majchrzak et al., 2013). Mobile technologies show most behavioral affordances (e.g., mobility, connectedness, interoperability, personalization (Cousins \& Robey, 2015), ubiquitous access (Melhuish \& Falloon, 2010)). Smartphones offer interactive affordances such as social networking, enhanced podcasts, and image and video blogging, with behavioral affordances such as geo-tagging and text notifications (Cochrane \& Bateman, 2010). As such, even a single technology could show behavioral affordances, interactive affordances, or both.

Even though affordance types are simply grouped based on the goals of the technology uses - people interaction or system interaction - the impacts of affordance types could be more clearly recognizable. As shown in the content in Appendix 1, behavioral affordances enhance engagement (Merolli, Gray, \& Martin-Sanchez, 2013), promote learning (Majchrzak et al., 2013), or satisfy personal needs (Cousins \& Robey, 2015), regardless of the place or devices used. Interactive affordances bring social connection (Treem \& Leonardi, 2012), continuous information sharing (Majchrzak et al., 2013; Cousins \& Robey, 2015), and collaboration (Cochrane \& Bateman, 2010). As such, particular affordance types bring certain actions as the outcome; an interactive affordance enhances information sharing among people, while a behavioral affordance is related to 
meeting personal needs such as learning. I believe that identifying affordance types helps us to more clearly conceptualize and examine the outcomes of the ISMP affordances. 


\section{METHODS}

For my dissertation, I pursued a mixed-method approach that includes both quantitative and qualitative data analyses. The integration of quantitative and qualitative approaches helps address limitations of each approach (Kaplan \& Duchon, 1988; Trauth \& Jessup, 2000). This adds further analytical value by providing means to theoretically and empirically triangulate phenomena that are not available when utilizing only a single approach.

\section{A. Data Sources}

It is recommended to analyze digital traces for sociomaterial practice research. Digital traces are a new type of instrumentation that captures individual and technological activities (Hedman, Srinivasan, \& Lindgren, 2013). It reveals an individual user's actions by capturing routines in digital artifacts. This study analyzed event log data, transaction data, and conversation text data in the ISMP technology as the digital traces. Besides, the data of interviews and focus groups were collected and analyzed to understand big pictures related to the use of ISMP. Patients' demographic information and clinical data were used to analyze the factors that affect the enactment of affordances and the outcome of affordances.

\section{Case study}

To explore the relationships around the use of ISMP, I conducted a case study. A large hospital in China (more than 3000 beds, 920 units, more than 2700 employees, more than $1,200,000$ out-patient visits per year) was chosen as a research site, because the case setting provides an opportunity to explore healthcare process changes with the adoption of a cutting-edge technology, ISMP. The president of the hospital showed a clear vision of enhancing patient-centered care using technologies. Technology and processes as well as 
culture and beliefs of employees are the concerns of the top managers. I judged this hospital to be an appropriate research site for studying technology-enabled phenomenon by gathering retrospective data over 1-year period of time (from September 2014 to October 2015) after June 2014 when the ISMP was put in use.

The hospital is the first in China to launch an ISMP in healthcare setting. At the time of the ISMP implementation, the hospital has a number of advanced health systems: A computerized physician order entry (CPOE) system, an electronic medical records (EMRs) system, a decision support system, data mining, a patient portal, online services platforms, knowledge/database management system, a medical card system for patient's identity and insurance coverage, and an ISMP. To design and implement the ISMP technology, an interface that integrates the various healthcare systems into a mobile device, a system development team of 60 personnel in four different companies were involved.

Before making a decision to implement the new technology, the hospital searched for an appropriate tool to meet patients' needs under the top management's direction. One solution is to use a social media platform (i.e., WeChat) which is one of the most popular mobile social media technologies used in China. It means that the hospital utilizes the space in the social media platform that is already popular among patients as a versatile technology. Integration of hospital system functionalities into a mobile technology allows patients to access virtual medial resources and efficient access to healthcare processes. Main functionalities of ISMP to support healthcare process for outpatients and healthcare providers are shown in Appendix 2.

Main users of the ISMP technology are outpatients and hospital staff: 5,914 outpatients $(64 \%)^{2}$ have been using ISMP and all physicians $(100 \%)$ in the hospital are

25,914 patients have been using out of 9,241 patients who visited and registered in the hospital EMR system for the period between Sep. 2014 and Oct. 2015. 
required to use ISMP. Patients and healthcare providers both access the same technology in a unified platform in order to perform e-healthcare processes or virtual healthcare consultations. The ISMP technology users would have benefits like real-time information sharing, alerts, and collaborations, which increase quality of care. It is an inexpensive, easy-to-use mean of communication to hold interpersonal or multi-group chatting sessions.

\section{Interview}

I conducted in-depth interviews with patients and healthcare providers to understand their perceptions of ISMP and their activities in the healthcare context. Interview results helped me to capture patients' and physicians' perceptions and actions with ISMP, which are defined as ISMP affordances in this study.

Semi-structured interviews were conducted in August 2015 with nine outpatient clinicians, three outpatients, a IS project manager, and two top managers, in total 15 interviewees. Interviewees are selected to represent the overall population related to clinical processes and administrative processes, considering age, position, and specialty. Table 6 shows the characteristics of the interviewees. The interview questions related to demographic information of interviewees, user perceptions and experiences (e.g., work experience of a physician and comfort level of ISMP technology use), technology (e.g., specific technical process), and behaviors and outcomes (e.g., how they interact with when using ISMP, and impacts on satisfaction and quality of care). The interview questions are shown in Appendix 3. All interviews, approximately $40 \mathrm{~min}$ on average, are audio recorded, transcribed, and coded. 
Table 6. Interview Participants

\begin{tabular}{|c|c|c|}
\hline Category & $\begin{array}{c}\text { Role of } \\
\text { Interviewee }\end{array}$ & Title of Interviewee (Number) \\
\hline \multirow{4}{*}{$\begin{array}{l}\text { Persons } \\
\text { related to } \\
\text { administrative } \\
\text { process }\end{array}$} & \multirow{2}{*}{$\begin{array}{c}\text { Top } \\
\text { management }\end{array}$} & President (1) \\
\hline & & Vice presidents (1) \\
\hline & IS manager & Project manager on the ISMP (1)* \\
\hline & $\begin{array}{l}\text { Clinical } \\
\text { function } \\
\text { managers }\end{array}$ & $\begin{array}{l}\text { Chief of quality control department (1), Chief of } \\
\text { patient satisfaction department (1), Chief of patient } \\
\text { record (1), Chief of medical staff (1), Chief of } \\
\text { nursing (1) }\end{array}$ \\
\hline \multirow{2}{*}{$\begin{array}{l}\text { Persons } \\
\text { related to } \\
\text { clinical } \\
\text { process }\end{array}$} & Physicians & $\begin{array}{l}\text { Physicians in OB/GYN (1), Neuro surgeon (1), } \\
\text { Neurology (1), Stomach surgeon (1), considering } \\
\text { position, age, specialty }\end{array}$ \\
\hline & Patients & Patients (3), considering age \\
\hline
\end{tabular}

- Two times of interviews are conducted with the project manager on the ISMP.

\section{Focus Group}

In addition to individual interviews, two focus groups with eight physicians were held in order to explore their views on what dimensions are important for the patient-centered care process and their perceptions of the ISMP uses. The topics consisted of how they use ISMP and the impacts in the healthcare processes that the ISMP technology use brought to the hospital. Detail questions of the focus groups are shown in Appendix 3. As Table 7 shows, specialties and positions of the eight clinicians participated are varied; Physicians in Urology, Pediatric, Oncology, Breast surgeon, Endocrinology, Liver surgeon, Gastroenterology, Orthopedics attended the focus groups. All the sessions were audiorecorded using digital audio recorders and later transcribed and coded.

Table 7. Focus Group Participants

\begin{tabular}{|c|l|c|}
\hline Group & \multicolumn{1}{|c|}{ Title of Participants (Number) } & Duration \\
\hline Physician 1 & Middle level physicians (3), low level physician (1) & $90 \mathrm{~min}$ \\
\hline Physician 2 & $\begin{array}{l}\text { High level physician (1), middle level physicians (2), } \\
\text { low level physician (1) }\end{array}$ & $90 \mathrm{~min}$ \\
\hline
\end{tabular}




\section{Archived Documents}

Documents on ISMP development and implementation are a valuable information source to understand the background around the technology implementation. The hospital documented the history of the ISMP technology development and implementation, from kickoff meeting records in March to ISMP release news article in June, 2014. In total, I was provided with nine documents which became the bases for the archival analysis. All nice documents specify potential users and potential usage of ISMP, indicating perceived affordances.

\section{Archived Data from ISMP}

Conversation contents and event logs were collected as digital traces to identify sequence of actions in the healthcare processes as well as ISMP affordances. Table 78 shows the data collected from ISMP and their statistics techniques for the analysis. The conversation texts between patients and corresponding physicians, all accumulative contents over a 14-month period, from September 2014 to October 2015, demonstrate longitudinal interactions. The event logs of all users in ISMP shows patients' and physician' all health care activities using the ISMP technology, representing actualized affordances. These data allow me to understand holistically healthcare activities and to develop a deeper understanding of the interactions between patients and physicians through the ISMP uses.

I collected ISMP transaction data for behavioral affordances and interactive affordances. As I mentioned before, behavioral affordances and interactive affordances are reflected with a user's actual actions when the users use specific technological features. Therefore, the ISMP system data, such as the number of scheduling requests that a patient 
made, represent users' behavioral affordances. The data of mobile consulting that a patient and a physician created were collected to measure an interactive affordance.

Table 8. Archived Transaction Data

\begin{tabular}{|c|c|c|c|c|c|c|c|}
\hline $\begin{array}{c}\text { Functio } \\
\text { nality }\end{array}$ & Data & Period & $\begin{array}{c}\text { Numb } \\
\text { er of } \\
\text { Patient }\end{array}$ & $\begin{array}{c}\text { Numb } \\
\text { er of } \\
\text { Physici } \\
\text { an }\end{array}$ & $\begin{array}{c}\text { Numb } \\
\text { er of } \\
\text { Data }^{3}\end{array}$ & $\begin{array}{c}\text { Avera } \\
\text { ge(/we } \\
\text { ek) }\end{array}$ & $\begin{array}{c}\text { Max } \\
\text { (of a } \\
\text { patient } \\
\text { ) }\end{array}$ \\
\hline \multirow{3}{*}{$\begin{array}{l}\text { Schedul } \\
\text { ing }\end{array}$} & $\begin{array}{l}\text { ISMP } \\
\text { Scheduling }\end{array}$ & $\begin{array}{l}\text { September } 2014 \\
\text { to October } 2015\end{array}$ & 12,679 & - & 28,232 & 543 & 79 \\
\hline & $\begin{array}{l}\text { Onsite } \\
\text { Scheduling }\end{array}$ & $\begin{array}{l}\text { September } 2014 \\
\text { to October } 2015\end{array}$ & 11,769 & - & 22,664 & 436 & 47 \\
\hline & $\begin{array}{l}\text { Kiosk } \\
\text { Scheduling }\end{array}$ & $\begin{array}{l}\text { September } 2014 \\
\text { to October } 2015\end{array}$ & 4,736 & - & 8,923 & 172 & 38 \\
\hline \multirow{2}{*}{$\begin{array}{l}\text { ISMP } \\
\text { Consulti } \\
\text { ng }\end{array}$} & $\begin{array}{l}\text { ISMP Mobile } \\
\text { Consulting }\end{array}$ & $\begin{array}{l}\text { September } 2014 \\
\text { to October } 2015\end{array}$ & 2,596 & 251 & 4,728 & 91 & 91 \\
\hline & $\begin{array}{l}\text { Conversation } \\
\text { Text in ISMP }\end{array}$ & $\begin{array}{l}\text { September } 2014 \\
\text { to October } 2015\end{array}$ & 11,300 & 2,032 & 13,332 & 256 & 84 \\
\hline \multirow{2}{*}{$\begin{array}{l}\text { Paymen } \\
\mathrm{t}\end{array}$} & $\begin{array}{l}\text { ISMP } \\
\text { Payment }\end{array}$ & $\begin{array}{l}\text { September } 2014 \\
\text { to October } 2015\end{array}$ & 1,939 & - & 2,164 & 42 & 8 \\
\hline & $\begin{array}{l}\text { Onsite } \\
\text { Payment }\end{array}$ & $\begin{array}{l}\text { September } 2014 \\
\text { to October } 2015\end{array}$ & 20,883 & - & 58,678 & 1,036 & 67 \\
\hline
\end{tabular}

Demographic information of patients and physicians are collected from the EMR system and the human resource system in the hospital. Those data are used as factors related to users that affect the emergence of affordances. Besides, I collected patients' clinical data from the EMR system for 3 years, one year before and one year after the introduction of the ISMP, so that I can compare the outcomes (e.g., the number of face-to-face visits or productivity) of patients and physicians who used the ISMP technology.

\section{B. Data analyses}

A mixed methods approach was applied 1) to identify various forms of ISMP affordances, 2) to reconfirm the affordance types, 3) examine the relationships of

\footnotetext{
${ }^{3}$ Data are transaction data of scheduling, consulting, and payments completed.
} 
affordance types, affordance dimensions, and outcomes, and 4) to investigate why users (patients and physicians) use /don't use the ISMP technology.

Existing affordance research in IS discipline suggests that the affordance theory naturally lends itself to qualitative means of examination (Michaels \& Carello, 1981). Many studies utilize the case study methods (e.g., Cousins \& Robey, 2015; Leonardi, 2011, 2013; Strong, Volkoff, et al., 2014). Recently, sociometric survey (Leonardi, 2013) and survey (Grgecic, Holten, \& Rosenkranz, 2015) were used to collect the data for affordances in IS discipline.

For this study, I utilized a mixed-methods approach which is novel for affordance research. First, I learned from event log data and conversation texts about the overall patterns of healthcare practices using process mining techniques and text mining techniques. Perceived affordances are identified based on the information of the interview, focus group, and documents. Actualized affordances are identified from the actual digital trace data, such as event log data and conversation texts. In order to understand and test the relationships related to affordances, typical qualitative analysis techniques such as grounded coding and quantitative approach such as statistical methods were used. The over approach of the data analysis was to using a qualitative approach to identify the types of affordances and perceived affordances of ISMP and their impacts, and then investigated the relationships among types of affordances, factors affecting affordances and impacts of affordances with objective quantitative data. The rich data in various sources provide me with holistic pictures into the healthcare practices with ISMP use and the relationships of the affordances for patient-centered care process.

I conducted grounded theory analysis according to the suggestions made by Berente and Seidel (2014) to build a theory using a mixed method approach. It guided me on how to analyze data, especially on sampling, synchronic analysis, reference lexicon, 
and diachronic analysis. Table 9 represents each step with their guidelines and how I incorporated them in this study. The data from the different sources were analyzed using different techniques.

Table 9. Activities in Grounded Analysis (Adapted from (Berente and Seidel, 2014))

\begin{tabular}{|c|c|c|c|c|}
\hline Activity & Goal & $\begin{array}{l}\text { Manual } \\
\text { Analysis }\end{array}$ & \multicolumn{2}{|c|}{ Computational Analysis } \\
\hline \multirow[t]{2}{*}{ Sampling } & $\begin{array}{c}\text { Develop } \\
\text { dataset }\end{array}$ & $\begin{array}{l}\text { Theoretical } \\
\text { sampling (e.g., } \\
\text { collect } \\
\text { additional data } \\
\text { based } \\
\text { on findings } \\
\text { and analysis) }\end{array}$ & \multicolumn{2}{|c|}{$\begin{array}{l}\text { Data extraction (e.g., map reduce } \\
\text { a large amount of trace data to } \\
\text { manageable volume based on } \\
\text { goals and current knowledge) }\end{array}$} \\
\hline & $\begin{array}{l}\text { Data in this } \\
\text { study }\end{array}$ & $\begin{array}{l}15 \text { Interview/ } \\
8 \text { focus group } \\
\text { participants } \\
\text { transcript, } 9 \\
\text { documents }\end{array}$ & $\begin{array}{l}\text { 14-month of } \\
\text { conversation text } \\
\text { in ISMP }\end{array}$ & $\begin{array}{l}\text { 14-month of event } \\
\log \text { data in ISMP }\end{array}$ \\
\hline \multirow{2}{*}{$\begin{array}{l}\text { Synchronic } \\
\text { Analysis }\end{array}$} & $\begin{array}{l}\text { Develop } \\
\text { Categories } \\
\quad \text { and } \\
\text { Associations }\end{array}$ & $\begin{array}{l}\text { Coding } \\
\text { - Identification } \\
\text { of similarities } \\
\text { - Identification } \\
\text { of correlations } \\
\end{array}$ & \multicolumn{2}{|c|}{$\begin{array}{l}\text { Synchronic relations: } \\
\text { - Categorization-relationships } \\
\text { among similar data } \\
\text { - Associations-relationships of } \\
\text { covariance among data }\end{array}$} \\
\hline & $\begin{array}{l}\text { Technique } \\
\text { in this study }\end{array}$ & $\begin{array}{l}\text { Open, Axial, } \\
\text { Selective } \\
\text { coding }\end{array}$ & $\begin{array}{l}\text { Text clustering }{ }^{4} \text {, } \\
\text { Conceptual map, }\end{array}$ & $\begin{array}{l}\text { Sequence analysis, } \\
\text { Process mining }{ }^{5},(\mathrm{~J} . \\
\text { Gaskin, Berente, } \\
\text { Lyytinen, \& Yoo, } \\
\text { 2014) }\end{array}$ \\
\hline $\begin{array}{l}\text { Reference } \\
\text { Lexicon }\end{array}$ & $\begin{array}{l}\text { Draw upon } \\
\text { Grammar }\end{array}$ & \multicolumn{3}{|c|}{$\begin{array}{l}\text { In all cases, the lexicon provides the pre-theoretic reference } \\
\text { for the identification of patterns in relation to a goal, using } \\
\text { the language and causal relations determined by one or } \\
\text { more scholarly communities. }\end{array}$} \\
\hline & $\begin{array}{l}\text { Lexicon }^{6} \text { in } \\
\text { this study }\end{array}$ & \multicolumn{3}{|c|}{$\begin{array}{l}\text { Affordance dimension (e.g., user, goal, technology } \\
\text { feature, situation, etc) }\end{array}$} \\
\hline
\end{tabular}

${ }^{4}$ Text clustering analysis results are created by SAS Text Miner software. SAS Text Miner software analyzes text data (unstructured data) to help discovering new information, topics and term relationships.

${ }^{5}$ Process mining analysis results are created by Fluxicon process mining software. The process mining technology in Fluxicon creates visual maps from process data, providing statistics and cases with filtering feature.

${ }^{6}$ Lexicon I used is shared by scholarly community. 


\begin{tabular}{|c|c|l|}
\hline $\begin{array}{c}\text { Diachronic } \\
\text { Analysis }\end{array}$ & $\begin{array}{c}\text { Generate } \\
\text { Theory }\end{array}$ & $\begin{array}{l}\text { In both cases, the generation of theory requires a } \\
\text { sensemaking process; that is, the analyst decides-based } \\
\text { on the empirical evidence-what concepts and } \\
\text { relationships (pre-theoretic understanding) are included in } \\
\text { a coherent theoretical scheme (theoretic understanding). }\end{array}$ \\
\hline
\end{tabular}

The first step is sampling to determine the datasets for this study. Three different sources and types of data were sampled for the analysis: 1) the interview scripts, the focus group transcript, and the documents; 2) the patient-physician conversation texts, and 3) the ISMP event log data archived in ISMP. Importantly, the conversation contents made by patients and physicians and the ISMP event log data were included as the digital trace data to reflect the actual usages of the technology. The written conversations show interactions between a patient and a physician when using the ISMP mobile consulting feature. The ISMP event log data allowed me to reveal real sequences of activities of patients and physicians in the healthcare processes.

Secondly, I analyzed the data to develop categories of affordances and to understand associations among the categories. For the analysis with the interview transcripts, the focus group transcripts, and the documents, I used coding techniques associated with a grounded theory method (Corbin \& Strauss, 2014; Urquhart, Lehmann, \& Myers, 2010). I used grounded theory coding strategies to identify open, axial, and selective codes (Corbin \& Strauss, 2014). During open coding, using an inductive approach allowed for common patterns to emerge about the ISMP technology uses. During axial coding, the data were coded for affordance dimensions (e.g., action, object properties, user characteristics, or goals). Sub-dimensions were adapted from the study of Gaskin et al. (2014), which are shown in Appendix 4.

Figure 1 provides an example for how I executed the coding processes. This example with an interview data for 'virtual healthcare consultation' shows how a theme of 
virtual healthcare consultation comes up and how the information are coded under the affordance dimensions. A pattern regarding virtual healthcare consultation comes up with a technological feature, ISMP mobile consulting feature. The participants of the interviews and the focus groups clearly mentioned how the use of the ISMP mobile consulting feature supports communications between patients and physicians, thus enables virtual medical consultation. This specifies the goals of their usages of the ISMP mobile consulting feature.

Next, the information was codified using abstracted codes for the affordance dimensions.

During selective coding, the emerging themes were consolidated into distinct theoretical patterns through constant comparisons of affordance dimensions and existing affordance literature. Then, I developed a theoretical explanation of the behaviors demonstrated in the ISMP uses with the abstraction of affordance dimensions. This was how I identified affordances and practices related to the ISMP uses.

\begin{tabular}{|c|c|c|}
\hline Step 1: Open Coding & Step 2: Axial Coding & Step 3: Selective Coding \\
\hline $\begin{array}{l}\text { Identification of themes in } \\
\text { the data } \\
\text { Identification of a theme from a } \\
\text { physician's interview, ("[It] } \\
\text { allows us [physicians] to anytime } \\
\text { understand some of the causes } \\
\text { or change of the patient. It is } \\
\text { possible to solve some medical } \\
\text { consultations, some difficult } \\
\text { cases, after the diagnosis and } \\
\text { treatment, outside the hospital } \\
\text { which provides great } \\
\text { convenience. It is said to just } \\
\text { open the phone immediately, } \\
\text { then it is a good user experience, } \\
\text { we can be more convenient } \\
\text { doctor.") }\end{array}$ & $\begin{array}{l}\text { Categorization of identified themes } \\
\text { into affordance dimensions } \\
\text { - Theme: Virtual physician } \\
\text { - User Role - a patient, a physician, } \\
\text { \# User - pair } \\
\text { - Action: '[physician's use of mobile } \\
\text { consulting] to understand some of the } \\
\text { causes or change of the patient' } \\
\text { - Technology : Feature - online consulting } \\
\text { Property - anytime } \\
\text { Modality - digital } \\
\text { - Goal: 'do medical consultations' } \\
\text { - Situation: 'after the diagnosis and } \\
\text { treatment, outside the hospital', } \\
\text { Process - clinical process }\end{array}$ & $\begin{array}{l}\text { Identification of affordances } \\
\text { through comparison of } \\
\text { abstraction } \\
\text { - Comparison to other texts } \\
\text { indicating same technology } \\
\text { features (e.g., the online } \\
\text { consulting feature) } \\
\text { - Comparison to other theme- } \\
\text { related text passage (e.g., } \\
\text { the theme of virtual } \\
\text { physician) } \\
\text { Comparison to other text } \\
\text { discussing similar material } \\
\text { properties (e.g., anytime) }\end{array}$ \\
\hline
\end{tabular}

Figure 1. Data Coding Process for 'Virtual Physician'

The same basic ideas can be applied to analysis with the trace data, the conversation texts and the ISMP event log data. Text clustering techniques and conceptual map were applied to find patterns from the text data. For analysis with the event log data, I applied a sequence analysis technique proposed by Gaskin et al. (2011). A technique of 
process analysis was performed with clustering statistical methods which enable analysis of sequences of the healthcare activity routines. Process mining technique supports the analysis of real healthcare processes in a bottom-up fashion from the actual data. The results of the process mining analysis reveal key actions in the real healthcare processes and clusters of affordance dimensions. In this way, the process mining techniques and the text mining techniques helped me to find key affordances of ISMP and their relationships. Third, I utilized affordance theory shared by IS discipline researchers. I compared patterns from the various analyses using affordance dimensions, such as an activity, an actor, a tool property, a goal, a task, and a situation (Berg, Lune, \& Lune, 2004; J. Gaskin et al., 2014). The affordance dimension information were examined through continuous comparisons of the abstractions of the information from the three difference data sources. Identified themes were triangulated across three different sources by comparing the analysis results with the qualitative data, the patient-physician consultation conversation texts, and the ISMP event log data. 


\section{RESULTS}

As I discussed earlier, I proposed three types of affordances (i.e., perceived affordance, behavioral affordance, and interactive affordance) and affordance dimensions (i.e., user, technology and information, and context including time, place, and situation). A mixedmethod approach was applied 1) to identify healthcare practices with ISMP, 2) to identify key affordances of ISMP, 3) to reconfirm the affordance types, 4) to examine the relationships among affordances, affordance dimensions, and outcomes in the healthcare context, and 5) to investigate why users (patients and physicians) use / don't use technological features in ISMP. I tried to jointly consider, rather than separately, various aspects of the same practices in order to holistically understand the interactions between patients and physicians. Understanding different types of affordances requires different sources of information. To capture perceived affordances, for example, data of interviews and focus-groups were used with documents accumulated during the period from the development to the release ISMP in the hospital. User's perceived affordances are identified from the user's expressions through the interviews and focus-groups. Designer's perceived affordances are specified in the documents, reflecting objective functional affordances of ISMP. However, actualized affordances can be captured by digital trace data such as ISMP log event data and conversation texts made by patients and physicians during their virtual consultations. Through the investigation of the interactions in terms of social structure, procedural structure, and contents in ISMP, I could understand how affordance dimensions are involved in the emergence of new healthcare practices and emergent affordances with the ISMP use. In addition, I could uncover how the relationships and the streams of activities are associated with each other.

Two affordances of the ISMP technology were identified that led to patient-

centered care: ubiquitous access and virtual healthcare consultation. During the 
identification process, I also confirmed three different types of affordance: perceived affordance, behavioral affordance, and interactive affordance. Patients' and physicians' technology actual uses as actualized affordances are often different with their perceptions about the technology as perceived affordances. This finding is consistent with the literature that addresses perception of a technology is a necessary but not sufficient condition for actualization (Stoffregen, Gorday, Sheng, \& Flynn, 1999). The occurrences of an affordance may be affected by configurations in affordance dimensions, leading to certain outcomes.

\section{A. Practices with ISMP}

Healthcare practices with ISMP were identified by applying analysis techniques of process mining and text mining with various sources of information, conversation texts, ISMP event log data, interview, focus group scripts, and documents. Figure 2 gives an overview of ISMP usage of main users, outpatients and physicians. Among 9,241 patients who visited the hospital for the studied time period, more than half of them (56\%) had used the ISMP scheduling feature, some patients (8\%) used the ISMP consulting feature. However, there were $36 \%$ of the patients who showed no use of the ISMP. All of the 579 physicians and 1,349 nurses were registered and should have used the ISMP technology, but only 19\% of the physicians used the ISMP consulting feature, mainly because participating in the ISMP consulting put their additional time and efforts.

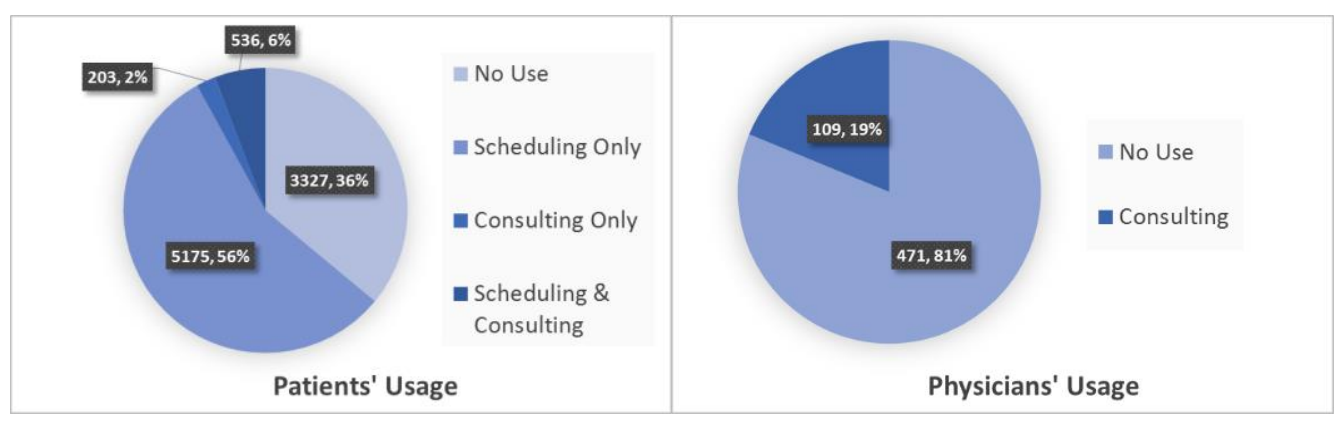

Figure 2. Overview of Patients' and Physicians' ISMP Usage 
First, with the ISMP event log data, I applied the procedures of sequence analysis proposed by Gaskin, Schutz, Berente and Lyytinen (2010). The results of the process mining analysis with real historical data revealed the real healthcare practices, specifically sequences of activities. They allowed me to find patterns of affordance dimensions including activities, users, technology features, location, and time. Figure 3 shows results of the process mining analysis with the actual usage data $(125,389$ event log data over the 14-month period of time). Figure 3(a) looks somewhat spaghetti-like as the analysis using all the data. Nevertheless, Figure 3(a) reveals two dominant healthcare routines as highlighted by dark-colored boxes: scheduling and consulting. The scheduling actions happen with three options: ISMP mobile scheduling feature, Kiosk, and through registration staff at the hospital. The consulting actions happen with two options: ISMP mobile consulting in a virtual world and face-to-face consulting at the hospital. With the data I have, I could figure out sequences of the activities with the ISMP mobile consulting feature, which show a sequential pattern (i.e., initiating a text conversation, sending texts, and then completing the conversation). 




(a) Activity Flow (with All Data)

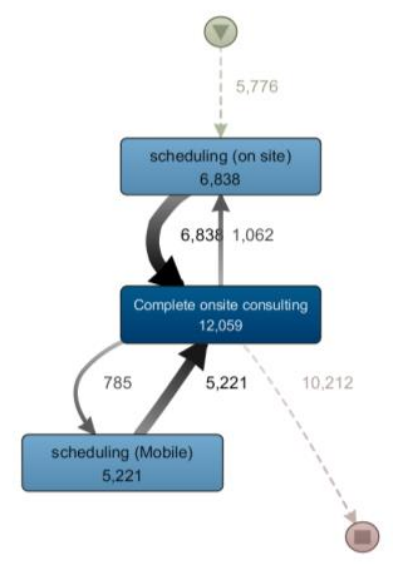

(b) Activity Flow (From Top 4 Variations)

Figure 3. Results of Process Mining Analysis with Event Logs Data in ISMP 
All the event logs generated 3,438 variants defined as specific sequences of activities. These patterns based on the digital trace data are much more complex than what the healthcare routines have been perceived of, which is illustrated in Appendix 5. The top variants consist of majority of the events. Table 10 summarizes the top 4 Variants. Variant 1, onsite scheduling then face-to-face consulting identified with 4,714 transactions (20\%), and Variant 2, ISMP scheduling and then face-to-face consulting with 3,651 transactions (15\%). Variants 3 (5\% of events) and 4 (3\% of events) repeat the activities of Variants 1 and 2, respectively. Most of Variants 1 and 3, which activities occurred through the use of onsite registration desks, happened during the morning operation hours as indicated by the blue-colored portion along the time dimension. Variants 2 and 4, which activities occurred through the use of the ISMP scheduling feature, happened during the period between $5 \mathrm{pm}$ and 7 am. Figure 3(b) shows the result of analysis with only the top four Variants, and now it clearly reveals two dominant sequences of activities: the onsite scheduling and with the ISMP scheduling followed by face-to-face consultations.

Table 10. Overview of Top Four Variants

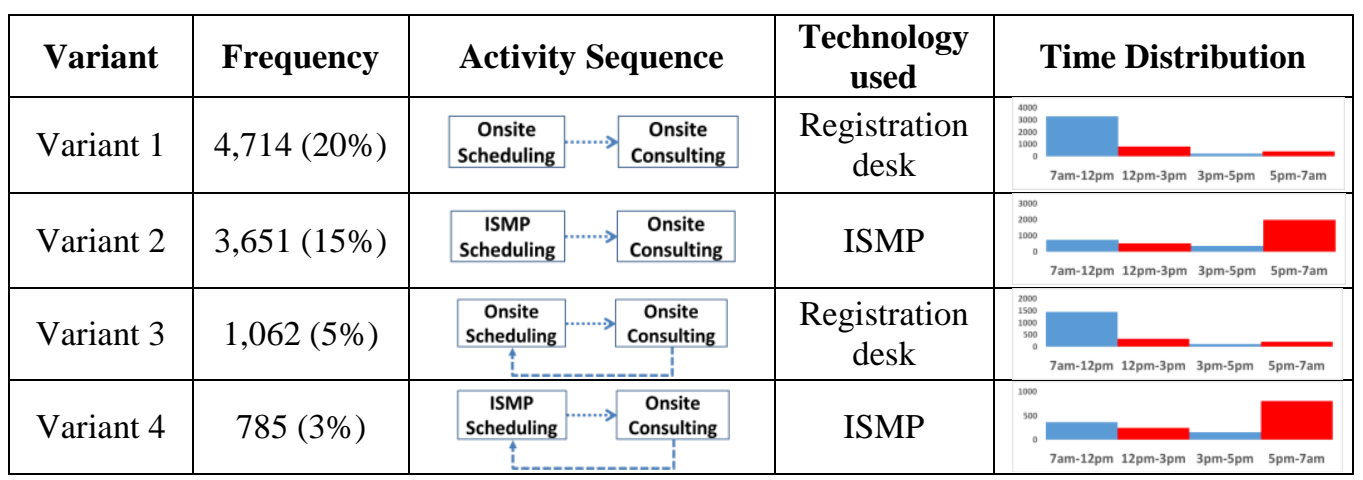

Another key action with ISMP is virtual healthcare consolation through which a patient and a physician share written conversations. Relatively the ISMP mobile consulting transactions are small portion (1.2\% of all the events, 1,444 transactions completed). The 
top variant related to the ISMP mobile consulting feature is variant 7 with 564 data of the initiation of the ISMP mobile consultation. Variant of the completion of the ISMP mobile consultation after initiation is variant 25 , and variant of the completion of the ISMP mobile consultation after initiation and continue is variant 49. The activities with the ISMP mobile consulting feature, however, has been increasing over time, as shown in Figure 4, with 13,332 conversation texts at the end of the studied period. As the ISMP mobile consulting usage increases, the numbers of patients and healthcare providers using the ISMP also increased accordingly. The healthcare providers responded to patients' texts moderately quick (6 minutes in median terms). However, a third of the conversation texts $(1,564$ out of 4,728 texts) failed to continue written conversation with healthcare professionals. This pattern indicates the need of investigation on why interactive affordances are and are not actualized in the situation of both patients and physicians.

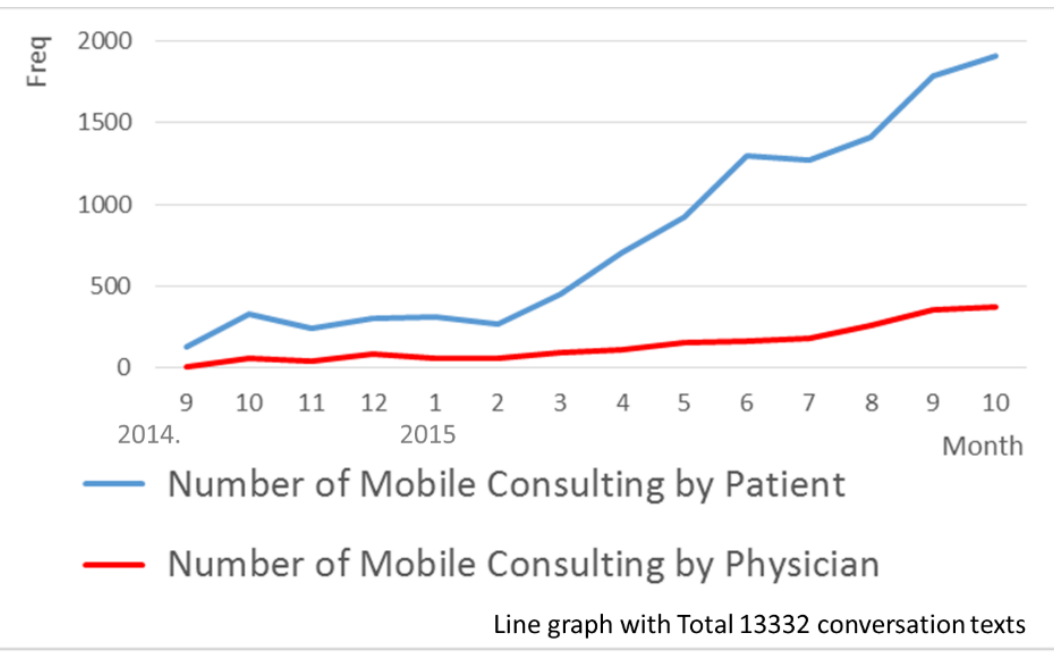

Figure 4. Trend of the ISMP Mobile Consulting Transactions

To analyze the conversation texts between patients and physicians archived in ISMP, I performed text mining techniques. Text clustering algorithm as one of text mining techniques was applied with 13,332 conversation text messages, treating each message 
created as an analysis unit. The result of the text clustering analysis shown in Figure 5 gave me insights about the interactions between physicians and patients when they use the ISMP mobile consulting feature. A practice identified was using the ISMP mobile consulting feature for a patient and a physician to ask and respond to questions about test results and healthcare guidelines, which refers to virtual healthcare consultation. Physicians' texts are clustered around three themes, specifying what users do with the ISMP mobile consulting feature: to give guidelines (48\%), to suggest to come to the hospital for an in-person visit (40\%), and to discuss about test results (13\%). Nearly half of the conversations (48\%) show that physicians do medical consulting in ISMP, such as giving guidelines on pain management, dietary, or physical routines. The remaining half $(53 \%)$ demonstrates that physicians do pre-diagnosis; physicians decide a disease or they recommend patients to visit a hospital next day after reading patients' test results. Those are main actions performed by physicians on ISMP, which are considered as virtual healthcare consultation in this study.

Patients' conversation texts show similar clusters as shown in Figure 5 (b). Patients ask physicians for professional opinions: asking physician's opinion about patients' test results $(56 \%)$, asking guidelines (33\%), and updating patients' conditions (12\%). More than a half of the conversations (56\%) are inquiries about test results that patients had viewed and that had made them worried. Below is a typical example of written conversations between a patient and a physician. A patient saw his or her test results and initiated a mobile consulting conversation by stating ' $D r$. A, my test results came out. Is 125 high? Will it be no problem, right?' Within 1 minute, the doctor responded to it with a simple answer, 'Not too high.' They continued the conversation by exchanging followup questions and answers. 


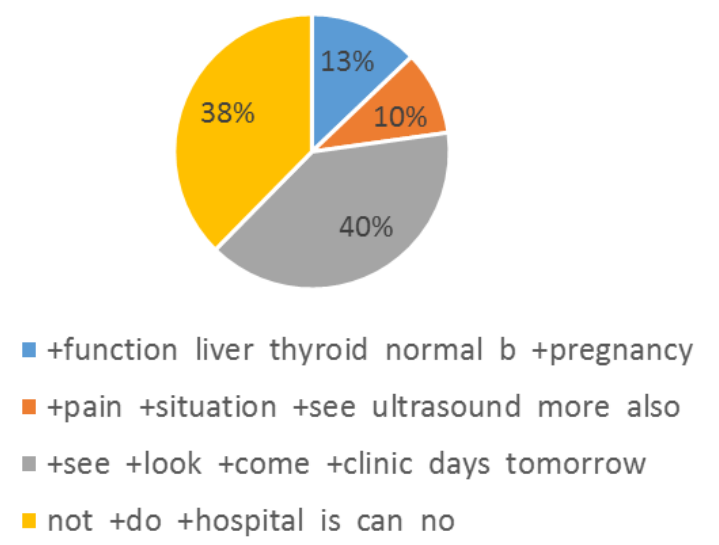

(a) With Texts Made by Physicians

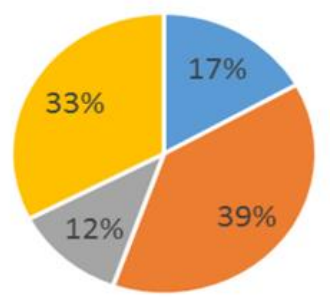

- +size $\mathrm{mm}$ bilateral c about

- hello +do dr task results

no +see right now thave

now days +eat how two

Figure 5. Results of Text Clustering of Texts Made by Physicians and Patients in the ISMP Mobile Consulting Feature (by SAS Text Miner)

Figure 6 is a conceptual map that expands links from the mostly used word. The analysis level of the data is the whole text pool. Words that many physicians actually wrote in the ISMP messaging feature is 'is big problem,' which indicates that physicians do diagnosis using ISMP. The next common expressions are 'is normal', 'no problem', 'not worry/necessarily afraid,' which indicate that physicians use ISMP to give his/her judgements on patients' test results or descriptions of problems. This supports the same practice with ISMP, virtual healthcare consultation that I identified with information from the other sources. 


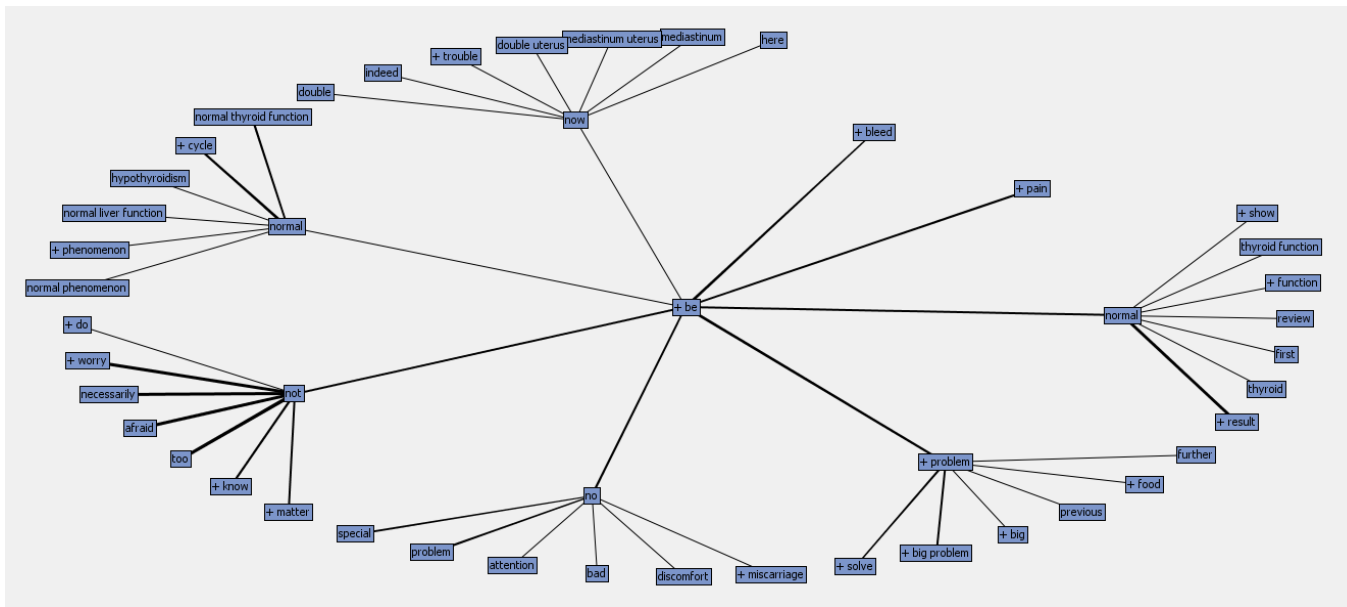

Figure 6. Results of Text Conceptual Map with Texts Made by Physicians in the ISMP Mobile Consulting Feature (by SAS Text Miner)

Table 1111 gives descriptions of the healthcare practices with ISMP that I identified according to the dimensions of affordances. Affordance theory suggests that affordances have core concepts including user, technology, goal, perception, actual use, which I titled as affordance dimensions. The affordance dimensions have important information about the affordance that emerges in a context with object properties and a user for a certain task (Stoffregen, 2003). Perceptions reflect perceived affordances and actual uses reflect actualized affordances.

Table 11. Description of Affordance Dimensions in the Healthcare Processes

\begin{tabular}{|c|l|l|}
\hline $\begin{array}{c}\text { Affordance } \\
\text { Dimension }\end{array}$ & \multicolumn{1}{|c|}{ Healthcare Practice } & Affordance Subdimension \\
\hline Object & $\begin{array}{l}\text { The ISMP technology features used by } \\
\text { patients or physicians, such as the } \\
\text { features of mobile consulting, } \\
\text { scheduling, and payment }\end{array}$ & $\begin{array}{l}\text { - Technological properties } \\
\text { that may lead to } \\
\text { emergence of affordance }\end{array}$ \\
\hline User & $\begin{array}{l}\text { A patient or a physician who use the } \\
\text { ISMP technology features to perform } \\
\text { healthcare processes }\end{array}$ & $\begin{array}{l}\text { - Role, gender } \\
\text { - User ability }\end{array}$ \\
\hline
\end{tabular}




\begin{tabular}{|c|l|l|}
\hline Goal & $\begin{array}{l}\text { The reasons that a user uses the ISMP } \\
\text { technology features, such as scheduling, } \\
\text { diagnosis, and follow-ups }\end{array}$ & $\begin{array}{l}\text { - User's purpose } \\
\text { - Situation involved (e.g., } \\
\text { when, where, what, and } \\
\text { why) }\end{array}$ \\
\hline Perception & $\begin{array}{l}\text { Perception of action possibilities in the } \\
\text { healthcare processes afforded by a } \\
\text { patient or a physician's uses of ISMP }\end{array}$ & $\begin{array}{l}\text { - Perceived affordance } \\
\text { Expected net value of } \\
\text { affordance }\end{array}$ \\
\hline Actual use & $\begin{array}{l}\text { The actual actions taken by a physician } \\
\text { and a patient in the healthcare processes }\end{array}$ & - Actualized affordance \\
\hline
\end{tabular}

\section{B. ISMP Affordances}

Based on the analysis with the ISMP event log data, the conversation text data, the scripts of the interviews and the focus groups, I identified two key affordances in the healthcare context - 'virtual healthcare consultation' and 'ubiquitous access' - and the dimensions of affordances - goals, user characteristics, and technological properties - as summarized in Table 12. Since listing merely affordances and constraints has been previously criticized (Bloomfield et al., 2010), I described the specific circumstances that enact the affordances in order to see how they were perceived and actualized by the users (Strong, Volkoff, et al., 2014). In this section, I described a definition of an affordance, the evidence that supports the affordance perceived and actualized, the affordance dimensions that affect the emergence of the affordance, and the impacts of the actualized affordance on the healthcare processes.

Table 12. Overview of Identified Affordances and Their Dimensions

\begin{tabular}{|c|l|l|}
\hline Affordance & Virtual Healthcare Consultation & \multicolumn{1}{|c|}{ Ubiquitous Access } \\
\hline User & A pair of a patient and a physician & An individual user as a patient \\
\hline $\begin{array}{c}\text { Object } \\
\text { property }\end{array}$ & Asynchronized & Ubiquitous \\
\hline Goal & Virtual healthcare consulting & $\begin{array}{l}\text { Access information as soon as } \\
\text { possible }\end{array}$ \\
\hline Perception & $\begin{array}{l}\text { Anytime and anywhere } \\
\text { communication with a medical } \\
\text { professional }\end{array}$ & Convenience \\
\hline
\end{tabular}




\begin{tabular}{|c|l|l|}
\hline $\begin{array}{c}\text { Patient's } \\
\text { actual use }\end{array}$ & $\begin{array}{l}\text { Access to care, } \\
\text { Shared healthcare decision making }\end{array}$ & $\begin{array}{l}\text { Access to care, } \\
\text { Emotional comfort }\end{array}$ \\
\hline $\begin{array}{c}\text { Physician's } \\
\text { actual use }\end{array}$ & $\begin{array}{l}\text { Understanding the patient, } \\
\text { Shared healthcare decision making }\end{array}$ & Efficiency \\
\hline Type & $\begin{array}{l}\text { Interactive affordance, } \\
\text { Perceived affordance }\end{array}$ & $\begin{array}{l}\text { Behavioral affordance, } \\
\text { Perceived affordance }\end{array}$ \\
\hline
\end{tabular}

\section{Affordance I: Virtual Healthcare Consultation}

'Virtual healthcare consultation' affordance is recognized when both a patient and a physician use the mobile consulting feature provided by the ISMP technology in order to conduct a virtual healthcare consultation. With the scripts of the interviews and the focus groups with physicians and patients in the hospital with the documents about the ISMP development and release, I conducted a qualitative analysis to identify ISMP affordances. Participants of the interviews and focus groups mentioned about the use of ISMP and details related to affordance dimensions. Virtual consulting is one of the ISMP features that most interviewees highlighted, similar to what has been investigated in academia (Constantinides \& Barrett, 2006; Thielst, 2011). Since virtual consulting is free of time and place limitations, patients can get medical professional services at anytime, even during off-operation hours, and from any place that is not necessarily at a hospital where patients normally go to get medical services in a traditional circumstance. Time of the consultation is related to a material property that enacts the affordance of 'virtual healthcare consultation.' There are two actors, a patient and a physician who are in the real world and the virtual world.

I found the 'virtual healthcare consultation' affordance as a perceived affordance in documents. Document 1 published by the hospital at the time of the ISMP release describes the hospital's explicit goal of the ISMP mobile consulting feature. It was designed for one-to-one communication between a patient and a healthcare provider, and 
highlighted its ultimate goal is to offer healthcare services to patients. This new functionality itself enacts the new affordance of virtual healthcare consultation.

'It is an online interaction between doctors and patients in the hospital. Healthcare providers give consulting virtually, and patients receive consulting. Patients provide healthcare providers with real-time information on the patients' health status. They both receive healthcare information using the mobile technology.' (Document 1)

Similar affordance is perceived by physicians as an expected net value of the ISMP consulting feature use. Some people value additional capability from 'anytime and anywhere' characteristic of the ISMP technology. The following quotation illustrates how Chief physician 1 perceives the ISMP technology use in the clinical process workflow of physicians. Physicians can get continuously patient's information anytime and are able to give quicker feedbacks to the patients, enabling continuous care outside of the hospital. The physician envisions that they can be convenient doctors by becoming virtual physicians who offer virtual medical services. Physician 2, who worked for more than 10 years in surgical oncology and has the ability to seize opportunities to use health technologies for medical care in the Internet era, perceives the same benefits of the use of ISMP consulting feature; patients can get timely and inexpensive professional services regardless of time and place. The technological properties that enables anytime and anywhere plays a critical role in articulating the affordance of 'virtual healthcare consultation'.

"[It] allows us [physicians] to anytime understand some of the causes or change of the patient. It is possible to solve some medical consultations, some difficult cases, after the diagnosis and treatment, outside the hospital, which provides a great convenience. It is said to just open the phone immediately, then it is a good 
user experience, we can be more convenient doctor." (Focus group, Chief Physician 1)

"It is really a great benefit to facilitate their timely and inexpensive medical treatment for them [patients]" (Focus group, Physician 2)

This affordance is actualized in the real healthcare processes. Figure 4 indicates that the use of the ISMP mobile consulting feature, as a measure of the interactive affordance of 'virtual healthcare consultation,' is significant. From the results of the process mining analysis with the real ISMP mobile consulting usage data, I found more variations in other affordance dimensions such as actor, place and time. Unlike the affordance of 'ubiquitous access', two groups of actors are involved: 2,492 patients and 109 physicians. Two-actor involvement necessitates a new type of affordance, an interactive affordance which is different from a behavioral affordance that involves only one actor. Some of the conversation texts were made by healthcare providers ( $13 \%$ of the 13,332 conversation texts), while most ( $87 \%$ ) were made by patients. Nearly half of the conversation texts were made at off-work hours $(46 \%){ }^{7}$ It clearly shows 'anytime' characteristics of the material plays a critical role in enacting the interactive affordance. Clinical department in which patients use the ISMP mobile consulting most is the OB/GYN department $(50 \%)$, followed by internal medicine (12\%). Detailed results of the process mining analysis are shown in Appendix 6.

From the results of the text mining analysis, I identified an actualized interactive affordance of 'virtual healthcare consultation.' The biggest cluster in Figure 5(b) describes the affordance of 'virtual healthcare consultations' that both a patient and a physician (as

\footnotetext{
${ }^{7}$ The regular operation hours include $7 \mathrm{am}-12 \mathrm{pm}$ and $3-5 \mathrm{pm}$. This hospital has lunch and nap time between $12 \mathrm{pm}-3 \mathrm{pm}$.
} 
actors) discussed about the patient's test results (as what activity) using the ISMP mobile consulting feature (as a material) for a purpose of deciding healthcare plans (as a goal). The second biggest cluster represents patients' needs to get healthcare guidelines to improve patients' health conditions. ${ }^{8}$ This case also represents the same affordance of 'virtual healthcare consultation' in which case a physician (as an actor) transfers medical advice information (as activity and a goal) to a patient (as an actor) via the ISMP mobile consulting feature (as a technology).

I found more evidences that reconfirm the affordance of "virtual healthcare consultation,' especially anytime and anywhere, in the conversation texts. Physicians answer patient's questions about test results and do diagnosis (e.g., a physician diagnosed an endometrial cancer via the ISMP). The mobile consulting feature is useful to patients who live far away from the hospital ('I do not live [the city where the hospital is], but I will go down [the city where the hospital is] tonight," Conversation text, Patient 1). Virtual healthcare consultation is good to care-givers who want to talk with physicians on behalf of older seniors, pregnant women, or children who are discomfort to travel to the hospital. This service is provided, regardless of physicians' time ('Oh, Dr. B sorry to disturb you so late,' Conversation text, Patient 2), even when a physician is off ('Today, I am out of clinic,' Conversation text, Physician 3). As such, the mobile consulting feature with properties for anytime and anywhere affects the healthcare processes by improving the level of access to care.

So far, I identified interactive affordances of ISMP based on the actions demonstrated by peoples' actual usage of the ISMP mobile consultation feature. The affordance of 'virtual healthcare consultation' is reflected with the action itself and

${ }^{8}$ Interestingly, not many patients ask about medication guidelines through the mobile consulting feature, because they are provided by other features like $\mathrm{O}_{2} \mathrm{O}$ or alert in the ISMP technology. 
measured by the ratio of the ISMP consulting use. A related affordance, 'anytime virtual healthcare consultation' is reflected with the 'anytime' characteristics of the action, and measured by the ratio of the ISMP mobile consulting completed during off-operation-hour. Initiation of a conversation text may indicate patient empowerment that can be measured by the number of patient-initiated conversations. Quick response can be measured by reciprocity, average of time period to get a first response. ISMP mobile consulting fee refunded, in this study, reflect the unmet requests or dissatisfactions of users. Patients can get refund if they get no response or a first response after 30 minutes. I collected data to represent the 'virtual healthcare consultation' affordance: event completed, event incomplete, time of event completed (grouped by operation-hour, off-operation-hour), and the number of event a patient initiated. According to the operational definitions defined in Table 13, the statistics of possible measures of the 'virtual healthcare consultation' affordance were calculated.

Table 13. Definitions of Possible Affordance Measures

\begin{tabular}{|l|l|l|}
\hline \multicolumn{1}{|c|}{ Measure } & \multicolumn{1}{|c|}{ Affordance } & \multicolumn{1}{c|}{ Operational Definition } \\
\hline $\begin{array}{l}\text { Frequency of action } \\
\text { (ISMP mobile } \\
\text { consulting, ISMP } \\
\text { mobile scheduling) }\end{array}$ & $\begin{array}{l}\text { Virtual } \\
\text { healthcare } \\
\text { consultation, } \\
\text { Ubiquitous } \\
\text { access }\end{array}$ & $\begin{array}{l}\text { The in-period cumulative number of action } \\
\text { (ISMP mobile consulting or ISMP mobile } \\
\text { scheduling) completed by a patient or a } \\
\text { physician. }\end{array}$ \\
\hline Ratio of action & $\begin{array}{l}\text { Virtual } \\
\text { healthcare } \\
\text { consultation, } \\
\text { Ubiquitous } \\
\text { access }\end{array}$ & $\begin{array}{l}\text { The in-period ratio of number of action using } \\
\text { ISMP (ISMP mobile consulting or ISMP } \\
\text { mobile scheduling) to total number of action } \\
\text { regardless technologies completed by a } \\
\text { patient or a physician. }\end{array}$ \\
\hline Time of action & $\begin{array}{l}\text { Anytime virtual } \\
\text { healthcare } \\
\text { consultation, } \\
\text { Anytime } \\
\text { ubiquitous } \\
\text { access }\end{array}$ & $\begin{array}{l}\text { Sum of the time code value of action (ISMP } \\
\text { mobile consulting or ISMP mobile } \\
\text { scheduling) completed: within operation } \\
\text { hour = 0, off-operation hour = 1. Ratio can } \\
\text { be considerable. }\end{array}$ \\
\hline Initiation by patient & Initiation & $\begin{array}{l}\text { The in-period cumulative number of mobile } \\
\text { consulting initiated by a patient. }\end{array}$ \\
\hline
\end{tabular}




\begin{tabular}{|l|l|l|}
\hline Incomplete action & $\begin{array}{l}\text { Quick virtual } \\
\text { healthcare } \\
\text { consultation }\end{array}$ & $\begin{array}{l}\text { The in-period cumulative number of mobile } \\
\text { consulting refunded. }\end{array}$ \\
\hline
\end{tabular}

Table 14 shows five measures of an interactive affordance of 'virtual healthcare consultation.' The OB/GYN and internal medicine departments show active usage of the ISMP mobile consulting (2,341 and 949 ISMP consultation completed, respectively), but there are still many incomplete ISMP consultation attempts. There are departments that show no use of ISMP consultation. The pediatric and surgery department show relatively lower percentages (1\% and $8 \%$ respectively) of the ISMP mobile consultation usages, compared to those of other departments (a percentage between 12\% - 14\%). Instead, these departments show higher ratio of incomplete ISMP consultation (83\% for pediatric department). In the interviews or focus groups, actually nobody in the pediatrics and surgery departments mentioned positive benefits from the use of the ISMP consulting feature. Besides, more ISMP consultation happens during off-operation-hours. As such, all the measures seem to relate each other, but each measure is slightly different. Each measure reflects a different affordance, and different affordances may produce different outcomes.

Participants in the interviews and the focus groups addressed the impacts of the 'virtual healthcare consultation' affordance on patient-centered care by sharing their real experiences with the ISMP mobile consultation. Physician 4 stated that the ISMP technology uses actually changed the real healthcare processes. Patients initiate a conversation text using the ISMP mobile consulting feature, which infers they become proactive patients. Physicians understand more about the patients, building common basis for relationships between them. The virtual interaction promotes shared understanding which plays a foundation role in shared decision making. 
Table 14. Statistics of Measures of 'Virtual healthcare consultation' Affordance

\begin{tabular}{|c|c|c|c|c|c|}
\hline $\begin{array}{c}\text { Departmen } \\
\mathbf{t}\end{array}$ & $\begin{array}{c}\text { Frequency } \\
\text { of ISMP } \\
\text { consulting } \\
\text { completed }\end{array}$ & $\begin{array}{c}\text { Ratio of } \\
\text { ISMP } \\
\text { consulting } \\
\text { completed }\end{array}$ & $\begin{array}{c}\text { Ratio of } \\
\text { Time9 of } \\
\text { ISMP } \\
\text { consulting } \\
\text { completed }\end{array}$ & $\begin{array}{c}\text { Number of } \\
\text { Initiation } \\
\text { by patient }\end{array}$ & $\begin{array}{c}\text { Number of } \\
\text { Incomplete } \\
\text { ISMP } \\
\text { consulting }\end{array}$ \\
\hline OB/GYN & $\mathbf{2 , 3 4 1}$ & $\mathbf{1 2 \%}$ & $\mathbf{6 9 \%}$ & 5,502 & $3,263(70 \%)$ \\
\hline $\begin{array}{c}\text { Internal } \\
\text { medicine }\end{array}$ & $\mathbf{9 4 9}$ & $\mathbf{1 3 \%}$ & $\mathbf{7 1 \%}$ & 2,257 & $1,402(70 \%)$ \\
\hline Pediatrics & 120 & $1 \%$ & $\mathbf{6 4 \%}$ & 576 & $456(\mathbf{8 3 \%})$ \\
\hline Men disease & 274 & $14 \%$ & $\mathbf{7 7 \%}$ & 699 & $447(72 \%)$ \\
\hline Surgery & 478 & $8 \%$ & $\mathbf{6 6 \%}$ & 926 & $648(66 \%)$ \\
\hline Dental & 69 & $37 \%$ & $28 \%$ & 147 & $91(68 \%)$ \\
\hline etc & 498 & $4 \%$ & $\mathbf{5 6 \%}$ & 957 & $577(66 \%)$ \\
\hline
\end{tabular}

$\circ$ Etc include emergency, CT, MRI, Diagnostic radiology, Hospice, Medical Oncology, Outpatient Rehabilitation, Pain specialist, and so on.

"Patients sent the results of a number of check-ups through [ISMP technology]. I

do give him answers to some personal questions. ... I recently discovered that communicating with a patient may be one side of a starting point, but it also increase the number of exchange communication with the patient. After we [physician and patient] communicate on the WeChat, I have a basic understanding of the patient." (Focus group, Physician 4)

The mobile consulting feature offers a new type of the healthcare services by facilitating interactions between a patient and a physician. The displays of these simple words actually gave patients emotional reliefs. As a response of a doctor's simple word, 'normal,' a patient expressed feeling in the mobile consulting feature like, 'You say normal, which make me quite at ease.' It illustrates the effect of the affordance of 'virtual healthcare consultation' on patient-centered care processes.

9 The ratio of off-operation hour code is applied. 


\section{Affordance II: Ubiquitous Access}

An affordance of 'ubiquitous access' is identified through the data analyses. Material agents that enact this affordance are the ISMP scheduling feature and the eHealth data including lab results and summary reports that can be assessed through ISMP. A user's goal regarding this affordance is convenience which is evident in the patient and the physician interviews ('It is convenient for patient when I get out, put all the results to see, including medical records', Interview, Physician 5) and ("I just want to know the results as soon as possible”, Interview, Patient 3).

The affordance of 'ubiquitous access' is recognized as a perceived affordance from Document 2. The following statement describes the designers' intentions to design the ISMP technology to make healthcare processes with less slack time. The need of 'accessibility as soon as possible' can be met with the affordance of 'ubiquitous access' enacted with ubiquitous technology property and the integration with hospital systems data.

"Patients access their lab results and medical records in no time... Patients make appointments with healthcare providers who they want and make payments for the healthcare services in no time" (Document 2)

The affordance of 'ubiquitous access' is actualized in the healthcare processes through the use of the scheduling, making payments, or querying medical records provided by ISMP. Like the 'virtual healthcare consultation' affordance, this affordance can also be assessed using derived measures from the actual action data. Intensity of mobile usage (e.g., scheduling) is measured by a ratio of the number of mobile activity (e.g., scheduling) over the total number of the activity completed regardless of technologies used. More importantly, that time measure accurately reflects the 'anytime ubiquitous access' affordance, and it assesses the availability of the health care. The detail definitions of each measure are described in Table 13. 
Table 15 shows three measures of the behavioral affordance of 'ubiquitous access.' The OB/GYN and pediatric departments showed active usage of the ISMP scheduling feature (13,461 and 4,201 ISMP scheduling completed). Most of departments showed about even ratios of ISMP scheduling usages $(41 \%-49 \%)$, except for the OB/GYN department. The values of the ratio and frequency of the two different types of affordance, shown in Tables 14 and 15, are quite different, but the values in the time of the two affordances are not different.

Table 15. Statistics of Measures of 'Ubiquitous Access' Affordance across Departments

\begin{tabular}{|c|c|c|c|}
\hline Department & $\begin{array}{c}\text { Frequency of } \\
\text { ISMP } \\
\text { scheduling } \\
\text { completed }\end{array}$ & $\begin{array}{c}\text { Ratio of ISMP } \\
\text { scheduling } \\
\text { completed }\end{array}$ & $\begin{array}{c}\text { Time of ISMP } \\
\text { scheduling } \\
\text { completed }\end{array}$ \\
\hline OB/GYN & $\mathbf{1 3 , 4 6 1}$ & $67 \%$ & $\mathbf{5 6 \%}$ \\
\hline Internal medicine & 3,477 & $\mathbf{4 7 \%}$ & $\mathbf{6 9 \%}$ \\
\hline Pediatrics & $\mathbf{4 , 2 0 1}$ & $\mathbf{4 1 \%}$ & $\mathbf{6 6 \%}$ \\
\hline Men disease & 879 & $\mathbf{4 6 \%}$ & $\mathbf{6 9 \%}$ \\
\hline Surgery & 3,036 & $\mathbf{4 9 \%}$ & $\mathbf{6 9 \%}$ \\
\hline Dental & 80 & $60 \%$ & $\mathbf{6 3 \%}$ \\
\hline etc & 3,098 & $82 \%$ & $\mathbf{5 6 \%}$ \\
\hline
\end{tabular}

$\circ$ Etc include emergency, CT, MRI, Diagnostic radiology, Hospice, Medical Oncology, Outpatient Rehabilitation, Pain specialist, and so on.

In the process mining analysis results in Figure 3(b), Variants 1 and 3 show a combination with a patient (a social agent), onsite registration desk at the hospital (a material agent), to make an appointment (an activity) for a face-to-face consultation with a physician (a goal). Variants 2 and 4 show differences in a combination of the ISMP scheduling feature and more off-operation-hours. It clearly suggests that the main ISMP routines in the healthcare context is scheduling (as an activity) that a patient (as an actor) uses the mobile scheduling feature (as a technology) for the ease of scheduling (as a goal). The pattern with Variants 2 and 4 point to an instance of the actualized affordance of 
'ubiquitous access.' The percentage of technologies used to schedule totally differ across the 4 Variants, $\chi^{2}(3,12059)=12,059, p=0.00$. The percentage of hours and departments differ, $\chi^{2}(3,12059)=2,433, p=0.00$ and $\chi^{2}(33,12059)=613, p=0.00$, respectively. Therefore, I can say that technology, time, and department are significantly different depending upon patterns of activities. If we know the outcomes of the patterned activities derived based on the combination of these factors, such as behavior changes or satisfaction, then we can reveal how differences in the affordance dimensions, including technology and time in this case, contribute to certain outcomes ${ }^{10}$.

Patients and healthcare providers as users perceived two benefits of the 'ubiquitous access' affordance in the healthcare processes: emotional comfort and convenience. The following quotations reflect Patient 4's perception of accessing eHealth data as soon as possible. Without the accessibility, the patient would keep worrying about the consequences due to possible diseases that are yet to be diagnosed or concluded. Chief Nurse 1 in the following quotation mentioned the values of information integrated in ISMP, such as registration, payment, and eHealth data, in improving convenience for patients. Interestingly, she added it is a visible benefit to everyone, which indicates it is obviously perceived by most users.

"I find it convenient. I just wanted to know the results as soon as possible, took a look at it, or some time I would be very worried." (Interview, Patient 4)

"One is the information in the WeChat hospital app... began using the WeChat hospital app for registration, making an appointment, finding test results, and making payments, etc., The patient is very convenient, but also saves their time,

10 The numbers of the outcome data for each variants are not enough to perform statistics tests in this study. 
and avoid their anxiety. This is visible benefit to everyone." (Interview, Chief Nurse 1)

Patients interviewed discussed the impacts of the actualized affordance of 'ubiquitous access.' For example, Patient 5, a pregnant woman who thinks the hospital medical equipment is better, comes to the hospital for her regular check-ups, even though she lives outside of the city. However, to see the results of the check-ups, she uses ISMP instead of a physical visit to the hospital. As a result, she saves her time by not traveling to the hospital and lining up for registrations. Patient 6, who is a fairly busy teacher, also addressed that the ISMP use improves the healthcare processes, especially access to care. Integration with the hospital system data enables patients' access to primary care with shorter waiting time and with ease in making appointments.

"I do not live in [the city where hospital is located], a little distance away from here... I try to come here for check-ups, but when the travel is relatively hard, because you never know when it [check-up reports] produced... You can arrange your time [with ISMP]. Then look at the result which is more convenient. They do not come to line up" (Interview, Patient 5)

"[Patient can make an appointment on] A same day can be. You make an appointment in advance, even for a full month and adjust the clock [in ISMP]." (Interview, Patient 6)

\section{Affordance Types}

While I analyzed the data from the various sources of information to identify the affordances, I reconfirmed three types of affordance: perceived affordance, behavioral affordance, and interactive affordance. By defining three types of affordance, it becomes easier to study the relationships among affordance dimensions, outcomes, and affordances. 
A perceived affordance emerges at the individual level. Action possibilities as perceived affordances are often related to the limitations (or expansions) of technology before a user's technology use. Perceived affordances are determined by a material's ability, an actor's capability, and a task's characteristics. Roles as a physician and a patient may be involved in enacting different perceived ISMP affordances. For example, a physician may think that the mobile screen is too small to carry image processing information, which perception limits the use of ISMP in certain work.

A behavioral affordance emerges at individual level, reflected by an actual action that a user uses a specific technology feature to perform a particular task. A user's skills, technology properties, task characteristics as well as situated context information are key factors involved in enacting a behavioral affordance. Patients' demographic information, as an example, may affect the creation of patients' behavioral affordances; some patient demographic factors have significant relations with the patient's behavioral affordance measures. Gender of patients is significantly related with the use of the ISMP scheduling feature. The male patient group scheduled less using ISMP $(\mathrm{M}=1.01, \mathrm{SD}=2.657)$ than the female patient group $(\mathrm{M}=1.67, \mathrm{SD}=2.825)$. This difference was significant, $\mathrm{t}(482)$ $=-3.485, p=0.001$. Also an individual's perceived affordances influence his or her behavioral affordances. Physicians who complained about the small-size screen of ISMP, for example, actually showed almost no use of ISMP.

An interactive affordance emerges at pair level or group level, which indicates that an interactive affordance is subject to the influences due to more users. Influencing factors include users' perceived affordances (e.g., physician's perceived affordances and patient's perceived affordances), situations involving with more actors (e.g., the patient wants to use ISMP, but the surgeon is not available because he is working at an operation room), and 
tasks that require collaboration (e.g., shared decision making). The 'virtual healthcare consultation' affordance is an interactive affordance because two actors were involved, a patient and a physician. Figure 7 shows two actors' nodes (patients and physicians) and ties (their relationships in the ISMP consultation) in a social network analysis. Among 109 physicians who used the ISMP consulting feature, only 3 physicians appeared to extensively use it which boxes are colored dark in Figure 7 (422 texts, 186 texts, and 152 texts made by each of the three physicians). The 3 physicians do not share patients; there are clear clusters around each physician. The ties between a physician and a patients represent their interactions in the ISMP consultation. The relationships representing as ties in ISMP could be new or the same with the relationships between the patient and the physician in the physical world.

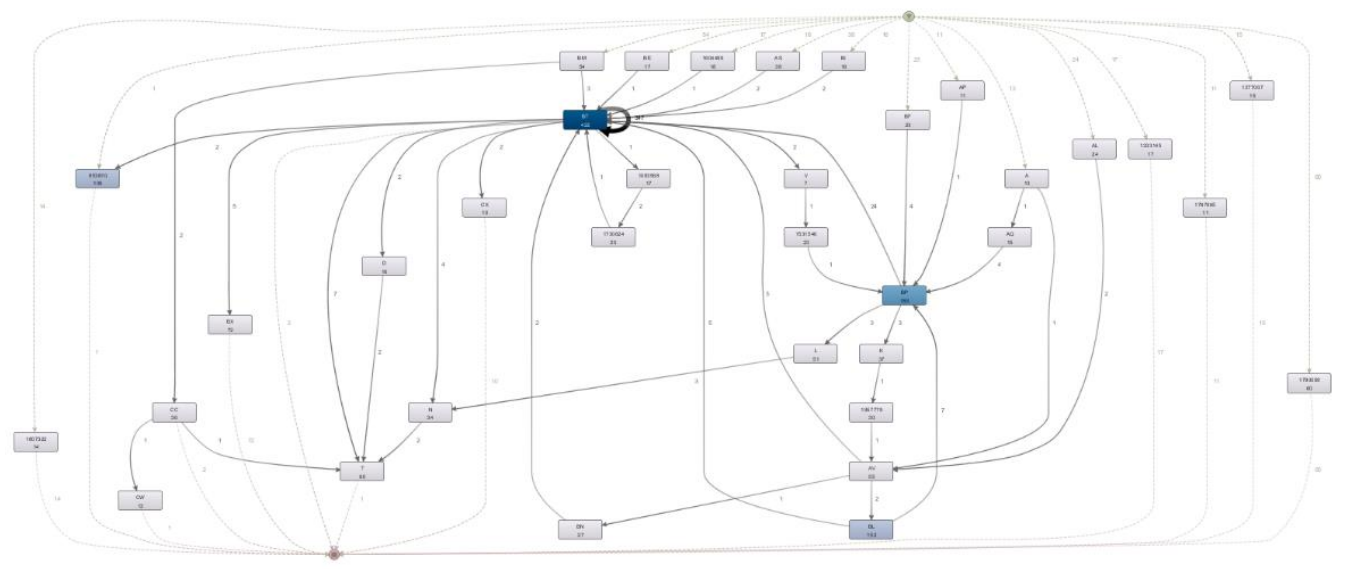

Figure 7. Result of Social Network Analysis for Interactions among Patients and Physician in the ISMP Mobile Consulting ${ }^{11}$

11 The letters in it represent doctors who wrote texts in ISMP, and the numbers represent patients who left messages to physicians. Patients and physicians who performed the ISMP mobile consultation less than 4 times are hidden, because they are too many patients and physicians who use only $1-2$ times for the last 1 year. 
An interviewee addressed an interactive affordance with a group chatting feature. The OB/GYN department offers clubs for patients by using a feature of group chatting in which usually at least a medical professional is involved. The club was created for the purpose of communicating among and educating a mass of patient groups. This group chatting feature enacts the interactive affordance at the group level, showing a new interactive affordance. Even though this study focuses on one-to-one level interactive affordances, one with the group chatting feature is also an instantiation of interactive affordances because the usage of the technology is for networked human interactions. Obstetrician 6 found benefits of the actual use of the clubs in the practices. It promotes patients to share relevant knowledge with each other and have medical professionals help them by sharing professional opinions and knowledge, thus makes it possible for the group of patients to learn and share knowledge. The impacts of the group-level interactive affordance would be a good future research topic because the impacts should be different than the individual level interactive affordance due to an additional layer of complexity with a mass of groups.

"We have a club, Obstetricians club or Mommy club, by the Obstetrician network that usually has obstetricians. We can communicate with each other, work each other, or send some things to learn like latest guidelines. What we do in Mommy club is to guide moms to enter the club. What we found there is a lot of knowledge, and communicating with each other so that they can educate themselves." (Interview, Physician 6)

\section{Relationships of Affordance Types and Influencing Factors}

As I mentioned before, some patient demographic factors significantly affect the emergence of behavioral affordances. Regression tests were used to see if length of a 
patient's stay in ISMP significantly predicts the ratio of the ISMP scheduling over all scheduling events which is a measure of a patient's behavioral affordance. The regression analysis result indicated the predictor explained $10.4 \%$ of the variance $\left(R^{2}=0.104\right.$, $F(1,1132)=12.279, p=0.00)$. The length of patient's stay in ISMP significantly decreased the ratio of ISMP scheduling over all scheduling events, $\beta=-0.092, S E=0.026, p=0.000$. Patients who registered early used the ISMP scheduling less.

However, physician demographic factors appear to have insignificant effect on the physician's interactive affordances. Independent t-tests and regression tests were used to examine if some physician's information as affordance dimensions affected physician's interactive affordance measures. No physician's demographic information (i.e., age, work experience, period to use ISMP, gender, education, title, specialty) appeared significant in affecting physician's interactive affordance measures (i.e., the frequency of the ISMP consulting, the accumulative number of texts made by physicians, ratio of the number of texts at off-operation-hours over that of operation-hour).

The use situation plays a critical role in the actualization of interactive affordances. From the finding that a small number of physicians use the ISMP consultation in Figure 7, factors that affect the enactment of an interactive affordances relate more to the users than to the technology. That could come from individual situation difference. Social network is changed with new ties caused by the ISMP use with the new function to connect patients and physicians. I found this pattern from the real usage data of the ISMP consulting feature; some patients tried first to contact the same physicians they met at the physical hospital before, but the patients could not reach the physicians for some reasons (e.g., the physicians may be too busy to use or don't want to give their opinions based on part of information). As a result, the patients quickly switched to a new physician and got responses from the new physician, making a new tie. As such, the ISMP mobile consulting uses as an 
interactive affordance could happen only if all users use the technology. Interactive affordances are affected by the situations of users that are two or more. If one of the users does not use the technology feature, then the interactive affordance failed to emerge, even though the technology gives possibilities to connect other users. This explains why the ISMP consultations showed lower percentage of the use (about 12\%) rather than the use of the ISMP scheduling feature (about 47\%).

The combination to users' situational factors affects the emergence of interactive affordances. The number of the ISMP consultations and the number of texts made at offoperation-hours as interactive affordance measures are positively associated with the ratio of the ISMP consultations with the same patient-physician user combination. Sobel test was applied and the results indicated that the ratio of the ISMP consultation with the same pair was a significant predictor of the number of the ISMP conversation texts made at offoperation-hours, $\beta=1.05, S E=0.49, p=0.032$. The texts made at off-operation-hours was a significant predictor of the number of the ISMP consultations, $\beta=0.30, S E=0.02, p=$ 0.00. However, when the off operation hour consultation conversation was added as a potential mediator, the ratio of same user combination was no longer a significant predictor of the number of the patient's ISMP consultation, $\beta=0.46, S E=0.34, p=0.178$. These results suggest that the number of the ISMP consulting at off-operation-hours is considered as a full mediator, and the indirect coefficient was significant, $\beta=0.32$, Sobel statistics $=$ 2.12, $p=0.034$. These relationships are illustrated in Figure 8. This finding, the same pair of a patient and a physician in both virtual consultation and face-to-face consultation promotes virtual healthcare consultations via ISMP, indicates it makes the relationship between patients and physicians stronger and it is an efficient way to perform a follow-up care. 


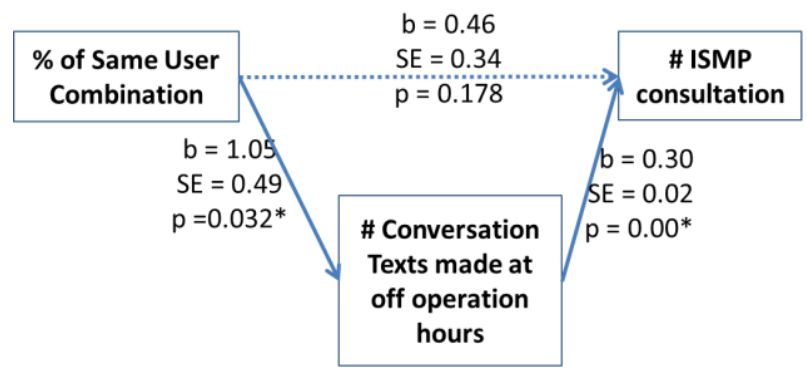

Figure 8. Relationships between User Combination and Interactive Affordances

Interestingly, I found that materials and situations induce the change of affordance types. In a situation that the information a patient wants is placed in the hospital systems even though the ISMP provides the patient with a function to view information, ISMP is useless to the patient. ("I sometimes at home want to see the B-list, but sometimes it has been placed to the hospital. This is not very convenient", Interview, Patient 7). This case describes a failure to actualize a behavioral affordance. As a response to this situation, Patient 9 turned to the ISMP mobile consulting feature to ask a medical professional to access the data stored in hospital systems ('Because the advice is not in IMSP technology, so I come to you [through mobile consulting feature]', Conversation text, Patient 8). It shows that the absence of the information as a material technology capability led to no actualization of the behavioral affordance, but at the same time created an interactive affordance. I found an evidence to support the change of affordance types. Changes in technological properties enact a new affordance, discarding old affordances, which is consistent with the concept of imbrication proposed by Leonardi (2011). There are three methods to make doctor's appointments: ISMP scheduling, Kiosk, or registration desk via staff at the hospital. Different technologies bring different types of affordances; ISMP scheduling and Kiosk are behavioral affordances, however, scheduling with registration staff is an interactive affordance. Later, the hospital made some changes in the technology 
by adopting a typical social media's property, sharing contents in a large group. This change in technology might result in changes in the affordances and/or affordance types.

\section{E. Relationship of Affordances and Outcomes}

The 'ubiquitous access' affordance and the 'virtual healthcare consultation' affordance represent behavioral affordances and interactive affordances, respectively. Each type of the affordances generates certain outcomes. The 'ubiquitous access' affordance enhances convenience and emotional comfort with the technology's ability to access anytime anywhere. It is consistent with prior studies that show behavioral affordances promote engagement (Majchrzak et al., 2013), learning (Melhuish \& Falloon, 2010; Cochrane \& Bateman, 2010), regardless of time, places or devices. The 'virtual healthcare consultation' affordance brings associations between patients and physicians through access to virtual medial resources that improves access to care and easy sharing of information that facilitate shared decision makings and empower patients. Consistent with prior literature that shows similar patterns, this study found that interactive affordances bring social connection (Treem \& Leonardi, 2012), continuous sharing of information, and collaboration (Cochrane \& Bateman, 2010).

Besides the process outcomes, I analyzed the ISMP system data and patients' clinical data to see the impacts of the affordance types on healthcare processes. The outcome measure used is difference in the numbers of face-to-face consultations before and after the ISMP implementation. ${ }^{12}$ To calculate the volume difference as an outcome

\footnotetext{
${ }^{12}$ First, I conducted regression analysis with volume difference in month as outcome data to check if there is a learning effect as time goes. However, it does not significantly affect the volume increase. Therefore, I made the variable accumulated, making the volume (before), which consist of the data between 2013.9 and 2014.5, and volume (after), which consist of the data between 2014.9 and 2015.5, to make comparisons easy.
} 
measure, the data were collected for two periods (Sep. 2013 - May 2014 and Sep. 2014 May 2015). Three months right after the implementation of ISMP, June 2014 to Aug. 1014, were excluded because the period is unstable because of the transition. Using data from the ISMP and the EMR systems, I tested the relationships between the affordances and the outcomes. The descriptive statistics of the outcome measure are shown in Table 16.

Table 16. Descriptive Statistics of Outcome Measures

\begin{tabular}{|c|c|c|c|c|c|c|c|}
\hline \multirow[t]{2}{*}{ Measure } & \multicolumn{3}{|c|}{$\begin{array}{c}\text { Pre-ISMP } \\
(2013.9-2014.5)\end{array}$} & \multicolumn{3}{|c|}{$\begin{array}{c}\text { Post-ISMP } \\
(2014.9-2015.5)\end{array}$} & \multirow{2}{*}{$\begin{array}{c}\% \\
\text { change }\end{array}$} \\
\hline & Mean & S.D & n & Mean & S.D & n & \\
\hline $\begin{array}{l}\text { Physician's } \\
\text { productivity }^{13}\end{array}$ & 137 & 282 & 378 & 137 & 280 & 417 & $100 \%$ \\
\hline $\begin{array}{l}\text { for Female } \\
\text { physician }\end{array}$ & 171 & 267 & 110 & 153 & 257 & 127 & $89 \%$ \\
\hline $\begin{array}{l}\text { for Male } \\
\text { physician }\end{array}$ & 123 & 288 & 267 & 130 & 290 & 289 & $106 \%$ \\
\hline $\begin{array}{c}\text { Patient's } \\
\text { hospital visit }^{14}\end{array}$ & 4.5 & 4.9 & 8,154 & 5.2 & 5.1 & 16,507 & $115 \%$ \\
\hline
\end{tabular}

Some patients' behavioral affordance measures are significantly related to the outcome measure. Regression analysis was used to test if the number of the ISMP scheduling significantly predicts the number of patient's physical visits to a doctor. The results of the regression analysis show that the number of the ISMP scheduling explained $37.5 \%$ of the variance $\left(\mathrm{R}^{2}=0.375, F(1,13139)=2145.28, p=0.000\right)$, and significantly predicted the ratio of the number of face-to-face consultations after ISMP implementation over that of before the implementation, $\beta=0.024, S E=0.001, p=0.000$. Therefore, as the number of the ISMP scheduling increases, the volume of patients' visits increases after the ISMP implementation. This is a significant relationship only between patient's behavioral

\footnotetext{
${ }^{13}$ Productivity is assessed by the number of face-to-face consultation of a physician per month.

${ }^{14}$ Hospital visit is assessed by the number of face-to-face consultations a patient completed for the 9 months.
} 
affordance measures and the outcome, not with interactive affordance measures and the outcome. It makes sense because interactive affordances do not affect the number of patient's visits.

I also checked the effects of affordance dimensions on the patient visit volume difference. Some patient factors (e.g., gender, same combination of users, and duration of stay in ISMP) appeared to be significant in affecting the volume of patients' visits (i.e., difference in volume of (after - before), ratio to increase volume). Regarding gender difference, the female patient group much more increased the volume of hospital visits compared to that of before the ISMP implementation, while the male patient group increased the volume, as Table 16 shows. This difference was significant, $t(425)=-2.209$, $p=0.046$. With the ratio of combinations with same users, the results of the regression analysis indicated that the ratio of same user combinations for virtual and face-to-face consultations significantly predicted the volume difference of after and before of the ISMP implementation, $\beta=0.197, S E=0.098, p=0.044$. Figure 9 illustrates a summary of the findings about the relationships around patient's affordances. 


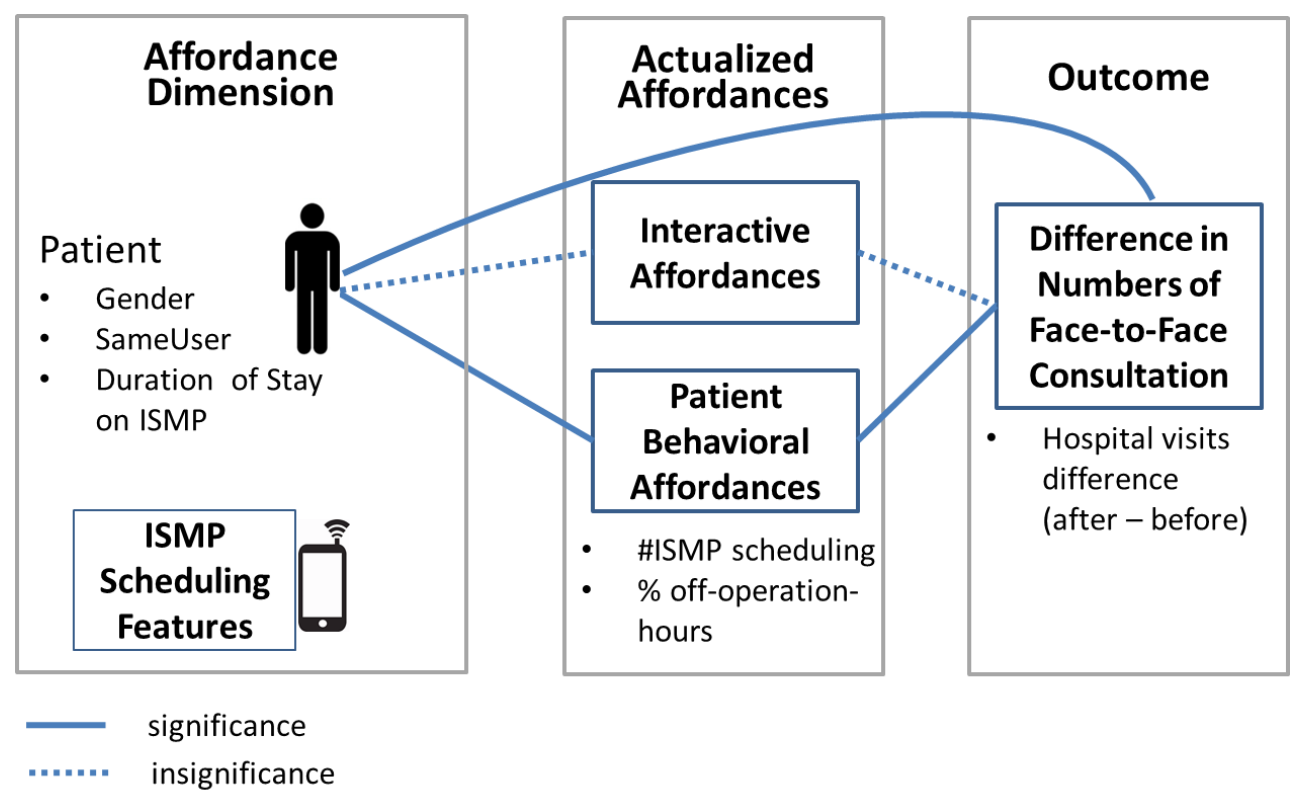

Figure 9. Relationships Related to Patient's Affordances

Physician demographic factors that may affect physician's interactive affordance were investigated. The outcome measure for physicians is difference in physician's productivity of (after - before) or ratio to increase work volume (after/before). Physician's gender, position, and specialty show relations with the outcome measure. No other physician information, such as age, work experience, duration of ISMP use, education, title, specialty, were found to be significant in affecting physicians' productivity difference. Regarding specialty, the physicians in the OB/GYN department show significantly smaller difference in productivity compared to that before the ISMP implementation $(M=3.40$, $S D=272)$ than in general department $(M=12.22, S D=138)$. The differences across departments were significant, $F(7,243)=3.251, p=0.003$. Regarding physician positions, the physician group had more increased work volume compared to that before the implementation of ISMP $(M=112.1, S D=641.37)$ than the attending physician group $(M$ $=1.87, S D=3.59)$, the chief physician group $(M=1.26, S D=1.03)$, the deputy chief physician group $(M=3.09, S D=17.56)$. This difference was significant, $F(3,367)=3.490$, 
$p=0.016$. Regarding gender difference, the female physician group shows higher increase ratio of work volume compared to that before the implementation of ISMP (M $=42.16$, SD $=387.33)$ than the male physician group $(\mathrm{M}=2.15, \mathrm{SD}=11.86)^{15}$. This difference was significant, $F(1,578)=3.25, p=0.072$. The results of regression analysis show that ages of physicians are significantly related to productivity difference compared to that before the implementation of ISMP, $\beta=0.020, S E=0.004, p=0.000$. However, there are no significant relationships between these demographic information and interactive affordance measures. However, interactive affordance measures, such as number of ISMP consultation and sum of conversation texts, show no significant relationships with the outcome measures. Figure 10 illustrates a summary of the findings about the relationships around physician's affordances.

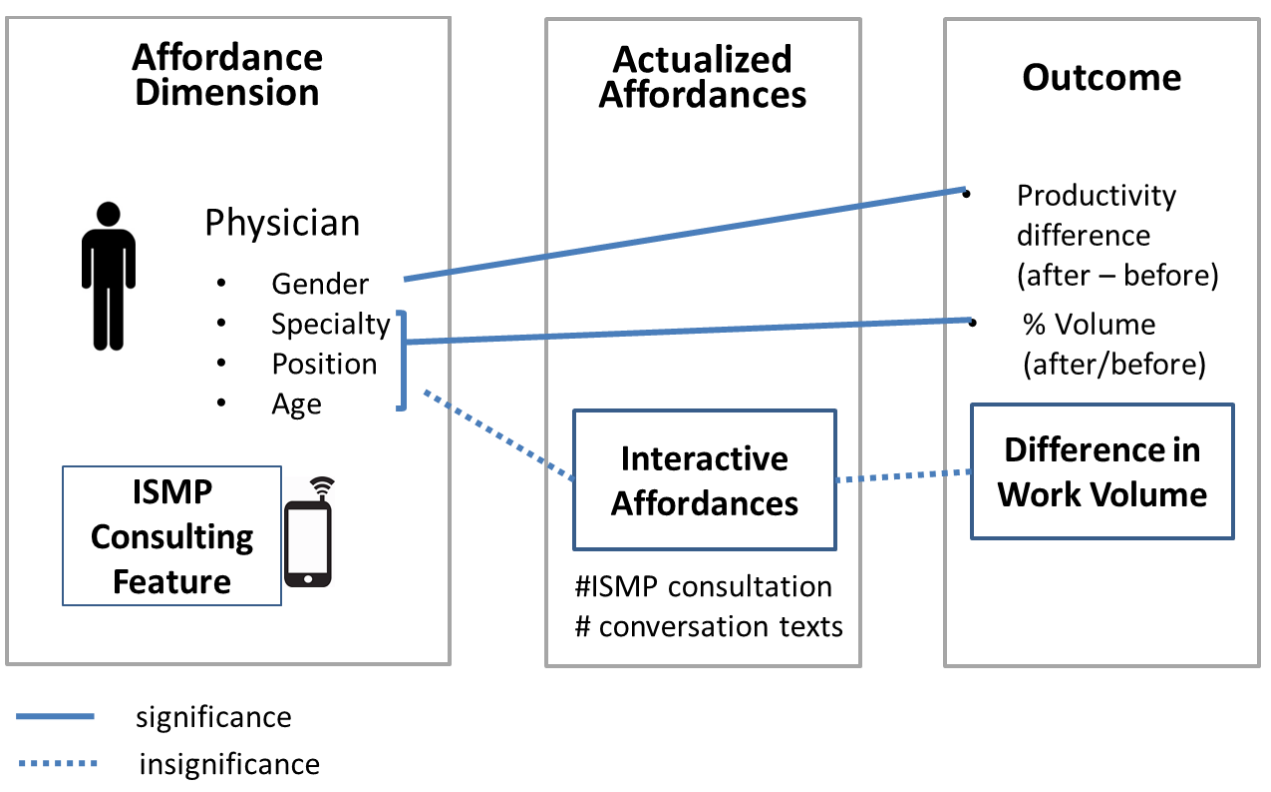

Figure 10. Relationships Related to Physician's Affordances

15 The data population is physicians who have worked in the hospital from the period of 'before,' Sep. 2013. 
The text mining results show the association of the ISMP consulting usage and outcome, unlike the previous analyses that indicate the use of ISMP mobile consulting has no relationships in the real world. Figure 11 shows a text conceptual map as a text mining analysis result with patient's conversation texts. It shows terms that co-occurs with a centered term, Thank. The text mining analysis result gave me a hint on mechanism to improve patient satisfaction. Based on the result, I could find that patients thank doctors for all doctor's medical services in ISMP. They also show appreciation to hospital because they know they can connect physicians in a virtual space that the hospital provides for both patients and physician to meet via ISMP. Therefore, I can conclude that the virtual healthcare consultation activity improves patient satisfaction. By synthesizing the analysis results of text mining and statistics analyses, interactive affordances improve patient satisfaction, not the volume.



Figure 11. Text Conceptual Map Analysis Result 
Based on the findings from the qualitative analysis results and statistics analysis results on the relationships of affordance types, affordance dimensions, and outcome. Figure 12 illustrates a synthesized summary of all the findings about the relationships around the ISMP affordances.

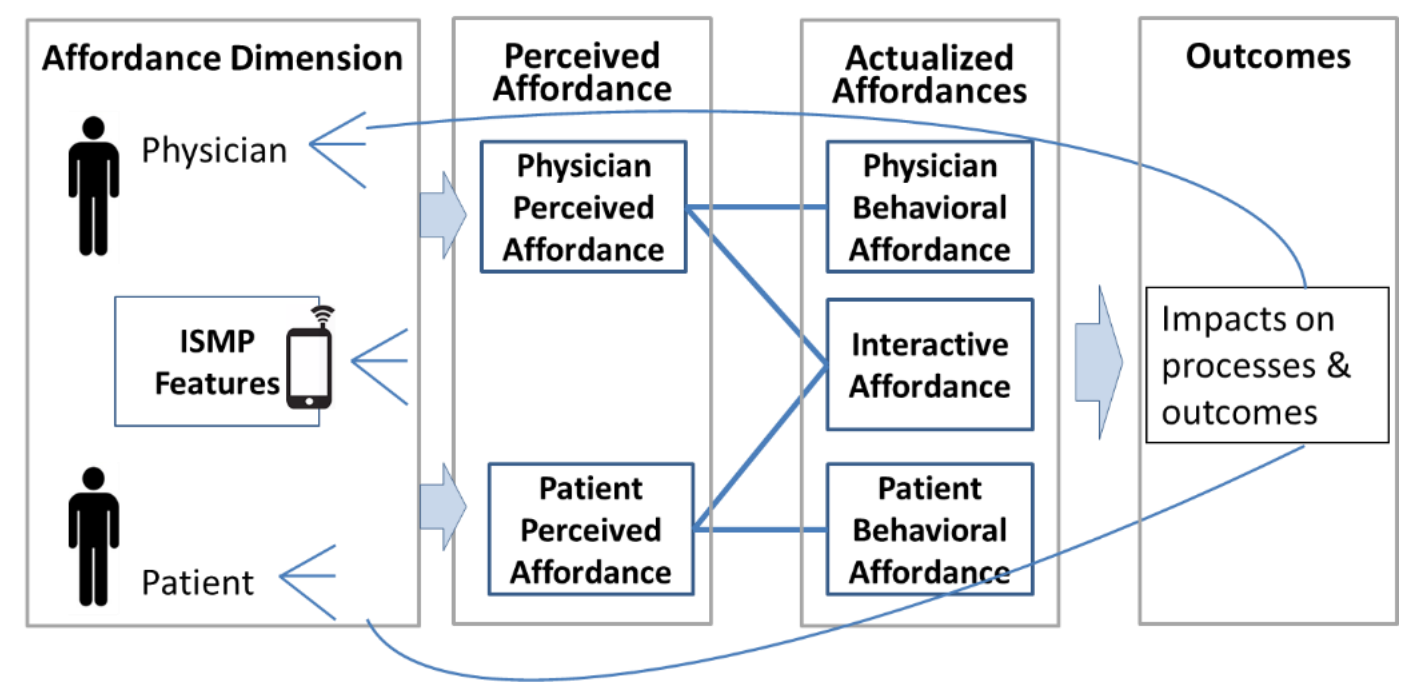

Figure 12. Relationships Related to Affordances in the Healthcare Context

\section{F. Why Are Some Affordances Not Perceived or Actualized}

Affordances are perceived (Shaw, Turvey, \& Mace, 1982) and actualized (Strong, Volkoff, et al., 2014), but not all affordances do. The ISMP system data, the documents, and the interview and focus group data clearly show that not all the affordances are perceived or actualized. I found that the designers' intentions were not perceived by all users, often because of material agents and tasks. Perceived affordances are not actualized for reasons of material's properties and situations. Personal factors matter in enacting both perceived affordances and actualized affordances. I categorize the reasons as relating to task, people, and role factors with technology. 


\section{Task \& Technology}

I found that technology properties and task characteristics play a role in enacting perceived affordances of ISMP. ISMP is a simple and easy equipment rather than a perfect tool suitable for all kinds of medical practices. Some healthcare providers think ISMP usages are limited in the context of their medical practices. This point was evidenced in an interview with an Orthopedics physician. Orthopedics is a unique practice requiring image data processing and imaging technology. The orthopedics physician mentioned that his job requires a large amount of information (He described it as 'a little book'). He complained about the lack of printing functionality in ISMP, which is critical for orthopedician's work. The current ISMP technology cannot afford the orthopedician's work to be completed, which resulted in a failure to enact even a perceived affordance.

However, some healthcare providers think that ISMP is very useful in the contexts of their practices. For example, OB/GYN physicians perceive possibilities of educating patients using ISMP. They created clubs for group education, which is more than what the designers expected. Patients also value the benefits of using ISMP in discussing about sensitive topic like their sexual life issues.

\section{Role \& Technology}

Roles of users, technology features or information in the technology matter in affordance actualization. A material property of the mobile consulting feature, asynchronized characteristic, leads to the enactment of the affordance of 'ubiquitous virtual healthcare consultation' by enabling the use anytime and anywhere. The affordance is perceived by patients as a benefit and has been actualized by patients, as shown in Figures 3, 4, and Table 14. However, the same material property has a negative influence on physicians who get time pressure under a situation in which the hospital policy required them to quickly 
response patients' inquires. Pediatrician 1, for example, addressed difficulties in answering in a timely manner (The rule here is that a physician is given at most 30 minutes to respond after a patient creates a new text conversation). Physicians or surgeons are too busy in the workplaces (e.g., operation rooms for surgeons) to take a look at alerts in ISMP. Therefore, many texts made by healthcare providers are during the off-work hours. Neurosurgeon 1 added that the ISMP use interrupts doctors' ponderation, which eventually lowers the satisfaction of patients. This interruption is a negative value of the ISMP technology use a doctor perceived.

"We [physicians] have to answer for half an hour, this is a very troublesome because we have to go to work and cannot always come up with a phone to see WeChat.” (Focus group, Pediatrician 1)

"I have tried to answer, and I found it hard. In fact, I think it depends on whether you are a physician or a surgeon. A lot of surgeons cannot go to work with a mobile device, and they cannot see WeChat all the time, because they focus on their thoughts in things around work. Looking at [ISMP technology] needs to take a break which is still influential, thus patients will feel bad." (Interview, Surgeon 1) Here is another case that both technology property and role both matter the actualization of affordances. A property of ISMP, not editable messages already sent, allows patients to keep all messages from physicians in patients' device. This persistent characteristics induces physicians to be hesitant in actively using the ISMP mobile consulting feature. Physicians transfer medical knowledge to patients as domain experts, and patients are receivers of knowledge services. Physician 8 in the internal medicine unit, for example, clearly mentioned that his judgment was based on the information a patient provided, which may not be accurate or correct. He understands the service of virtual consultation as a strategy of the hospital but also shows hopes for organizational moves for 
changes to handle the limitations of ISMP. The organizational moves can be either material changes such as expansion of the technology's ability to edit messages or changes of social rules such as redefinition to access health data.

"I answered seven questions [before], no longer able to go. ... [when physicians give answer patients' questions], I emphasize that what I answer was only on my own behalf some of the points." (Focus group, Physician 8)

\section{People}

Personal factors influence the entanglement in perceived affordances and actualized affordances. Individual differences in gender, age, social economic status, absorptive ability, and attitude toward the technology play a role in the use of the ISMP technology. I just showed that user's gender affects a behavioral affordance in the healthcare process. Many old people cannot afford purchasing a smartphone, which results in no use of ISMP. It could be an explanation for why many chronic disease patients, most of whom are old, do not use ISMP.

People have different levels of absorptive capability when it comes to use new technology or adapting to a new routine. Not all patients are aware that healthcare is actually available through the ISMP uses. Some had no chance to get to know other health technologies, thus do not use them and miss the opportunity to access possible healthcare. Patients show differences in their abilities to understand health information and apply the information to their health situations. Some patients intuitively know how to use new technologies for achieving their healthcare goals. The following quotation demonstrates Patient 10's absorptive ability to use the ISMP mobile consulting feature to get second opinions from virtual medical professionals, which is novel and beyond the designer's intentions. 
"Dr. A just replied with another opinion to the suggestion that Dr. B gave. Two drugs can help the problem... Then what do you think?" (Conversation text, Patient 10)

User's attitude towards a technology plays a role in technology use. The hospital designed communications between patients and physicians in an asynchronized way, but some patients still want to use it in a synchronized way like making phone calls, instead of written conversation in ISMP. The synchronized method may lead to lower probability to have conversation between them, as the following quotation shows. Patient 11 left a message with his phone number in the ISMP technology, and Physician 9 replied with his willingness to make a phone call, but not right away.

'Please call Tel [123456789]' 'Dr. C, I ask you not online?' (Conversation text, Patient 11)

'Yes, but it will be later' (Conversation text, Physician 9) 


\section{DISCUSSION}

\section{A. Summary}

The main contribution of this study is the development of a comprehensive affordance theory using a mixed-method approach. I proposed three types of affordance: perceived affordance, behavioral affordance, and interactive affordance. I identified two affordances of an integrative social media platform (ISMP) from the analysis with objective actual technology usage data and subjective user perception data, which contributes to a small but growing stream of IS research that view technology use patterns as relationships among technologies, users, tasks, and situations.

From the real historical data, I found two main interactions related to the use of ISMP: scheduling and consulting with ISMP. From the point of sequences of activities, those two interactions are dominant showing certain patterns, but different combinations of activity sequences, technological features, and time distribution. Without the ISMP use activates happened usually in mornings. Activities involved with the ISMP use usually occur at night time. As such, the use of ISMP determines somehow where and when to use it. Much of scheduling were completed with the use of ISMP, instead of meeting staff at the hospital. Activities in ISMP as virtual healthcare consultations are more similar with face-to-face one in real world. However, the relationships between patients and physicians has been changed since the adoption of ISMP. I found that the use of the ISMP consulting feature not only supports relationships between patients and physicians established before in the real world, but it also provides with an opportunity to create a new association with a physician for a patient in the virtual world.

Among many possible ISMP affordances in the healthcare context, the "ubiquitous access' and 'virtual healthcare consultation' affordances are recognized as key affordances 
that make the patient-centered care process possible. The ubiquitous access affordance is enacted with anytime anyplace properties of the ISMP features. It enables patients' anytime access to information in the hospital systems from any locations, such as scheduling information and patient's medical data. This semi-automation information transferring provides patients with emotional comfort and convenience to make doctor's appointments. The virtual healthcare consultation affordance is enacted with a new function of ISMP that virtually connects patients and physicians. Interestingly, prior consultation experience between the same patient and same physician promotes the use of the ISMP mobile consulting feature. It indicates this affordance effectively supports follow-ups, making continuous care and shared healthcare decision-making possible. As such, the two affordances affect healthcare processes and promote patient-centered care process.

The three types of affordance (perceived affordance, behavioral affordance, interactive affordance) are related to each other but each of the affordance types has own characteristics. Perceived affordances are relatively simple, restricting or expanding possible affordances provided by the technology. It depends on a user's ability to understand technology's usage. Actualized affordances including behavioral affordances and interactive affordances are much more contextualized. Specific material elements and specific tasks limit some possibilities for actions. Actual choice out of the possible actions depends on a user's situation and perceived affordances. In contrast, interactive affordances are subject to being influenced by factors related to multiple users. If one of the users does not want to or cannot use the technology features, interactive affordances around the features fail to emerge. Therefore, a combination of those factors is required to provide answers on questions related to how to actualize affordances. Identification of a new category of affordances (interactive affordances) and categorization of affordance types provide a theoretical contribution to the conceptualization of affordances in literature. 
Related to the research question 3, technology properties were identified to influence the enactment of affordances with other factors. One is tasks that affect the enactment of perceived affordance with the properties of ISMP. Roles are more involved with enactment of actualized affordance, such as the emergence of the virtual healthcare consultation affordance. In addition, I found individual differences such as absorptive capacity and attitude toward the technology affect both perceived and actualized affordances. Rather each factor itself, the relationship between the factors and ISMP technology elements together produce the enactment of affordances. Different factors show different effects on the enactment of perceived affordances and the enactment of actualized affordances.

One of the goals of this study is to understand and examine relationships among the affordance type, affordance dimension, and their outcomes, from a big picture perspective. I found that patient's and physician's factors have significant relationships with outcome. Behavioral affordances also show significant relationships with the outcome, but interactive affordances do not show significant relationships with the outcome that is volume difference of after and before of the ISMP implementation. ISMP scheduling usage may relate to the increase of patent's visit volume, while ISMP consulting usage may not influence on the volume increase. The outcome measure, volume increase, may be influenced by other business factors such as hospital promotion campaign or adoption of other health products, services, or systems. However, the text mining analysis result indicate the ISMP mobile consulting usage improves patient satisfaction. Having patient's health condition data or satisfaction data give additional measures for patientcentered care outcomes. Additionally, the analysis clearly showed that different affordance types due to users are related to users' differences in either user's demographic information or user's situations. 


\section{B. Implications for Research}

The first theoretical contribution of this study is the investigation of an emerging technology which combines properties of social media technology and those of mobile technology, integrated with legacy hospital systems including an electronic medical records system, a scheduling, and a payment system. ISMP incorporates various technical features and information in other systems, especially, in a pervasive technology used by the majority of people. The presence of the 'virtual healthcare consultation' provides patients with a new method of communication, which encourages mutual trust between patients and physicians. This kind of technology has not been introduced or empirically investigated in academia; it is still a nascent concept.

Second, this study contributes to the affordance theory literature. I demonstrated that the affordance lens is suitable to provide rich insights into health IT-related phenomena. I also instantiated affordance types in the healthcare context, and developed an understanding about how they are perceived and actualized. Unlike many prior studies that recognize perception and actualization of affordance (e.g., Bernhard, Recker, \& Burton-Jones, 2013; Strong, Volkoff, et al., 2014) or organization-level affordances (e.g., Leonardi, 2013; Strong, Johnson, et al., 2014), this study classifies three types of affordances, perceived affordance, behavioral affordance, and interactive affordance. The three types of affordance can be used as a foundation for organizational affordances, shared affordances, or collective affordances. For example, a set of affordances that I

found can be considered as a collective affordance proposed by Leonardi (2013) (Leonardi, 2013). The 'virtual healthcare consultation' affordance appears often with the action of medical record requests which processes are supported by other departments, such as specific clinical departments, radiology, and several labs. An internal medicine physician mentioned and perceived the two activities as a complete process. However, it 
does not happen all the time. Some patients view their lab results using ISMP, but do not value and use the ISMP consulting feature. As such, even the collective affordance should be understood in combination with lower-level affordances, such as an interactive affordance and a behavioral affordance. Especially one-to-one level affordances are a main topic of this study. These concepts are applicable to the affordances of technologies shared by many users. Understanding how each affordance contributes to and how different affordances interact with each other may suggest new mechanisms for changes.

Through the investigation using the mixed-method approach, the analysis results show that perceived affordances are related to a technology's material capability and the a actor's attitude toward the technology in the context of the practices. However, actual usages are unpredictable and actualized affordances are not the same as perceived ones. Behavioral affordances and interactive affordances as actualized affordances are influenced more by specific situations including an actor's roles with elements of material including information in the technology than by other factors. These findings add to the extant affordance literature which will improve our understanding about what actually happens to the healthcare process when implementing such integrative technologies as the ISMP.

This study benefited from a robust methodology. A mixed-method approach was applied to understanding healthcare practices and to identifying ISMP affordances, starting with both objective real system usage data and subjective perception data on the technology use. It is vital that health IT research should use multiple methods and approaches in order to understand the complex healthcare problems (Carayon et al., 2015). My efforts in looking at the real life practices with various sources of information help me to understand the phenomenon through triangulation. In addition, it allows me to look at the problems with holistic views and to find better (optimal) explanations to the problems and solutions. 
By examining the actual data without a priori hypothesized thoughts on the roles of technology or social actors, I have an unbiased view to find roles of other elements in this complete IT-related phenomenon which otherwise may have been ignored. I believe that affordances that highlights either anytime, anywhere ("how"), or anyone ("who") have the power to provide generative mechanisms for either individuals or organizations to achieve desirable outcomes (Volkoff \& Strong, 2013).

\section{Implications for Practice}

First, my dissertation study shows the complexity and explanation based on the concept of affordance about a new health IT phenomenon that closely reflects the actual healthcare processes, based on the real data. The introduction of a new ISMP technology has changed the healthcare processes, as people tend to make more doctor's appointments via ISMP, because of the affordance of 'ubiquitous access' enabled by the anytime characteristic of the ISMP. The affordance of 'virtual healthcare consultation' promotes interactions and communications between patients and physicians. I found that patients use more the ISMP consultation to support the ties that the patients and the physicians keep in the physical world, with a mediator of conversation texts made at off-operation-hours. Furthermore, the ISMP uses change people's perceptions about the healthcare service: “[ISMP technology] is a kind of subconscious transformation" (Interview, Physician 8). It offers the possibility to move to a virtual hospital consisting of virtual medical resources and virtual healthcare processes.

Second, by identifying the different types of affordances of ISMP, this study can guide healthcare organizations to offer solutions for the patient-centered care process. Organizations can improve the healthcare processes by inducing the actualization of the two affordances. Organizations face two choices, make changes either in the material or in 
the social. Often situations can be controlled. For example, this case shows difficulties of the use of the ISMP consulting features for physicians who are too busy most of time. As an example of the hospital's efforts to solve the problem, the management made changes in the material by adopting the property of social media technology, sharing information with anybody in a group. This change puts more power to the 'quick' affordance from the 'desired specific users' affordance. This change produced an immediate outcome that almost all patients' consultation conversation request texts were answered by medical professionals. If we know what affordance leads to the ultimate outcomes like patient satisfaction or patient's health condition, healthcare organizations are able to devote appropriate attention and efforts to achieve their goals.

\section{Limitations}

First, the data set that was used to measure behavioral affordances (e.g., the number of the use of the scheduling feature) did not include all user data on all ISDP features. It would be more useful to analyze a complete data set with all user's activities which varied widely. I was not able to obtain every affordances-related activity data due to the restrictions of the healthcare institution's policy and vendor contract. Hopefully I can include the data of the action of health data query as measures of the behavioral affordances in a healthcare context, but was unable to obtain these in this study. In addition, I expect there are some affordances that may be actualized in the future (e.g., virtual organization), but that were not able to be actualized during the timespan of the data collection. The full examination of these affordances and influencing factors requires additional efforts, which I leave for future work.

I tried to apply a mixed-method approach for the analysis of information from various sources. One part is the conversational text using text mining techniques, which 
provided me with a quick analysis of the results and rich information. However, the algorithm should be reconsidered due to the nuances involved in the language. For example, 'No problem' in Chinese has alternative meanings such as 'You are welcome/thank you' depending on the use situation, but the text mining technique considered it as only 'No problem.' In this study, I performed text mining with two subgroups, a patient group and a physician group. In the latter group the phrases mean 'no problems', whereas in the patient group it may mean an alternative meaning of 'thank you.' Thus, this is a need to clarify the specific meanings of texts depending on the particular contexts of their use.

Actualized affordances should be different across departments due to the uniqueness of each disease treatment. They may differ even within the same healthcare context. The examination of the impacts of each specific affordance improves generalization of the findings. As such, differentiating the three types of affordance might help to understand how IT affect clinical practices.

\section{E. Future Research}

I outline future research ideas that can build upon the foundation of this study's implications and limitations. Different levels of affordances were identified, such as individual-level affordances, group-level affordances, and organization-level affordances (Bélanger, Cefaratti, Carte, \& Markham, 2014; Burton-Jones \& Gallivan, 2007; Leonardi, 2013). This study fills a gap in the affordance theory literature with pair-level affordances which have been missing in the literature. Further theoretical categorization work can extend the affordance types I proposed: behavioral affordance and interactive affordance. For example, affordances around the use of the group-chat feature or discussion boards 
may need further theorizing efforts. We should discuss different conceptualizations of multi-level affordances in a greater depth.

The analysis results indicate that perceived affordances change over time in terms of before, during, or after technology use. Not only functionality (Neisser, 1976) but also performance (Benbasat \& Schroeder, 1977) matter in enacting affordances. For example, among different alternative ways of making doctor's appointments (e.g., the ISMP scheduling feature, the hospital kiosk, or the hospital registration desk), more patients have recently used the ISMP technology to make doctor's appointments. Changes in the usages may alter perceived affordances and the actualized affordances. The relationships among the affordances may in turn change clinical process and outcomes. It would be interesting to examine this change in real world practices.

The analysis explores how the ISMP affordances contribute to the patient-centered care. An important aspect of future research on affordances is to increase quantitative research. Therefore, I would quantitatively evaluate the impacts of ISMP affordances on the patient-centered care processes and its outcomes. The potential research space is defined by the avenues of replication, extension, and generation (Berthon, Pitt, Ewing, \& Carr, 2002). I could extend this study by adding constructs and measures to reflect the healthcare practices with ISMP. Additionally, I would examine the mediating role of the patient-centered care processes in the relationships between the affordances of ISMP and their outcomes such as the satisfaction of patients and physicians. 


\section{CONCLUSIONS}

A comprehensive focus on technologies to support patient's healthcare processes is surprisingly absent from health IT literature. ISMP, as a disruptive technology, threatens the traditional healthcare delivery method, showing the potentials to transform healthcare toward a more patient-centered care process. However, IT use-related phenomena are complex; the same technology is used differently by different users. In order to understand and study the complex IT phenomena, factors that induce an individual user to use specific features of a technology has become a focal point of interest.

I used the concept of affordances to explore ISMP affordances and their effects on patients' and physicians' activities through different uses of ISMP features. With mixedmethod analyses results, I identified two forms of ISMP affordances that facilitate patientcentered care processes: ubiquitous access and virtual healthcare consultation. These affordances represent a behavioral affordance and an interactive affordance, respectively. Through the investigation on how those affordances were actualized, the study showed that some of affordance dimensions play an enabling role in the enactment of the affordances that lead to patient-centered care. The effects of the ISMP affordances depend on not only features that an individual user perceives to be afforded but also a user's situation such as roles of social actors in the healthcare context. 


\section{REFERENCES}

Abouzahra, Mohamed, \& Tan, Joseph. (2013). The Role of Mobile Technology in Enhancing the Use of Personal Health Records. International Conference on Health Information Technology Advancement, 9.

Agarwal, Ritu, \& Karahanna, Elena. (2000). Time flies when you're having fun: cognitive absorption and beliefs about information technology usage. MIS quarterly, 24(4), 665-694.

America, Institute of Medicine. Committee on Quality of Health Care in. (2001). Crossing the quality chasm: A new health system for the 21st century. National Academies Press.

Anderson, R.M., Funnell, M.M., Butler, P.M., Arnold, M.S., Fitzgerald, J.T., \& Feste, C.C. (1995). Patient empowerment: results of a randomized controlled trial. Diabetes care, 18(7), 943949.

Bai, Xin. (2010). Affordance of ubiquitous learning through cloud computing. Frontier of Computer Science and Technology (FCST), 2010 Fifth International Conference.

Bélanger, France, Cefaratti, Meghann, Carte, Traci, \& Markham, Steven E. (2014). Multilevel research in information systems: Concepts, strategies, problems, and pitfalls. Journal of the Association for Information Systems, 15(9), 614.

Belkora, Jeffrey K, Loth, Meredith K, Volz, Shelley, \& Rugo, Hope S. (2009). Implementing decision and communication aids to facilitate patient-centered care in breast cancer: a case study. Patient Education and Counseling, 77(3), 360-368.

Benbasat, Izak, \& Schroeder, Roger G. (1977). An experimental investigation of some MIS design variables. MIS quarterly, 37-49.

Berente, N., \& Seidel, S. (2014). Big Data \& Inductive Theory Development: Towards Computational Grounded Theory?. Twentieth Americas Conference on Information Systems, Savannah, 2014.

Berg, Bruce Lawrence, Lune, Howard, \& Lune, Howard. (2004). Qualitative research methods for the social sciences (5), Pearson Boston, MA.

Bergvik, S., Wynn, R., \& Sørlie, T. (2008). Nurse training of a patient-centered information procedure for CABG patients. Patient education and counseling, 70(2), 227-233.

Bernhard, Eike, Recker, Jan C, \& Burton-Jones, Andrew. (2013). Understanding the actualization of affordances: A study in the process modeling context.

Berthon, Pierre, Pitt, Leyland, Ewing, Michael, \& Carr, Christopher L. (2002). Potential research space in MIS: A framework for envisioning and evaluating research replication, extension, and generation. Information Systems Research, 13(4), 416-427.

Berwick, D.M. (2009). What 'patient-centered' should mean: confessions of an extremist. Health Affairs, 28(4), 555-565. 
Bhargava, Hemant K, \& Mishra, Abhay Nath. (2014). Electronic Medical Records and Physician Productivity: Evidence from Panel Data Analysis. Management Science, 60(10), 2543-2562.

Bitton, Asaf, Schwartz, Gregory R, Stewart, Elizabeth E, Henderson, Daniel E, Keohane, Carol A, Bates, David W, \& Schiff, Gordon D. (2012). Off the Hamster Wheel? Qualitative Evaluation of a Payment-Linked Patient-Centered Medical Home (PCMH) Pilot. Milbank Quarterly, 90(3), 484-515.

Bloomfield, Brian P, Latham, Yvonne, \& Vurdubakis, Theo. (2010). Bodies, Technologies and Action Possibilities When is an Affordance? Sociology, 44(3), 415-433.

Bonabeau, Eric. (2009). Decisions 2.0: The power of collective intelligence. MIT Sloan management review, 50(2), 45-52.

Borghi, A.M., Flumini, A., Natraj, N. and Wheaton, L.A. (2012). One hand, two objects:

Emergence of affordance in contexts. Brain and Cognition, 80 (1), 64-73.

Braddock, Clarence H. (2012). Supporting shared decision making when clinical evidence is low. Medical Care Research and Review, 1077558712460280.

Brodie, Roderick J, Hollebeek, Linda D, Juric, Biljana, \& Ilic, Ana. (2011). Customer engagement: conceptual domain, fundamental propositions, and implications for research. Journal of Service Research, 1094670511411703.

Brodie, Roderick J, Ilic, Ana, Juric, Biljana, \& Hollebeek, Linda. (2013). Consumer engagement in a virtual brand community: An exploratory analysis. Journal of Business Research, 66(1), 105 114.

Burton-Jones, Andrew, \& Gallivan, Michael J. (2007). Toward a deeper understanding of system usage in organizations: a multilevel perspective. MIS quarterly, 657-679.

Burton-Jones, Andrew, \& Straub Jr, Detmar W. (2006). Reconceptualizing system usage: An approach and empirical test. Information systems research, 17(3), 228-246.

Carayon, Pascale, Kianfar, Sarah, Li, Yaqiong, Xie, Anping, Alyousef, Bashar, \& Wooldridge, Abigail. (2015). A systematic review of mixed methods research on human factors and ergonomics in health care. Applied ergonomics, 51, 291-321.

Cegala, D.J., \& Post, D.M. (2009). The impact of patients' participation on physicians' patientcentered communication. Patient education and counseling, 77(2), 202-208.

Chemero, Anthony. (2003). An outline of a theory of affordances. Ecological psychology, 15(2), 181-195.

Clarke, Andrew, \& Steele, Robert. (2012). Secure and reliable distributed health records:

Achieving query assurance across repositories of encrypted health data. 45th Hawaii International Conference on System Sciences.

Cochrane, Thomas, \& Bateman, Roger. (2010). Smartphones give you wings: Pedagogical affordances of mobile Web 2.0. Australasian Journal of Educational Technology, 26(1). 
Constantinides, Panos, \& Barrett, Michael. (2006). Negotiating ICT development and use: The case of a telemedicine system in the healthcare region of Crete. Information and Organization, $16(1), 27-55$.

Corbin, Juliet, \& Strauss, Anselm. (2014). Basics of qualitative research: Techniques and procedures for developing grounded theory. Sage publications.

Cousins, Karlene, \& Robey, Daniel. (2015). Managing work-life boundaries with mobile technologies: An interpretive study of mobile work practices. Information Technology \& People, 28(1), 34-71.

Davis, K., Schoenbaum, S.C., \& Audet, A.M. (2005). A 2020 Vision of Patient-Centered Primary Care. Journal of General Internal Medicine, 20(10), 953-957.

Davidson, Elizabeth, \& Vaast, Emmanuelle. (2010). Digital entrepreneurship and its sociomaterial enactment. 43th Hawaii International Conference on System Sciences.

DeSanctis, Gerardine, \& Poole, Marshall Scott. (1994). Capturing the complexity in advanced technology use: Adaptive structuration theory. Organization science, 5(2), 121-147.

Eisenhardt, Kathleen M. (1989). Building theories from case study research. Academy of management review, 14(4), 532-550.

Elwyn, G., Edwards, A., Kinnersley, P., \& Grol, R. (2000). Shared decision making and the concept of equipoise: the competences of involving patients in healthcare choices. The British journal of general practice, 50(460), 892.

Furrer, Carrie, \& Skinner, Ellen. (2003). Sense of relatedness as a factor in children's academic engagement and performance. Journal of educational psychology, 95(1), 148.

Gaskin, James, Berente, Nicholas, Lyytinen, Kalle, \& Yoo, Youngjin. (2014). Toward generalizable sociomaterial inquiry: a computational approach for zooming in and out of sociomaterial routines. Mis Quarterly, 38(3), 849-871.

Gaskin, James E, Schutz, Douglas M, Berente, Nicholas, \& Lyytinen, Kalle. (2010). The DNA Of Design Work: Physical And Digital Materiality In Project-Based Design Organizations. Academy of Management (pp. 1-6).

Gaskin, James, Thummadi, Veeresh, Lyytinen, Kalle, \& Yoo, Youngjin. (2011). Digital Technology and the variation in design routines: a sequence analysis of four design processes.

Gavin, L.A., Wamboldt, M.Z., Sorokin, N., Levy, S.Y., \& Wamboldt, F.S. (1999). Treatment alliance and its association with family functioning, adherence, and medical outcome in adolescents with severe, chronic asthma. Journal of Pediatric Psychology, 24(4), 355-365.

Gerteis, M., Edgman-Levitan, S., Daley, J., \& Delbanco, T.L. (1993). Through the patient's eyes: understanding and promoting patient-centered care. Jossey-Bass San Francisco.

Gibson, James Jerome. (1979). The ecological approach to visual perception. Psychology Press.

Giddens, Anthony. (1984). The constitution of society: Outline of the theory of structuration. University of California Press. 
Goh, J. M., Gao, G., \& Agarwal, R. (2011). Evolving work routines: Adaptive routinization of information technology in healthcare. Information Systems Research, 22(3), 565-585

Goldkuhl, Göran. (2008). Actability Theory Meets Affordance Theory: Clarifying HCI in IT Usage Situations. European Conference on Information Systems (pp. 790-801).

Greener, J.M., Joe, G.W., Simpson, D.D., Rowan-Szal, G.A., \& Lehman, W.E.K. (2007). Influence of organizational functioning on client engagement in treatment. Journal of substance abuse treatment, 33(2), 139.

Greenhalgh, Trisha, Hinder, Susan, Stramer, Katja, Bratan, Tanja, \& Russell, Jill. (2010). Adoption, non-adoption, and abandonment of a personal electronic health record: case study of HealthSpace. BMJ: British Medical Journal, 341, c5814.

Greenhalgh, Trisha, Stramer, Katja, Bratan, Tanja, Byrne, Emma, Russell, Jill, \& Potts, Henry WW. (2010). Adoption and non-adoption of a shared electronic summary record in England: a mixed-method case study. BMJ: British Medical Journal, 340, c3111.

Grgecic, Daniel, Holten, Roland, \& Rosenkranz, Christoph. (2015). The Impact of Functional Affordances and Symbolic Expressions on the Formation of Beliefs. Journal of the Association for Information Systems, 16(7), 580.

Grumbach, Kevin, \& Grundy, Paul. (2010). Outcomes of implementing patient centered medical home interventions. Washington. DC Patient-Centered Primary Care Collaboration.

Gurol-Urganci, Ipek, de Jongh, Thyra, Vodopivec-Jamsek, Vlasta, Car, Josip, \& Atun, Rifat. (2012). Mobile phone messaging for communicating results of medical investigations. Cochrane Database System Review, 6.

Hawker, Mark D. (2010). Social networking in the National Health Service in England: a quantitative analysis of the online identities of 152 primary care trusts. Studies in Health Technology and Information, 160(1), 356-360.

Hedman, Jonas, Srinivasan, Nikhil, \& Lindgren, Rikard. (2013). Digital traces of information systems: Sociomateriality made researchable. In the 34th International Conference on Information Systems.

Heesen, C., Solari, A., Giordano, A., Kasper, J., \& Köpke, S. (2011). Decisions on multiple sclerosis immunotherapy: new treatment complexities urge patient engagement. Journal of the neurological sciences, 306(1), 192-197.

Hibbard, Judith H, \& Greene, Jessica. (2013). What the evidence shows about patient activation: better health outcomes and care experiences; fewer data on costs. Health affairs, 32(2), 207-214.

Hillestad, Richard, Bigelow, James, Bower, Anthony, Girosi, Federico, Meili, Robin, Scoville, Richard, \& Taylor, Roger. (2005). Can electronic medical record systems transform health care? Potential health benefits, savings, and costs. Health Affairs, 24(5), 1103-1117.

Hutchby, Ian. (2001). Technologies, texts and affordances. Sociology, 35(2), 441-456. 
Jackson, George L, Powers, Benjamin J, Chatterjee, Ranee, Bettger, Janet Prvu, Kemper, Alex R, Hasselblad, Vic, .. . Kendrick, Amy S. (2013). The patient-centered medical home: a systematic review. Annals of internal medicine, 158(3), 169-178.

Jacobson, David E. (1986). Types and timing of social support. Journal of health and Social Behavior, 250-264.

James, J, Hibbard, J, Agres, T, Lott, R, \& Dentzer, S. (2013). Health policy brief: patient engagement. Health Affairs, 1-6.

Kahn, K.L., Schneider, E.C., Malin, J.L., Adams, J.L., \& Epstein, A.M. (2007). Patient centered experiences in breast cancer: predicting long-term adherence to tamoxifen use. Medical care, 45(5), 431-439.

Kaplan, Bonnie, \& Duchon, Dennis. (1988). Combining qualitative and quantitative methods in information systems research: a case study. MIS quarterly, 571-586.

Kuijer, R.G., Ybema, J.F., Buunk, B.P., De Jong, G.M., Thijs-Boer, F., \& Sanderman, R. (2000). Active engagement, protective buffering, and overprotection: Three ways of giving support by intimate partners of patients with cancer. Journal of Social and Clinical Psychology, 19(2), 256275.

Lau, Francis, Price, Morgan, Boyd, Jeanette, Partridge, Colin, Bell, Heidi, \& Raworth, Rebecca. (2012). Impact of electronic medical record on physician practice in office settings: a systematic review. BMC medical informatics and decision making, 12(1), 10.

Leclerq, Aurelie, Carugati, Andrea, Giangreco, Antonio, da Cunha, Joao Viera, \& Jensen, Tina Blegind. (2009). A sociomaterial view of the scaffolding of work practices with information technology. In International Conference on Information Systems 2009, 197.

Leonardi, Paul M. (2011). When flexible routines meet flexible technologies: Affordance, constraint, and the imbrication of human and material agencies. MIS quarterly, 35(1), 147-167.

Leonardi, Paul M. (2013). When does technology use enable network change in organizations? A comparative study of feature use and shared affordances. MIS Quarterly, 37(3), 749-775.

Liaw, T., Lawrence, M., \& Rendell, J. (1996). The effect of a computer-generated patient-held medical record summary and/or a written personal health record on patients' attitudes, knowledge and behaviour concerning health promotion. Family Practice, 13(3), 289-293.

Lukyanenko, R., Parsons, J., \& Wiersma, Y. F. (2014). The IQ of the crowd: understanding and improving information quality in structured user-generated content. Information Systems Research, 25(4), 669-689.

Majchrzak, Ann, Faraj, Samer, Kane, Gerald C, \& Azad, Bijan. (2013). The contradictory influence of social media affordances on online communal knowledge sharing. Journal of Computer-Mediated Communication, 19(1), 38-55.

Markus, M Lynne, \& Silver, Mark S. (2008). A foundation for the study of IT effects: A new look at DeSanctis and Poole's concepts of structural features and spirit. Journal of the Association for Information Systems, 9(10), 5. 
McCance, T., Slater, P., \& McCormack, B. (2008). Using the caring dimensions inventory as an indicator of person-centred nursing. Journal of Clinical Nursing, 18(3), 409-417.

McCormack, B. (2004). Person-centredness in gerontological nursing: an overview of the literature. Journal of Clinical Nursing, 13(s1), 31-38.

McCormack, B., \& McCance, T.V. (2006). Development of a framework for person-centred nursing. Journal of advanced Nursing, 56(5), 472-479.

Melhuish, Karen, \& Falloon, Garry. (2010). Looking to the future: M-learning with the iPad. Computers in New Zealand Schools: Learning, Leading, Technology, 22(3), 1-16.

Merolli, Mark, Gray, Kathleen, \& Martin-Sanchez, Fernando. (2013). Health outcomes and related effects of using social media in chronic disease management: A literature review and analysis of affordances. Journal of Biomedical Informatics, 46(6), 957-969.

Michaels, Claire F. (2000). Information, perception, and action: What should ecological psychologists learn from Milner and Goodale (1995)? Ecological Psychology, 12(3), 241-258.

Michaels, Claire F, \& Carello, Claudia. (1981). Direct perception. Prentice-Hall Englewood Cliffs, NJ.

Morgan, Robert M, \& Hunt, Shelby D. (1994). The commitment-trust theory of relationship marketing. The journal of marketing, 20-38.

Morie, Jacquelyn Ford, \& Chance, Eric. (2011). Extending the reach of health care for obesity and diabetes using virtual worlds. Journal of diabetes science and technology, 5(2), 272-276.

Naqvi, Nasir, Shiv, Baba, \& Bechara, Antoine. (2006). The role of emotion in decision making a cognitive neuroscience perspective. Current Directions in Psychological Science, 15(5), 260-264.

Neisser, Ulric. (1976). Cognition and reality: Principles and implications of cognitive psychology. WH Freeman/Times Books/Henry Holt \& Co.

Norman, J. (2001). Ecological psychology and the two visual systems: Not to worry!. Ecological psychology, 13(2), 135-145.

Nutting, Paul A, Miller, William L, Crabtree, Benjamin F, Jaen, Carlos Roberto, Stewart, Elizabeth E, \& Stange, Kurt C. (2009). Initial lessons from the first national demonstration project on practice transformation to a patient-centered medical home. The Annals of Family Medicine, 7(3), 254-260.

Oborn, Eivor, Barrett, Michael, \& Davidson, Elizabeth. (2011). Unity in diversity: electronic patient record use in multidisciplinary practice. Information Systems Research, 22(3), 547-564.

Orlikowski, Wanda J. (2000). Using technology and constituting structures: A practice lens for studying technology in organizations. Organization science, 11(4), 404-428.

Orlikowski, Wanda J. (2007). Sociomaterial practices: Exploring technology at work. Organization studies, 28(9), 1435-1448. 
Orlikowski, Wanda J. (2009). The sociomateriality of organisational life: considering technology in management research. Cambridge Journal of Economics, bep058.

Orlikowski, Wanda J, \& Scott, Susan V. (2008). 10 sociomateriality: challenging the separation of technology, work and organization. The academy of management annals, 2(1), 433-474.

Pearlin, Leonard I, Semple, Shirley, \& Turner, Heather. (1988). Stress of AIDS caregiving: A preliminary overview of the issues. Death Studies, 12(5-6), 501-517.

Phillips, Kathryn A, Trosman, Julia R, Kelley, Robin K, Pletcher, Mark J, Douglas, Michael P, \& Weldon, Christine B. (2014). Genomic sequencing: assessing the health care system, policy, and big-data implications. Health Affairs, 33(7), 1246-1253.

Pousti, Hamid, Urquhart, Cathy, \& Linger, Henry. (2014). Exploring the Role of Social Media in Chronic Care Management Information Systems and Global Assemblages.(Re) Configuring Actors, Artefacts, Organizations (pp. 163-185). Springer.

Prahalad, Coimbatore K, \& Ramaswamy, Venkat. (2004). Co-creation experiences: The next practice in value creation. Journal of interactive marketing, 18(3), 5-14.

Protheroe, J., Rogers, A., Kennedy, A.P., Macdonald, W., \& Lee, V. (2008). Promoting patient engagement with self-management support information: a qualitative meta-synthesis of processes influencing uptake. Implementation Science, 3(1), 44.

Robinson, J.H., Callister, L.C., Berry, J.A., \& Dearing, K.A. (2008). Patient-centered care and adherence: Definitions and applications to improve outcomes. Journal of the American Academy of Nurse Practitioners, 20(12), 600-607.

Romm, F.J., \& Hulka, B.S. (1979). Care process and patient outcome in diabetes mellitus. Medical Care, 748-757.

Schulman, B.A. (1979). Active patient orientation and outcomes in hypertensive treatment: application of a socio-organizational perspective. Medical Care, 267-280.

Schwamm, Lee H. (2014). Telehealth: seven strategies to successfully implement disruptive technology and transform health care. Health Affairs, 33(2), 200-206.

Scott, Susan V, \& Orlikowski, Wanda J. (2009). 'Getting the truth': exploring the material grounds of institutional dynamics in social media.

Seidel, Stefan, Recker, Jan C, \& Vom Brocke, Jan. (2013). Sensemaking and sustainable practicing: functional affordances of information systems in green transformations. Management Information Systems Quarterly, 37(4), 1275-1299.

Selfe, S.A., Matthews, Zoe, \& Stones, R.W. (1998). Factors influencing outcome in consultations for chronic pelvic pain. Journal of Women's Health, 7(8), 1041-1048.

Shaw, Robert, Turvey, Michael T, \& Mace, William. (1982). Ecological psychology: The consequence of a commitment to realism. Cognition and the symbolic processes, 2, 159-226.

Silow-Carroll, S., Alteras, T., \& Stepnick, L. (2006). Patient-centered Care for Underserved Populations: Definition and Best Practices. Economic and Social Research Institute. 
Sjöström, Jonas, \& Goldkuhl, Göran. (2003). The semiotics of user interfaces-a socio-pragmatic perspective. International Workshop on Organisational Semiotics.

Stewart, M. (2001). Towards a global definition of patient centred care: The patient should be the judge of patient centred care. BMJ: British Medical Journal, 322(7284), 444.

Stinchcombe, Arthur L, McDill, Mary Sexton, \& Walker, Dollie R. (1968). Demography of organizations. American Journal of Sociology, 221-229.

Stoffregen, Thomas A. (2003). Affordances as properties of the animal-environment system. Ecological Psychology, 15(2), 115-134.

Stoffregen, Thomas A, Gorday, Kathleen M, Sheng, Yang-Yi, \& Flynn, Steven B. (1999). Perceiving affordances for another person's actions. Journal of Experimental Psychology: Human Perception and Performance, 25(1), 120.

Strong, Diane M, Johnson, Sharon A, Tulu, Bengisu, Trudel, John, Volkoff, Olga, Pelletier, Lori R, . . Garber, Lawrence. (2014). A theory of organization-EHR affordance actualization. Journal of the Association for Information Systems, 15(2), 53-85.

Stuart, Ian, McCutcheon, David, Handfield, Robert, McLachlin, Ron, \& Samson, Danny. (2002). Effective case research in operations management: a process perspective. Journal of Operations Management, 20(5), 419-433.

Sundar, S Shyam, Bellur, Saraswathi, \& Jia, Haiyan. (2012). Motivational technologies: a theoretical framework for designing preventive health applications Persuasive Technology. Design for Health and Safety (pp. 112-122). Springer.

Svahn, Fredrik, Henfridsson, Ola, \& Yoo, Youngjin. (2009). A threesome dance of agency: Mangling the sociomateriality of technological regimes in digital innovation. International Conference on Information Systems 2009, 5.

Thielst, Christina Beach. (2011). Social media: ubiquitous community and patient engagement. Frontiers of health services management, 28(2), 3-14.

Trauth, Eileen M, \& Jessup, Leonard M. (2000). Understanding computer-mediated discussions: positivist and interpretive analyses of group support system use. MIs Quarterly, 43-79.

Treem, Jeffrey W, \& Leonardi, Paul M. (2012). Social media use in organizations: Exploring the affordances of visibility, editability, persistence, and association. Communication yearbook, 36, 143-189.

Turvey, Michael T. (1992). Affordances and prospective control: An outline of the ontology. Ecological psychology, 4(3), 173-187.

Urquhart, Cathy, Lehmann, Hans, \& Myers, Michael D. (2010). Putting the 'theory' back into grounded theory: guidelines for grounded theory studies in information systems. Information systems journal, 20(4), 357-381.

Varshney, Upkar. (2005). Pervasive healthcare: applications, challenges and wireless solutions. Communications of the Association for Information Systems, 16(1), 3. 
Volkoff, Olga, \& Strong, Diane M. (2013). Critical Realism and Affordances: Theorizing ITAssociated Organizational Change Processes. Mis Quarterly, 37(3), 819-834.

Vyas, Dhaval, Chisalita, Cristina M, \& Van Der Veer, Gerrit C. (2006). Affordance in interaction. the Proceedings of the 13th European conference on Cognitive ergonomics: trust and control in complex socio-technical systems.

Warren, William H. (1984). Perceiving affordances: visual guidance of stair climbing. Journal of experimental psychology: Human perception and performance, 10(5), 683.

Weinstein, James N, Clay, Kate, \& Morgan, Tamara S. (2007). Informed patient choice: patientcentered valuing of surgical risks and benefits. Health Affairs, 26(3), 726-730.

Wilson, E Vance, Wang, Weiyi, \& Sheetz, Steven D. (2014). Underpinning a Guiding Theory of Patient-Centered E-Health. Communications of the Association for Information Systems, 34(16), 337-350.

Yin, Robert K. (1994). Applied social research methods series Case study research: Design and methods, 3 .

Young, Lance Brendan, Chan, Paul S, Lu, Xin, Nallamothu, Brahmajee K, Sasson, Comilla, \& Cram, Peter M. (2011). Impact of telemedicine intensive care unit coverage on patient outcomes: a systematic review and meta-analysis. Archives of internal medicine, 171(6), 498-506.

Zammuto, Raymond F, Griffith, Terri L, Majchrzak, Ann, Dougherty, Deborah J, \& Faraj, Samer. (2007). Information technology and the changing fabric of organization. Organization Science, 18(5), 749-762. 
APPENDICES 


\section{Appendix 1 - Affordance in Literature}

Table A. Affordance of Social Media Technology

\begin{tabular}{|c|c|c|c|}
\hline $\begin{array}{c}\text { Technological } \\
\text { Property } \\
\end{array}$ & Affordance & Action & Study \\
\hline \multicolumn{2}{|l|}{ Social media } & Use in organization & \multirow{5}{*}{$\begin{array}{l}\text { (Treem } \\
\& \\
\text { Leonardi, } \\
\text { 2012) }\end{array}$} \\
\hline $\begin{array}{l}\text { Displays text, Status } \\
\text { updates }\end{array}$ & Visibility & $\begin{array}{l}\text { Work behavior, Metaknowledge, } \\
\text { Organizational activity streams }\end{array}$ & \\
\hline $\begin{array}{l}\text { History of activity, } \\
\text { Discussion recorded }\end{array}$ & Persistence & $\begin{array}{l}\text { Sustaining knowledge over time, } \\
\text { Creating robust forms of } \\
\text { communication, Growing content }\end{array}$ & \\
\hline $\begin{array}{l}\text { Asynchronous text- } \\
\text { based entries }\end{array}$ & Editability & $\begin{array}{l}\text { Regulating personal expressions, } \\
\text { Targeting content, Improving } \\
\text { information quality }\end{array}$ & \\
\hline $\begin{array}{l}\text { Relations to others } \\
\text { displayed (e.g., } \\
\text { Friends), "Like" } \\
\text { button }\end{array}$ & Association & $\begin{array}{l}\text { Supporting social connection, } \\
\text { Access to relevant information, } \\
\text { Enabling emergent connection }\end{array}$ & \\
\hline & $\begin{array}{l}\text { Online communal knowledge } \\
\text { sharing }\end{array}$ & \multirow{5}{*}{$\begin{array}{l}\text { (Majchrz } \\
\text { ak et al., } \\
\text { 2013) }\end{array}$} \\
\hline Retweets & Metavoicing & $\begin{array}{l}\text { Foster productive knowledge } \\
\text { conversations when the } \\
\text { mechanism of critical mass is } \\
\text { invoked. But, inhibit productivity } \\
\text { knowledge conversations when } \\
\text { they promote biased and } \\
\text { inaccurate information. }\end{array}$ & \\
\hline Alerts & $\begin{array}{l}\text { Triggered } \\
\text { attending }\end{array}$ & $\begin{array}{l}\text { Foster productive knowledge } \\
\text { conversations by motivating more } \\
\text { people to engage because of the } \\
\text { minimal effort involved. But, } \\
\text { inhibit productivity knowledge } \\
\text { conversations when serendipity, } \\
\text { contextualization, and trust are } \\
\text { harmed. }\end{array}$ & \\
\hline $\begin{array}{l}\text { Display of } \\
\text { connections }\end{array}$ & $\begin{array}{l}\text { Network- } \\
\text { informed } \\
\text { associating }\end{array}$ & $\begin{array}{l}\text { Foster productive knowledge } \\
\text { conversations as knowledge } \\
\text { workers strive to expand their } \\
\text { social capital in pursuit of } \\
\text { intellectual capital. But, inhibit } \\
\text { productivity knowledge } \\
\text { conversations as preferential } \\
\text { attachment is activated. }\end{array}$ & \\
\hline $\begin{array}{l}\text { Custom-developed } \\
\text { code } \\
\end{array}$ & $\begin{array}{l}\text { Generative } \\
\text { role-taking }\end{array}$ & $\begin{array}{l}\text { Foster productive knowledge } \\
\text { conversations through reflectively }\end{array}$ & \\
\hline
\end{tabular}




\begin{tabular}{|c|c|c|c|}
\hline & & $\begin{array}{l}\text { reframing the conversation to } \\
\text { remove temporary barriers that } \\
\text { have emerged in the conversation. } \\
\text { But, inhibit productivity } \\
\text { knowledge conversations when } \\
\text { organizational memory is lost. }\end{array}$ & \\
\hline \multicolumn{2}{|l|}{ Social media } & Chronic disease care process & \multirow{3}{*}{$\begin{array}{l}\text { (Pousti et } \\
\text { al., 2014) }\end{array}$} \\
\hline $\begin{array}{l}\text { Synchronous and } \\
\text { asynchronous } \\
\text { interactions, Store the } \\
\text { history of interaction, } \\
\text { Retrieve data }\end{array}$ & $\begin{array}{l}\frac{\text { Emotional }}{\text { support }} \\
\underline{\text { affordance }}\end{array}$ & $\begin{array}{l}\text { Provide patients with emotional } \\
\text { support }\end{array}$ & \\
\hline $\begin{array}{c}\text { Create information, } \\
\text { Different formats } \\
\text { such as text, video, } \\
\text { audio }\end{array}$ & $\frac{\text { Empowerme }}{\underline{\text { nt affordance }}}$ & Empower patient and cares & \\
\hline \multicolumn{2}{|l|}{ Social media } & $\begin{array}{l}\text { Chronic } \\
\text { disease management }\end{array}$ & \\
\hline Self-presentation & Identity & $\begin{array}{l}\text { Norms of patient } \\
\text { identity protection and patient } \\
\text { records ownership, } \\
\text { less suitable for stigmatizing } \\
\text { conditions }\end{array}$ & \multirow{8}{*}{$\begin{array}{l}\text { (Merolli } \\
\text { et al., } \\
2013 \text { ) }\end{array}$} \\
\hline Blogs, virtual worlds & Identity & More anonymous interaction & \\
\hline $\begin{array}{l}\text { Wall, board, message } \\
\text { posting with } \\
\text { asynchrony }\end{array}$ & Flexibility & $\begin{array}{l}\text { Provides a sense of } \\
\text { time-space freedom of } \\
\text { communication, enhance } \\
\text { engagement }\end{array}$ & \\
\hline $\begin{array}{l}\text { Ability to connect } \\
\text { individuals }\end{array}$ & Structure & $\begin{array}{l}\text { Enhance information sharing and } \\
\text { collaboration, facilitate and guide } \\
\text { chronic disease sufferers with } \\
\text { their self-management and given } \\
\text { online management more } \\
\text { direction, but risk with poor } \\
\text { quality and/or misleading } \\
\text { information }\end{array}$ & \\
\hline Professional input & Structure & $\begin{array}{l}\text { Improve effectiveness, decrease } \\
\text { attrition rates }\end{array}$ & \\
\hline $\begin{array}{l}\text { Storytelling, express } \\
\text { emotions, share } \\
\text { information in } \\
\text { blogging }\end{array}$ & Narration & $\begin{array}{l}\text { Believe blogs is a relatively } \\
\text { reputable source of information } \\
\text { but well suited as a way to } \\
\text { problem solve and manage } \\
\text { emotions }\end{array}$ & \\
\hline YouTube & Narration & Increase emotional engagement & \\
\hline Not addressed & Adaptation & $\begin{array}{l}\text { Obtaining information, } \\
\text { Consolidate existing } \\
\text { relationships, Get supports }\end{array}$ & \\
\hline
\end{tabular}


Table B. Affordance of Mobile Technology

\begin{tabular}{|c|c|c|c|}
\hline $\begin{array}{c}\text { Technology / } \\
\text { Feature }\end{array}$ & Affordance & Action & Study \\
\hline \multicolumn{2}{|l|}{ Mobile technology } & Not addressed & \multirow{6}{*}{$\begin{array}{l}\text { (Cousins \& } \\
\text { Robey, } \\
2015)\end{array}$} \\
\hline Not addressed & Mobility & $\begin{array}{l}\text { Flexibility and permeability of } \\
\text { physical boundaries of place, } \\
\text { psychological boundary }\end{array}$ & \\
\hline Not addressed & Connectedness & $\begin{array}{l}\text { Continuous communication at all } \\
\text { times, multitasking for temporal } \\
\text { boundary, manage relationships }\end{array}$ & \\
\hline Not addressed & Interoperability & $\begin{array}{l}\text { Various devices and applications, } \\
\text { psychological boundary }\end{array}$ & \\
\hline Not addressed & Identifiability & $\begin{array}{l}\text { Self-presentation, distant mobile } \\
\text { co-presence }\end{array}$ & \\
\hline Not addressed & Personalization & $\begin{array}{l}\text { Satisfy personal preferences or } \\
\text { needs }\end{array}$ & \\
\hline \multicolumn{2}{|l|}{ iPad } & Education & \\
\hline $\begin{array}{c}\text { Functionality and } \\
\text { connectivity of a } \\
\text { laptop, with the } \\
\text { mobility of a } \\
\text { smartphone }\end{array}$ & $\begin{array}{l}\text { Portability, } \\
\text { Affordable and } \\
\text { ubiquitous } \\
\text { access, } \\
\text { Situated, 'just- } \\
\text { in-time' } \\
\text { learning } \\
\text { opportunities, } \\
\text { Connection and } \\
\text { convergence, } \\
\text { Individualised } \\
\text { and } \\
\text { personalised } \\
\text { experiences }\end{array}$ & Better education & $\begin{array}{l}\text { (Melhuish } \\
\text { \& Falloon, } \\
\text { 2010a) }\end{array}$ \\
\hline \multicolumn{2}{|l|}{ Smartphone } & Not specific & \multirow{5}{*}{$\begin{array}{l}\text { (Cochrane } \\
\& \\
\text { Bateman, } \\
\text { 2010) }\end{array}$} \\
\hline $\begin{array}{l}\text { Record and share } \\
\text { live } \\
\text { Events }\end{array}$ & $\begin{array}{l}\text { Video } \\
\text { streaming }\end{array}$ & $\begin{array}{l}\text { Real time event, data and } \\
\text { resource capturing and } \\
\text { collaboration }\end{array}$ & \\
\hline $\begin{array}{l}\text { Geo-tag original } \\
\text { photos, geo- } \\
\text { locate events on } \\
\text { Google Map }\end{array}$ & Geo-tagging & Enable rich data sharing & \\
\hline $\begin{array}{l}\text { Post short } \\
\text { updates }\end{array}$ & Microblogging & $\begin{array}{l}\text { Asynchronous communication, } \\
\text { collaboration and support }\end{array}$ & \\
\hline $\begin{array}{l}\text { Notices for } \\
\text { course and } \\
\text { support }\end{array}$ & $\begin{array}{c}\text { Text } \\
\text { notifications }\end{array}$ & $\begin{array}{l}\text { Scaffolding, learning and } \\
\text { administrative } \\
\text { Support }\end{array}$ & \\
\hline
\end{tabular}




\begin{tabular}{|c|c|c|c|}
\hline $\begin{array}{l}\text { Capture and } \\
\text { upload images } \\
\text { and video of } \\
\text { ideas and events }\end{array}$ & $\begin{array}{c}\text { Direct image } \\
\text { and } \\
\text { Video blogging }\end{array}$ & $\begin{array}{l}\text { Student journals, eportfolios, } \\
\text { presentations, peer and lecturer } \\
\text { critique }\end{array}$ & \\
\hline $\begin{array}{c}\text { 2D codes } \\
\text { scanned by } \\
\text { camera phone to } \\
\text { reveal URL, text, } \\
\text { etc }\end{array}$ & Mobile codes & $\begin{array}{l}\text { Situated Learning - providing } \\
\text { context } \\
\text { Linking }\end{array}$ & \\
\hline $\begin{array}{l}\text { Remote recording } \\
\text { of audio, tagged } \\
\text { with GPS and } \\
\text { images, etc }\end{array}$ & $\begin{array}{l}\text { Enhanced } \\
\text { student } \\
\text { Podcasts }\end{array}$ & $\begin{array}{l}\text { Situated and collaborative } \\
\text { learning } \\
\text { - providing context linking }\end{array}$ & \\
\hline $\begin{array}{c}\text { Social } \\
\text { networking tools }\end{array}$ & $\begin{array}{c}\text { Social } \\
\text { networking }\end{array}$ & $\begin{array}{l}\text { Formative peer and lecturer } \\
\text { feedback } \\
\text { Collaboration of groups }\end{array}$ & \\
\hline \multicolumn{2}{|l|}{ Hybrid Mobile } & Education & \multirow[b]{2}{*}{ (Bai, 2010) } \\
\hline $\begin{array}{c}\text { Narrative } \\
\text { functions and } \\
\text { existing Web } 2.0 \\
\text { applications } \\
\end{array}$ & $\frac{\text { Ubiquitous }}{\text { learning }}$ & $\begin{array}{l}\text { More pervasive and equitable } \\
\text { education }\end{array}$ & \\
\hline \multicolumn{2}{|l|}{ Mobile Technology } & Use of healthcare record & \multirow[b]{2}{*}{$\begin{array}{l}\text { (Abouzahra } \\
\text { \& Tan, } \\
\text { 2013) }\end{array}$} \\
\hline Not addressed & $\begin{array}{c}\text { Ubiquitous } \\
\text { connectivity, } \\
\text { Physical } \\
\text { attachment, } \\
\text { Viewing and } \\
\text { authoring } \\
\text { Capabilities, } \\
\text { and Context } \\
\text { awareness }\end{array}$ & $\begin{array}{l}\text { Use of mobile personal health } \\
\text { records }\end{array}$ & \\
\hline \multicolumn{2}{|c|}{ Mobile applications or Websites } & Healthcare & \multirow[b]{2}{*}{$\begin{array}{l}\text { (Sundar et } \\
\text { al., 2012) }\end{array}$} \\
\hline Not addressed & $\begin{array}{l}\text { Navigability, } \\
\text { Interactivity, } \\
\text { Customization }\end{array}$ & $\begin{array}{l}\text { Enhance motivation for } \\
\text { preventive care, change health- } \\
\text { related behaviors }\end{array}$ & \\
\hline
\end{tabular}


Table C. Affordance of Healthcare Technology

\begin{tabular}{|c|c|c|c|}
\hline $\begin{array}{l}\text { Technology / } \\
\text { Feature }\end{array}$ & Affordance & Action & Study \\
\hline \multicolumn{2}{|l|}{ EH R system } & $\begin{array}{l}\text { The use of EH R system in an } \\
\text { organization }\end{array}$ & \multirow{7}{*}{$\begin{array}{l}\text { (Strong, } \\
\text { Volkoff, et } \\
\text { al., 2014) }\end{array}$} \\
\hline $\begin{array}{l}\text { Common database } \\
\text { for storing patient } \\
\text { information } \\
\text { Structured data entry } \\
\text { forms }\end{array}$ & $\begin{array}{l}\text { Capturing and } \\
\text { archiving digital } \\
\text { data about } \\
\text { patients }\end{array}$ & Document everything & \\
\hline $\begin{array}{l}\text { Common database } \\
\text { filled with patient } \\
\text { information } \\
\text { Technical } \\
\text { infrastructure for } \\
\text { anytime, anywhere } \\
\text { access }\end{array}$ & $\begin{array}{l}\text { Accessing and } \\
\text { using patient } \\
\text { information } \\
\text { anytime from } \\
\text { anywhere }\end{array}$ & $\begin{array}{l}\text { Access other providers' } \\
\text { patients, anytime, anywhere }\end{array}$ & \\
\hline $\begin{array}{l}\text { Messaging features } \\
\text { Patient information } \\
\text { stored and available } \\
\text { real-time anywhere }\end{array}$ & $\begin{array}{l}\text { Coordinating } \\
\text { patient care } \\
\text { across sites, } \\
\text { facilities and } \\
\text { providers }\end{array}$ & $\begin{array}{l}\text { Collaboration among } \\
\text { colleagues, coordination with } \\
\text { urgent care staff }\end{array}$ & \\
\hline $\begin{array}{l}\text { Standard data entry } \\
\text { forms } \\
\text { Stored protocols and } \\
\text { procedures for each } \\
\text { role } \\
\text { Restricted access to } \\
\text { EHR features by } \\
\text { role }\end{array}$ & $\begin{array}{l}\text { Standardizing } \\
\text { data, process, } \\
\text { and roles }\end{array}$ & $\begin{array}{l}\text { Ask standardized } \\
\text { questions in an order }\end{array}$ & \\
\hline $\begin{array}{l}\text { Audit trail of what } \\
\text { was done, by whom, } \\
\text { and when } \\
\text { Lists of tasks to do, } \\
\text { by role and the } \\
\text { current status } \\
\text { of each }\end{array}$ & $\begin{array}{l}\text { Monitoring } \\
\text { organizational } \\
\text { operations }\end{array}$ & Monitoring real time. & \\
\hline $\begin{array}{l}\text { Standardized data \& } \\
\text { functionality } \\
\text { Audit trail } \\
\text { Features for defining } \\
\text { pools (e.g., the } \\
\text { nursing } \\
\text { pool) } \\
\text { Message forwarding } \\
\& \\
\text { messaging to pools }\end{array}$ & $\begin{array}{l}\text { Substituting } \\
\text { healthcare } \\
\text { professional for } \\
\text { each other }\end{array}$ & Coordination & \\
\hline
\end{tabular}




\begin{tabular}{|c|c|c|c|}
\hline $\begin{array}{l}\text { Decision support } \\
\text { features } \\
\text { (e.g., medication } \\
\text { alerts based on } \\
\text { patient data) } \\
\text { Easy access to } \\
\text { online clinical } \\
\text { references }\end{array}$ & $\begin{array}{l}\text { Incorporating } \\
\text { rich information } \\
\text { into clinical } \\
\text { decision making }\end{array}$ & $\begin{array}{l}\text { Basic pre-functionality for } \\
\text { diagnosis }\end{array}$ & \\
\hline $\begin{array}{l}\text { Templates that can } \\
\text { capture the decision } \\
\text { rules of one role for } \\
\text { use by another role }\end{array}$ & $\begin{array}{l}\text { Shifting work } \\
\text { across roles }\end{array}$ & Change roles & \\
\hline \multicolumn{2}{|l|}{ Virtual worlds } & $\begin{array}{l}\text { Healthcare for Obesity and } \\
\text { Diabetes }\end{array}$ & \multirow[b]{2}{*}{$\begin{array}{l}\text { (Morie \& } \\
\text { Chance, } \\
\text { 2011) }\end{array}$} \\
\hline Not addressed & $\begin{array}{l}\text { Accessibility, } \\
\text { Social } \\
\text { connectivity, } \\
\text { Avatar usage }\end{array}$ & Not addressed & \\
\hline
\end{tabular}




\section{Appendix 2 - Functionalities of the Integrative Social Media Platform}
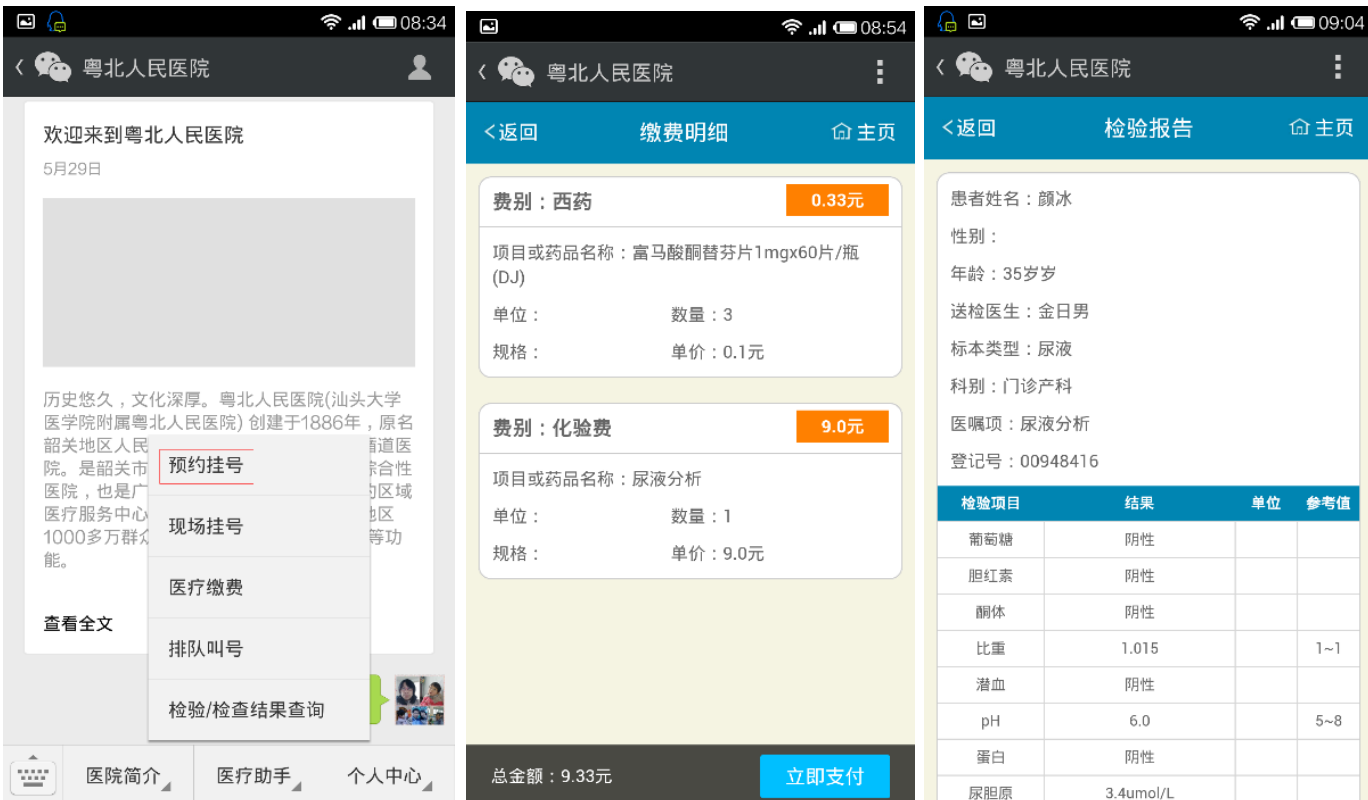

患者姓名 : 颜冰

性别 :

年龄 : 35 岁岁

送检医生 : 金日男

标本类型 : 尿液

科别:门诊产科

\begin{tabular}{|l|l|}
\hline 费别 : 化验费 9.0 元 \\
\hline
\end{tabular}

医嘱项: 尿液分析

项目或药品名称 : 尿液分析

单位: 数量 : 1

规格：单价：9.0元

登记号 : 00948416

\begin{tabular}{|c|c|c|c|}
\hline 箠给项目 & 结果 & 单位 & 考值 \\
\hline 菊萄祝 & 阴性 & & \\
\hline 胆红素 & 阴性 & & \\
\hline 酮体 & 阴性 & & \\
\hline 比重 & 1.015 & & $1 \sim 1$ \\
\hline 潜血 & 阴性 & & \\
\hline pH & 6.0 & & $5 \sim 8$ \\
\hline 蛋白 & 阴性 & & \\
\hline 尿胆原 & $3.4 \mathrm{umol} / \mathrm{L}$ & & \\
\hline
\end{tabular}
a. Homepage
b. Scheduling \& Payment
c. Test Result Data
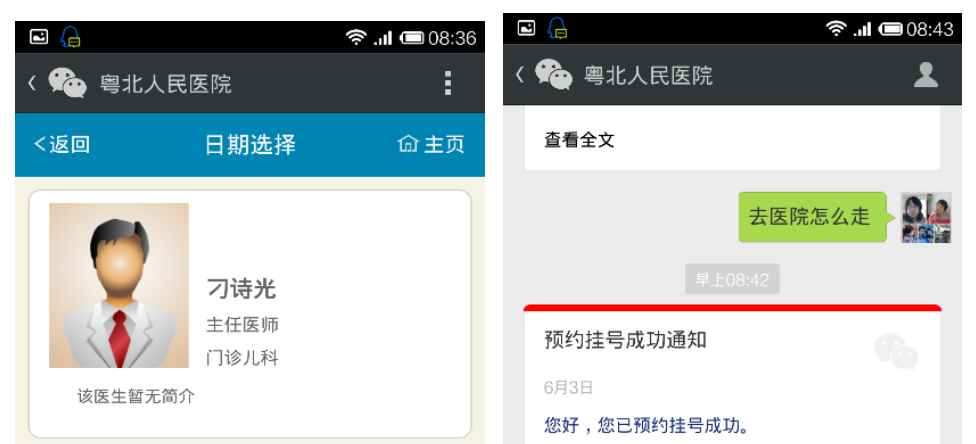

\begin{tabular}{|c|c|c|c|}
\hline 日期 & 上午 & 下午 & 晩上 \\
\hline $\begin{array}{c}2014-06-04 \\
\text { 星期三 }\end{array}$ & 预约 & 预约 & \\
\hline $\begin{array}{c}2014-06-05 \\
\text { 星期四 }\end{array}$ & & 预约 & \\
\hline $\begin{array}{c}2014-06-06 \\
\text { 星期五 }\end{array}$ & 预约 & \\
\hline $\begin{array}{c}\text { 2014-06-08 } \\
\text { 星期天 }\end{array}$ & 预约 & 预约 & \\
\hline $\begin{array}{c}\text { 2014-06-10 } \\
\text { 星期二 }\end{array}$ & 预约 & 预约 & \\
\hline
\end{tabular}

$$
\text { , 忽已顶约挂号成功。 }
$$

$$
\begin{aligned}
& \text { 姓名: 刘霖月 } \\
& \text { 性别: 女 }
\end{aligned}
$$

预约医院：粵北人民医院

预约科室 : 门诊儿科

预约医生 : 刀诗光

流水号: 08:40:05

就诊时间 : 2014年06月04日 上年

11:00-12:00, 请您提前到达取号

详情

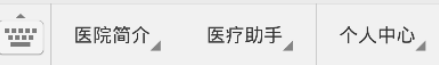
d. Human Connection
e. Conversation

Figure A. Screenshots of The Integrative Social Media Platform 


\section{Values added on healthcare processes:}

- $\quad$ Access to healthcare: Patients provide healthcare providers with real-time data on the patients' health status. They receive healthcare services like mobile consulting and scheduling and healthcare information like education materials using the mobile technology.

- $\quad$ Access to medical records and test results: Patients access their lab results and medical records using the mobile technology, not waiting for them to see at the hospital.

- $\quad$ Personalized service: Patients are provided with medical treatment guidelines that are personalized using $\mathrm{O}_{2} \mathrm{O}$ feature and mobile consulting patients.

- $\quad$ Medical alert: Patients receive appropriate and necessary information on medical treatments that doctors prescribed.

- Patient education: Patients receive educational and/or targeted information about population health on a regular basis.

- $\quad$ System Compatibility: The mobile technology has capability to integrate EMR system, patient portals, and other healthcare system used in the hospital.

\section{Values added on management process:}

- $\quad$ No waiting time: In no time, patients make appointments with healthcare providers who they want and make payments for the healthcare services.

- Instant reminders: The mobile technology alerts users a coming appointment that a patient made.

- Location-based real-time information: The mobile technology provides with real-time information about situations around parking lots, doctor offices, which offer transparency of the healthcare-related process, using Smart parking Wizard.

- $\quad$ Patient satisfaction survey: When treatment process is complete, the mobile technology automatically prompts patients to ask for a satisfaction survey to collect how patients feel about the hospital and healthcare services. 


\section{Appendix 3 - Guiding Questions for Interview and Focus Group}

Table A. Questions for Interview

\begin{tabular}{|c|c|}
\hline Construct & Interview Questions \\
\hline $\begin{array}{l}\quad \text { Outcomes } \\
\text {-Patient Satisfaction } \\
\text {-Physician } \\
\text { Satisfaction }\end{array}$ & $\begin{array}{l}\text { - How did you assess the values of the use of WeChat } \\
\text { hospital app, in terms of cost, time, profit, relationship } \\
\text { with patients? } \\
\text { - What are the unexpected effects of the WeChat hospital } \\
\text { app usage? (e.g., stress) } \\
\text { - Has the use of WeChat hospital app changed how } \\
\text { consultations are conducted? How a clinician's work is } \\
\text { organized? }\end{array}$ \\
\hline $\begin{array}{l}\text { Patient-Centered } \\
\quad \text { Care Process } \\
\text {-Access to care } \\
\text {-Patient Engagement } \\
\text {-Focus on Patient } \\
\text {-Shared Decision } \\
\text { Making }\end{array}$ & $\begin{array}{l}\text { - How would you define patient-centered care } \\
\text { innovation? } \\
\text { - How the technology or the information in it is used for } \\
\text { administrative or clinical purpose? }\end{array}$ \\
\hline $\begin{array}{l}\text { Behavioral } \\
\text { Affordance }\end{array}$ & $\begin{array}{l}\text { - How often do you use the WeChat hospital app? } \\
\text { - What do you do with the WeChat hospital app? } \\
\text { How and what technical features/characteristics has } \\
\text { WeChat hospital app made the healthcare more patient- } \\
\text { centered (e.g., changes in patients' engagement or } \\
\text { patient's relationship with a physician)? } \\
\text { - Why do you use WeChat hospital app? }\end{array}$ \\
\hline $\begin{array}{l}\text { Interactive } \\
\text { Affordance }\end{array}$ & $\begin{array}{l}\text { - How do you use it for communication between a } \\
\text { patient and a physician? }\end{array}$ \\
\hline $\begin{array}{l}\text { Perceived } \\
\text { Affordance }\end{array}$ & $\begin{array}{l}\text { - What is meaning of your use of the WeChat hospital } \\
\text { app? }\end{array}$ \\
\hline
\end{tabular}

\section{Questions for Focus Group}

\section{Background information}

Please provide the following background information to help us understand the context of your response.

1. Name of unit you have contacted : (e.g., Pediatric department)

3. Years of your first experience in this hospital :

4. Months of your experience with using the WeChat hospital app : months 
5. Please indicate your gender:

Female Male

6. Please indicate your age :

\begin{tabular}{|c|c|}
\hline Construct & Discussion Questions \\
\hline $\begin{array}{l}\quad \text { Outcomes } \\
\text {-Patient Satisfaction } \\
\text {-Physician } \\
\text { Satisfaction }\end{array}$ & $\begin{array}{l}\text { - How did you assess the values of the use of WeChat } \\
\text { hospital app, in terms of cost, time, profit, relationship } \\
\text { with patients? } \\
\text { - What are the unexpected effects of the WeChat hospital } \\
\text { app usage? } \\
\text { - Has the use of WeChat hospital app changed how } \\
\text { consultations are conducted? How a clinician's work } \\
\text { (patient's administrative transaction) is organized? }\end{array}$ \\
\hline $\begin{array}{l}\quad \text { Patient-Centered } \\
\quad \text { Care Process } \\
\text {-Patient's Access to } \\
\text { care } \\
\text {-Patient Engagement } \\
\text {-Focus on Patient } \\
\text {-Shared Decision } \\
\text { Making }\end{array}$ & $\begin{array}{l}\text { - How do you know the hospital service is patient- } \\
\text { centered care? } \\
\text { - What technology helps to facilitate patient-centered } \\
\text { care? } \\
\text { - How technologies or information are used for } \\
\text { administrative or clinical purpose? }\end{array}$ \\
\hline $\begin{array}{l}\text { Behavioral } \\
\text { Affordance }\end{array}$ & $\begin{array}{l}\text { - How often do you use the WeChat hospital app? } \\
\text { - What do you do with the WeChat hospital app? } \\
\text { - How and what technical features/characteristics has } \\
\text { WeChat hospital app made the healthcare more patient- } \\
\text { centered (e.g., changes in patients' engagement or } \\
\text { patient's relationship with a physician)? } \\
\text { - Why do you use WeChat hospital app? }\end{array}$ \\
\hline $\begin{array}{l}\text { Interactive } \\
\text { Affordance }\end{array}$ & $\begin{array}{l}\text { - How do you use it for communication between a patient } \\
\text { and a physician? }\end{array}$ \\
\hline $\begin{array}{l}\text { Perceived } \\
\text { Affordance }\end{array}$ & $\begin{array}{l}\text { - What is meaning of your use of the WeChat hospital } \\
\text { app? } \\
\text { - How useful do you think the technology or information } \\
\text { are? } \\
\text { - How easy do you think the technology or information } \\
\text { are? }\end{array}$ \\
\hline
\end{tabular}




\section{Appendix 4 - Code Book}

Coding scheme was adapted from the study of Gaskin et al. (J. Gaskin et al., 2014).

\begin{tabular}{|c|c|c|c|}
\hline Dimension & Subdimension & Value & Instances \\
\hline \multirow[b]{2}{*}{ Actor } & Role & Patient, Physician & \\
\hline & individual/group & $\begin{array}{l}\text { Individual, Pair, Group, } \\
\text { Organization }\end{array}$ & \\
\hline \multirow{2}{*}{ Technology } & Feature & $\begin{array}{l}\text { Mobile consulting, } \\
\text { Query medical records, } \\
\text { Scheduling, etc }\end{array}$ & $\begin{array}{l}\text { Use of text/audio/video } \\
\text { Use of optional elements }\end{array}$ \\
\hline & Modality & Physical, Digital & $\begin{array}{l}\text { This technology } \\
\text { shows/represents } \\
\text { This information is about }\end{array}$ \\
\hline \multirow{3}{*}{ Situation } & Process & $\begin{array}{l}\text { Administration process, } \\
\text { Clinical process }\end{array}$ & \\
\hline & Location & $\begin{array}{l}\text { Collocation, Local, } \\
\text { Remote, Mixed }\end{array}$ & \\
\hline & \multicolumn{2}{|l|}{ When } & \\
\hline \multirow{3}{*}{ Activity } & Interaction & Behavior, Interaction & \\
\hline & Type & $\begin{array}{l}\text { Generate, Transfer } \\
\text { information, Negotiate, } \\
\text { Execute, Choose }\end{array}$ & $\begin{array}{l}\text { I used } \\
\text { I looked at } \\
\text { I consulted } \\
\text { Often, regularly }\end{array}$ \\
\hline & Goal & & $\begin{array}{l}\text { I want } \\
\text { My objective } \\
\text { I am driven by }\end{array}$ \\
\hline \multicolumn{3}{|c|}{ Perceived Affordance } & $\begin{array}{l}\text { I saw/ realized / found / } \\
\text { thought } \\
\text { The value/advantage is } \\
\text { This is good/difficult } \\
\text { I had to put in a lot of effort }\end{array}$ \\
\hline \multicolumn{3}{|c|}{ Actualized Affordance } & $\begin{array}{l}\text { I was able to } \\
\text { I successfully } \\
\text { I performed } \\
\text { I was supported in } \\
\text { It enabled me }\end{array}$ \\
\hline \multicolumn{2}{|c|}{ Impact on PCCP } & $\begin{array}{l}\text { Access to care, Patient } \\
\text { engagement, Focus to } \\
\text { patient, Shared decision } \\
\text { making }\end{array}$ & $\begin{array}{l}\text { The } \\
\text { result/outcome/effect/conseq } \\
\text { uence } \\
\text { In the end / Overall } \\
\text { It changed / added } \\
\text { I learned } \\
\text { What I would do differently }\end{array}$ \\
\hline
\end{tabular}

Below shows overall structure of codes for each affordance. 


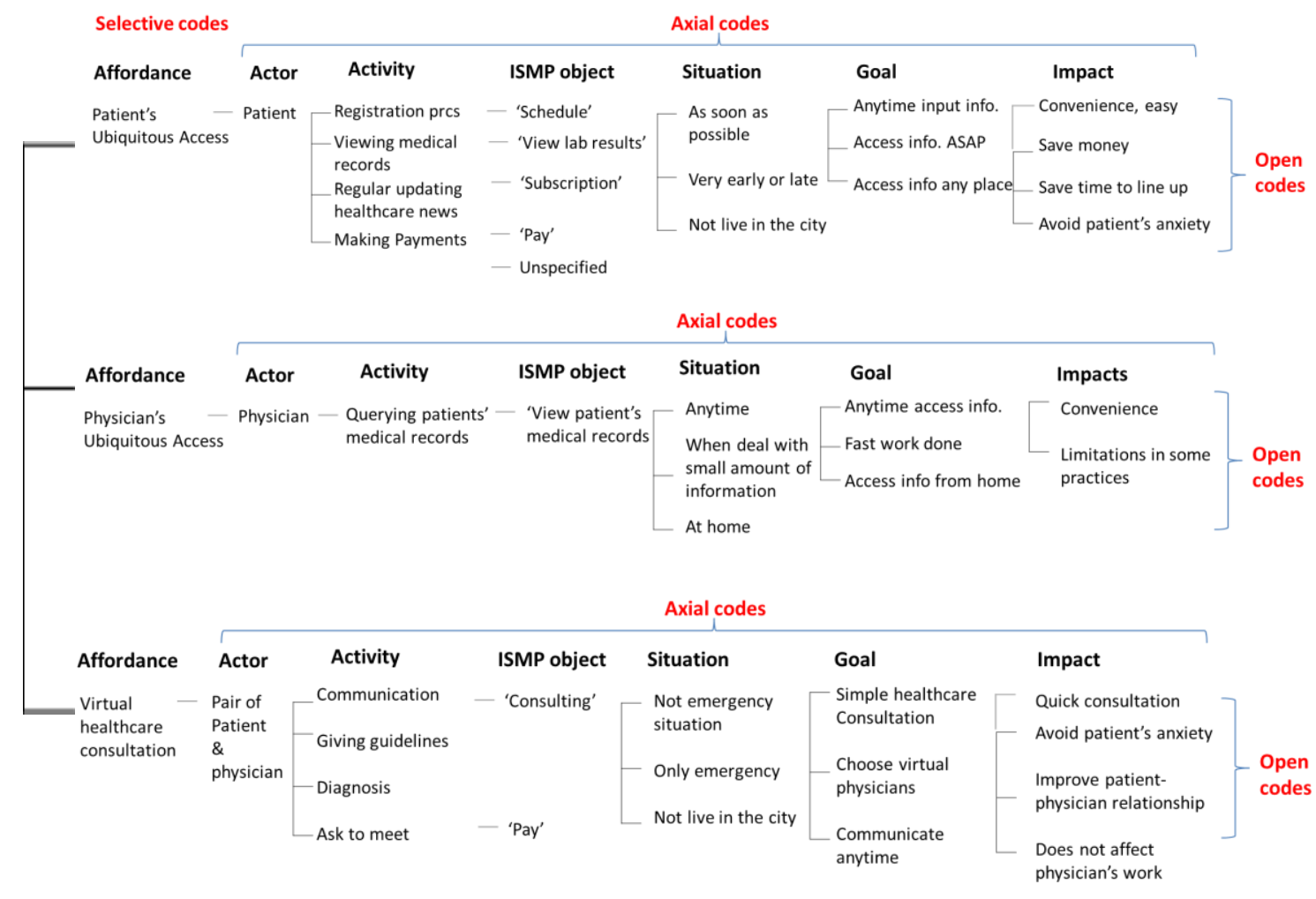




\section{Appendix 5 - Healthcare Processes}

Figure A. ISMP enabled healthcare process chart perceived (using MS Visio)

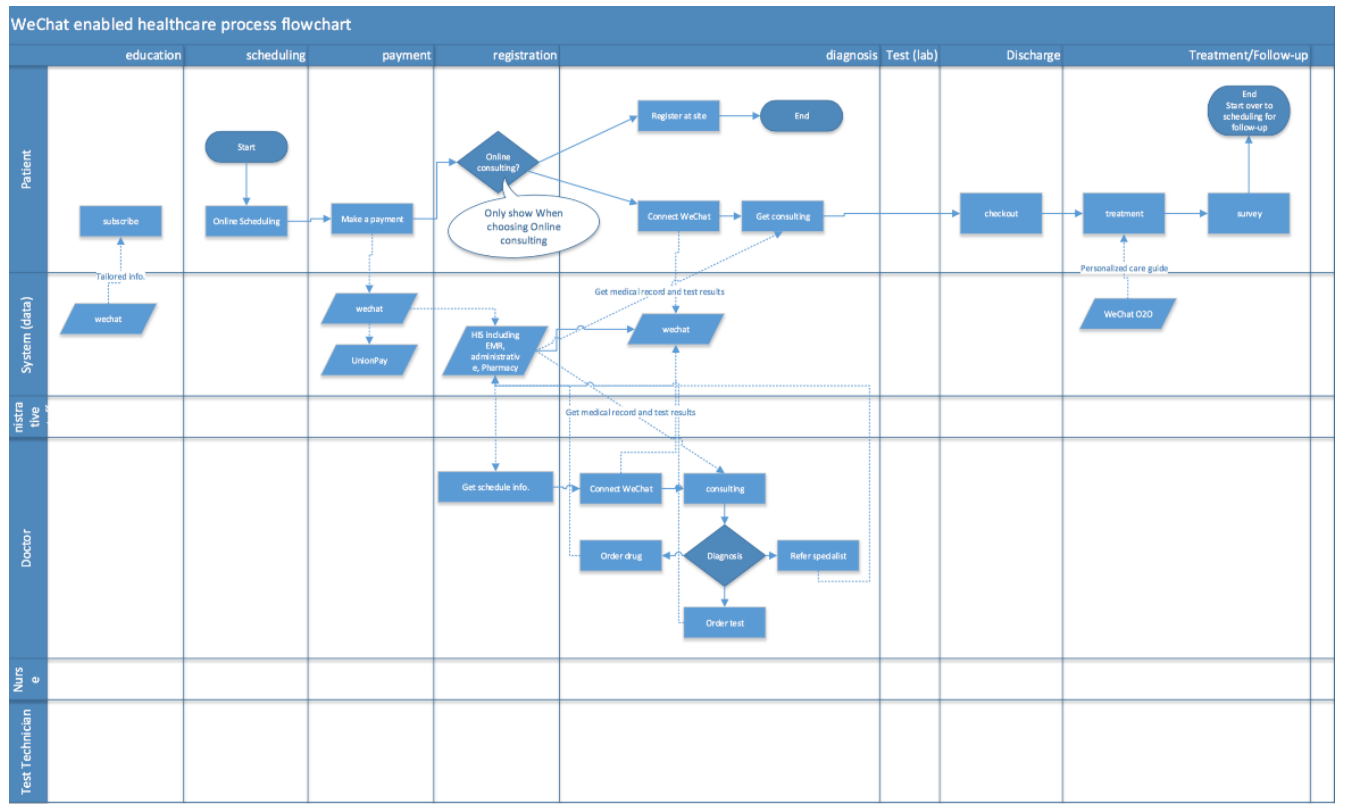

Figure B. ISMP enabled healthcare process illustrated in a hospital document, perceived by hospital

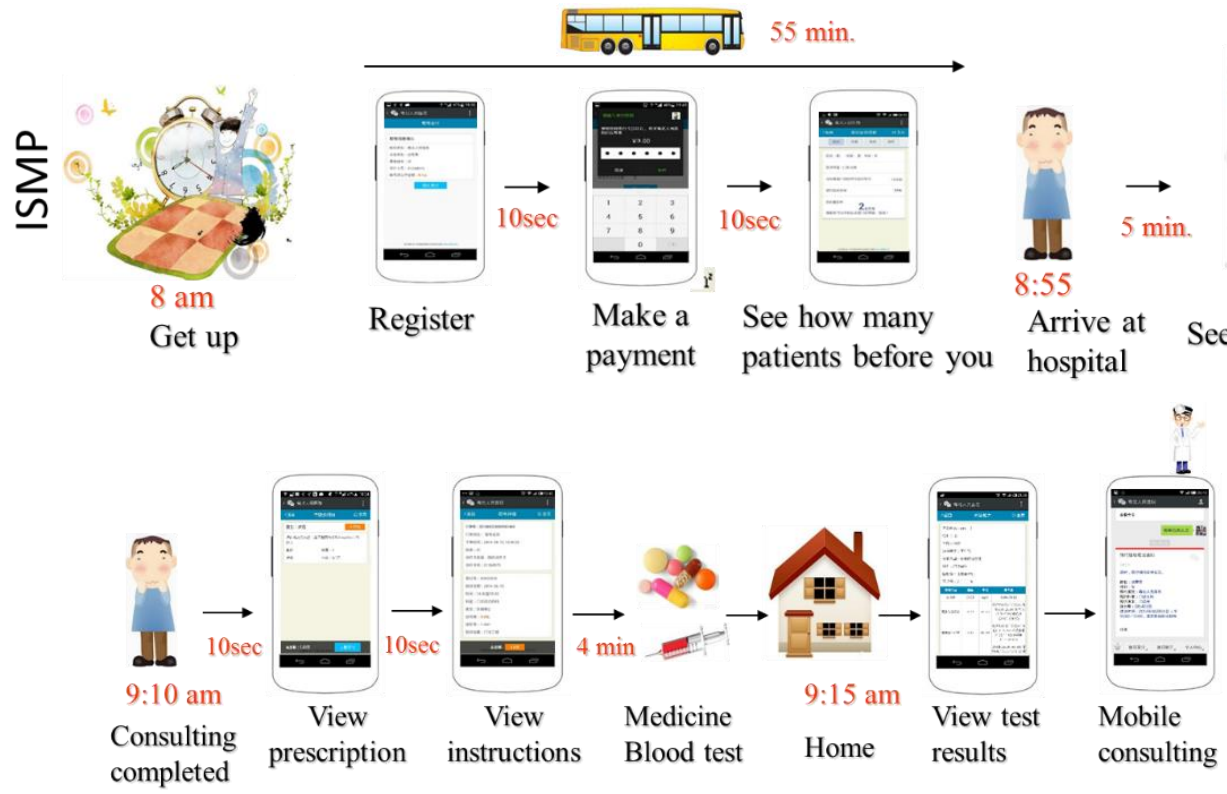


Appendix 6 - Process Mining Analysis Results

\section{Figure A. Activity Flow (Regular Work Hour)}

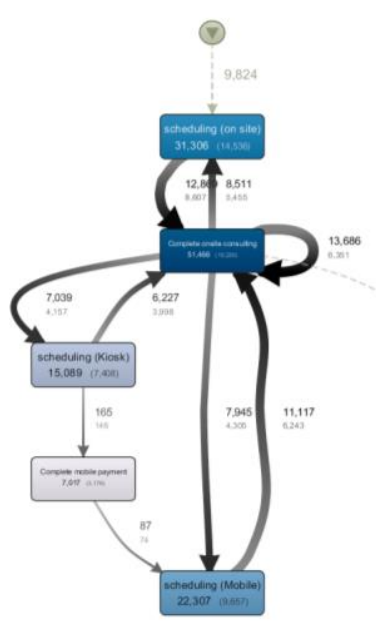

Figure B. Activity Flow (Off-Work Hour)

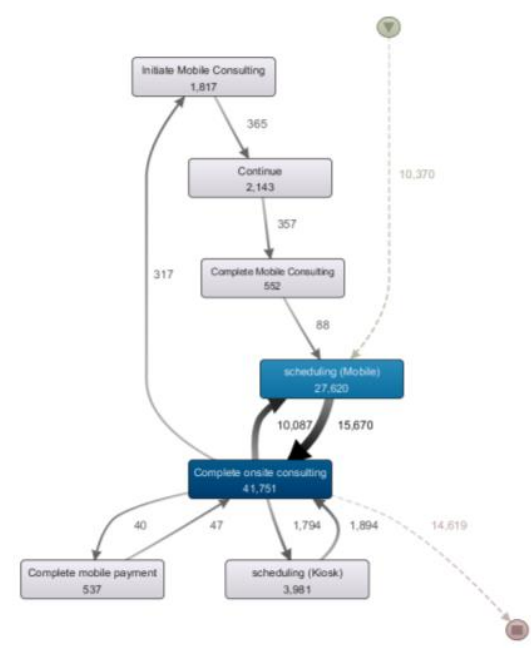

In Figure A, mobile consulting usage is barely seen during regular hour. Compared to the activity flow in the regular hour, mobile consulting usage is salient in Figure B. However, face-to-face onsite consultation is still large portion of all the activities, which indicate doctor's work.

Figure C. Activity Flow (in OB/GYN and Internal Medicine)




The data in only two units show clear activity patterns; scheduling with ISMP for onsite consulting and followed by mobile consulting.

\section{Figure D. Patients Flow across Departments (Overall)}

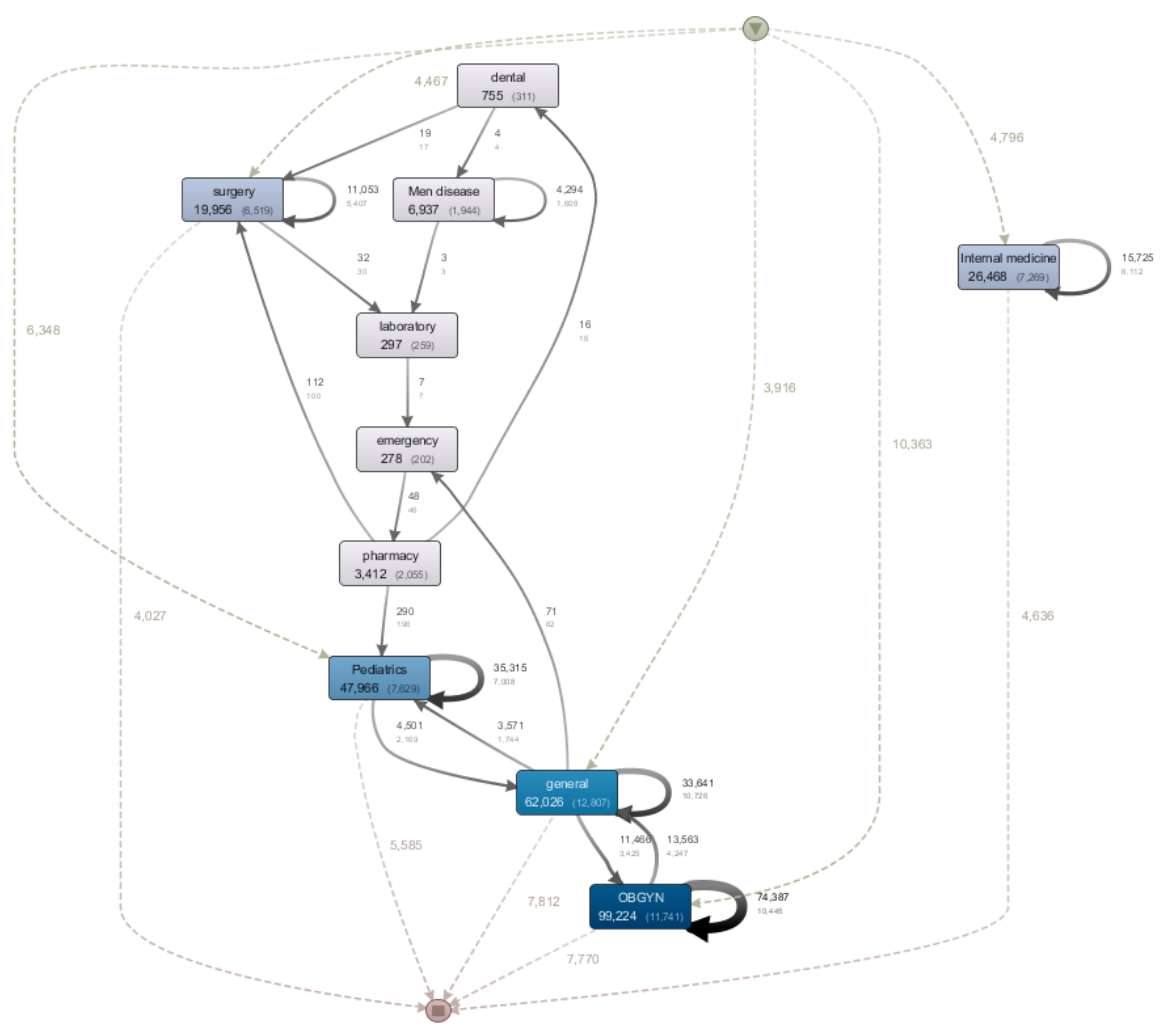

The department which patients use the ISMP mobile consulting feature most is OB/GYN (50\%, 11,741 patients), next is internal medicine (15\%, 7,269 patients). 
VITAE

INKYOUNG HUR

\section{EDUCATION}

1996 - 2001 Bachelor of Science in Industrial Engineering

Busan National University, Busan, South Korea

2008 - 2010 Master of Science in Industrial Engineering

Purdue University, West Lafayette, IN

Dual major (Certificate): Statistics

Regenstrief Center for Healthcare Engineering (RCHE) graduate scholar

2012 - 2016 Doctor of Philosophy in Information Systems and Business Analytics

Florida International University, Miami, FL

Major Professor: Weidong Xia (Chair)

Presidential Fellowship, 2012 - 2015

\section{PUBLICATIONS}

Samak, A. C., Hur, I., Kim, S. H., \& Yi, J. S. (2016) An Experimental Study of Decision Process with Interactive Technology. Journal of Economic Behavior \& Organization.

Hur, I., Lee, R., \& Schmidt, J. J. (2015, August). How Healthcare Technology Shapes Health Literacy? A Systematic Review. Paper presented at the 21st Americas Conference on Information Systems (AMCIS) conference. Puerto Rico, USA.

Hur, I., \& Cousins, K. (2014, December). Engagement in Online Health Care Community: A Critical Discourse Analysis. In the proceeding of the Organizations and Society in Information Systems (OASIS) workshop. Auckland, New Zealand.

Kwon, B. C., Hur, I., \& Yi, J. S. (2014). A Review of Web-Based Dietary Interventions: From the Human-Computer Interaction Practitioners' Perspective. Human Factors and Ergonomics in Manufacturing \& Service Industries, 24(3), 241-261.

Hur, I., Kim, S. H., Samak, A., \& Yi, J. S. (2013). A Comparative Study of Three Sorting Techniques in Performing Cognitive Tasks on a Tabular Representation. International Journal of Human-Computer Interaction, 29(6), 379-390.

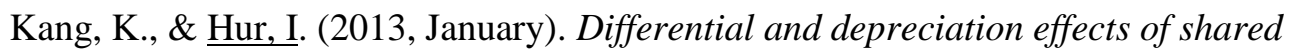
experience: evidence from software projects. In System Sciences (HICSS), 2013 46th Hawaii International Conference on. Hawaii, USA.

Hur, I., Kwon, B.C., \& Yi, J. S. (2010). A Review of Web-Based Dietary Interventions from the HF/E Perspective. In the proceeding of the 3rd International Conference on Applied Human Factors and Ergonomics (AHFE). Miami, USA.

Hur, I. (2010). Extracting Components of Effective Web Dietary Interventions: Review and 
Comparison of Papers in the Healthcare Domain and the Human Computer Interaction Domain. In the proceedings of the 6th Korean-American Scientists and Engineers

Association (KSEA) Young Generation Technical and Leadership Conference. Washington D.C., USA.

Hur, I., \& Yi, J. S. (2009). Simulsort: Multivariate data exploration through an enhanced sorting technique. In the proceedings of the 10th Human-Computer Interaction International (HCII) Conference Novel Interaction Methods and Techniques. San Diego, USA.

Hur, I., Ning, Z., Yehle, K., Plake, K., Mobley, A., Morales, C., \& Yi, J. S. (2009). Food for the Heart: A Web-based Dietary Intervention for Patients with Heart Disease. In the proceedings of Cancer Prevention and Healthcare Retreat and Poster Competition. West Lafayette, USA.

Hur, I., Hwang, I., \& Yu, D. (2006). A Case Study on the Process Productivity Model for Software Projects in Korea. In the proceedings of the 3th Software Measurement European Forum (SMEF). Rome, Italy.

Hur, I. (2002). Software Measurement Series (total four articles). Daily Economy. South Korea. 